Supplementary Information

For

\title{
Visible-Light-Promoted Cascade Radical Cyclization: Synthesis of Chroman-4-ones and Dihydroquinolin-4-ones
}

\author{
Hong-Li Huang, ${ }^{\dagger \dagger}$ Ji-Yuan Du, ${ }^{\dagger}$ Qian-Li Li,${ }^{\dagger}$ Fei Gao,${ }^{\star}$ Chun-Lin $\mathrm{Ma}^{\dagger}$ \\ ${ }^{\dagger}$ College of Chemistry and Chemical Engineering, Liaocheng University, Liaocheng, \\ Shandong 252059, China.*E-mail: huanghongli@lcu.edu.cn. \\ ${ }^{\star}$ Institude of Translation Medicine, Shanghai University, Shanghai, 2004444, China
}

\section{Table of Contents}

1. Light Source, Material of the Irradiation Vessel and Experimental Set-up Photograph. S2

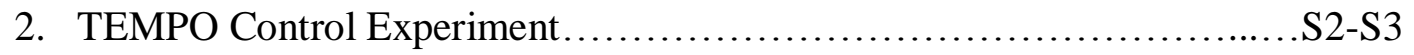

3. Copies of NMR Spectra ........................................S3-S46 


\section{Light Source, Material of the Irradiation Vessel and Experimental Set-up}

\section{Photograph}

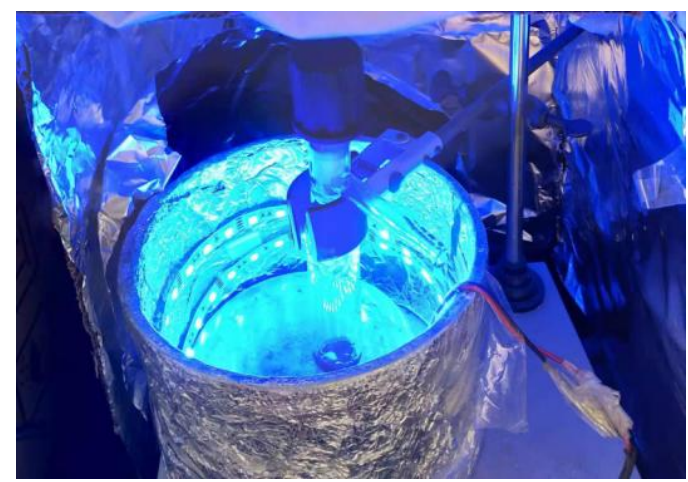

Small scale reaction

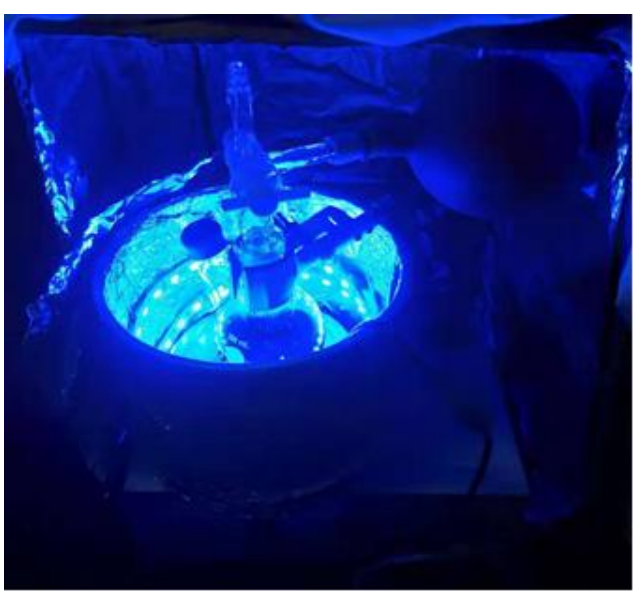

Large scale reaction

The light source used for photochemical experiments was a $5 \mathrm{~W}$ blue leds belt, purchased from JD.COM

Manufacturer: Gree Think. China

Model: 12v3528

Broadband source: $\lambda=460-470 \mathrm{~nm}$

Material of the irradiation vessel: Schlenk tube

Distance from the light source to the irradiation vessel: $6.0 \mathrm{~cm}$ (Not use any filters)

Photographed: Hong-Li Huang

\section{TEMPO Control Experiment}<smiles>C=CCOc1ccccc1C=O</smiles>

$1 \mathrm{a}$

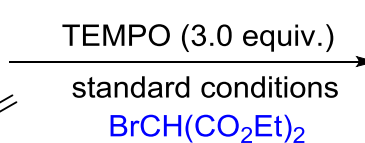

2a<smiles>CCOC(=O)CCC1COc2ccccc2C1=O</smiles>

3aa, $0 \%$<smiles>CCOC(=O)ON1C(C)(C)CCCC1(C)C</smiles>

GC-MS detected 
GC-MS data:

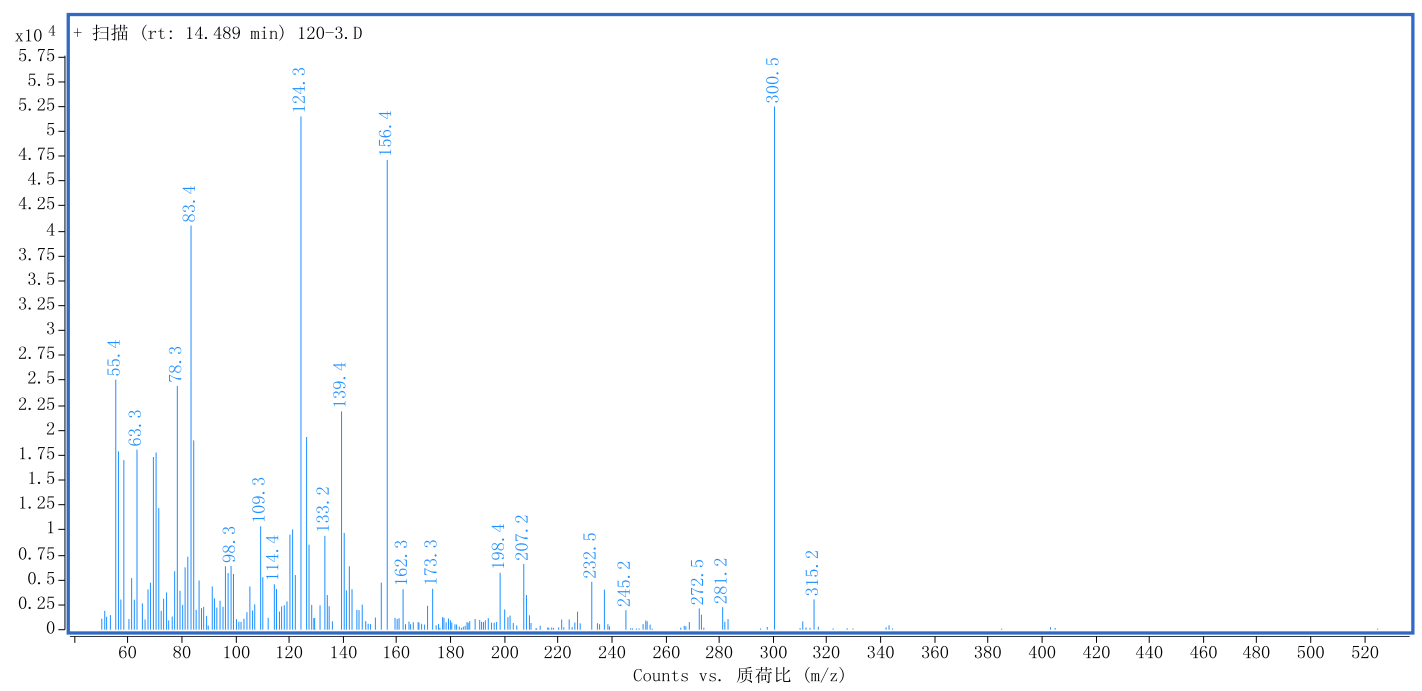

3. Copies of NMR Spectra

\section{1w NMR}

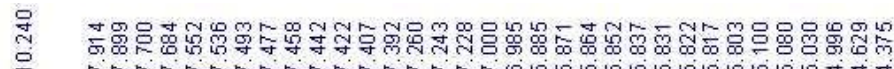

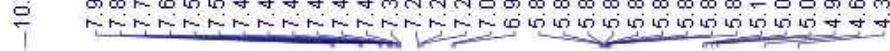
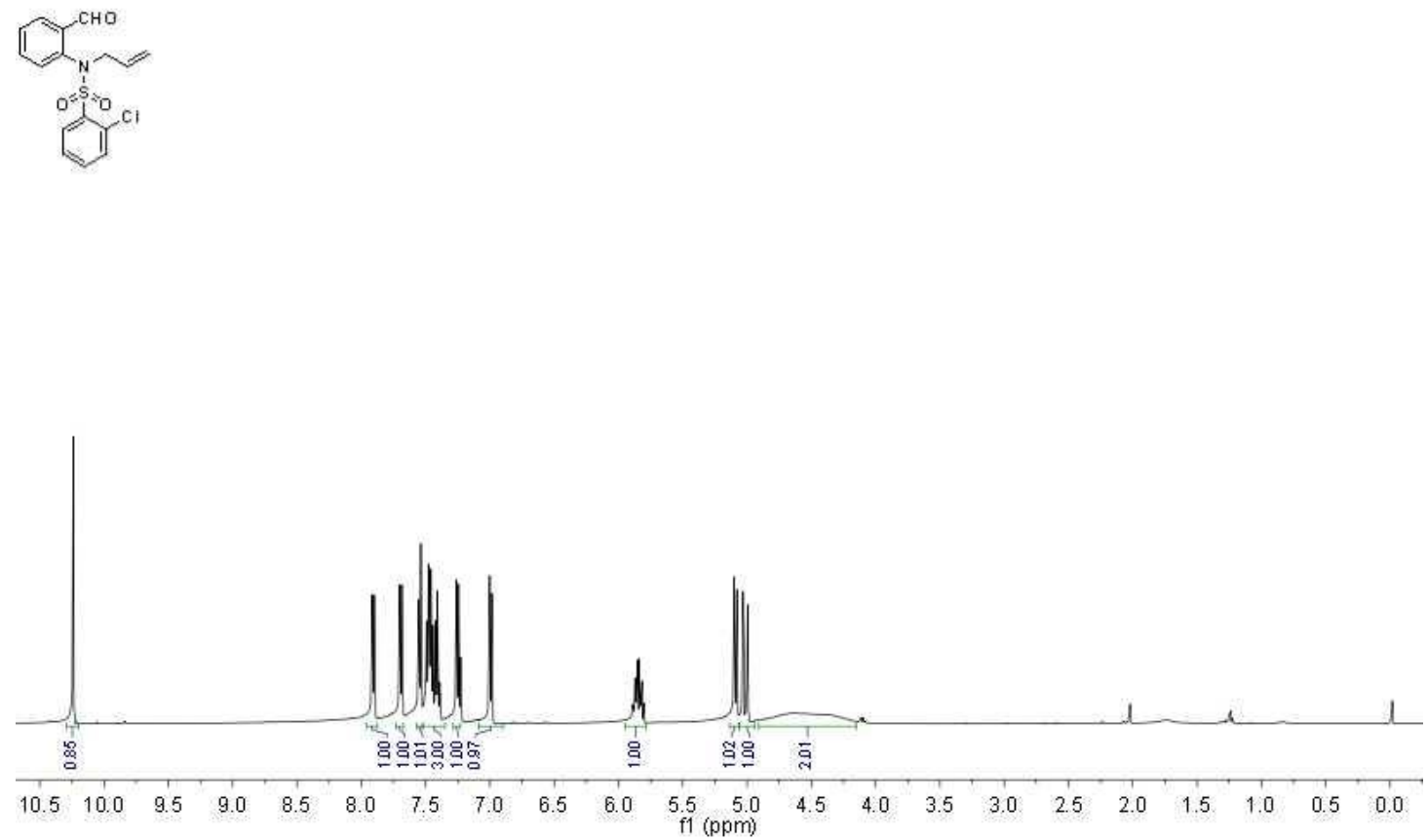

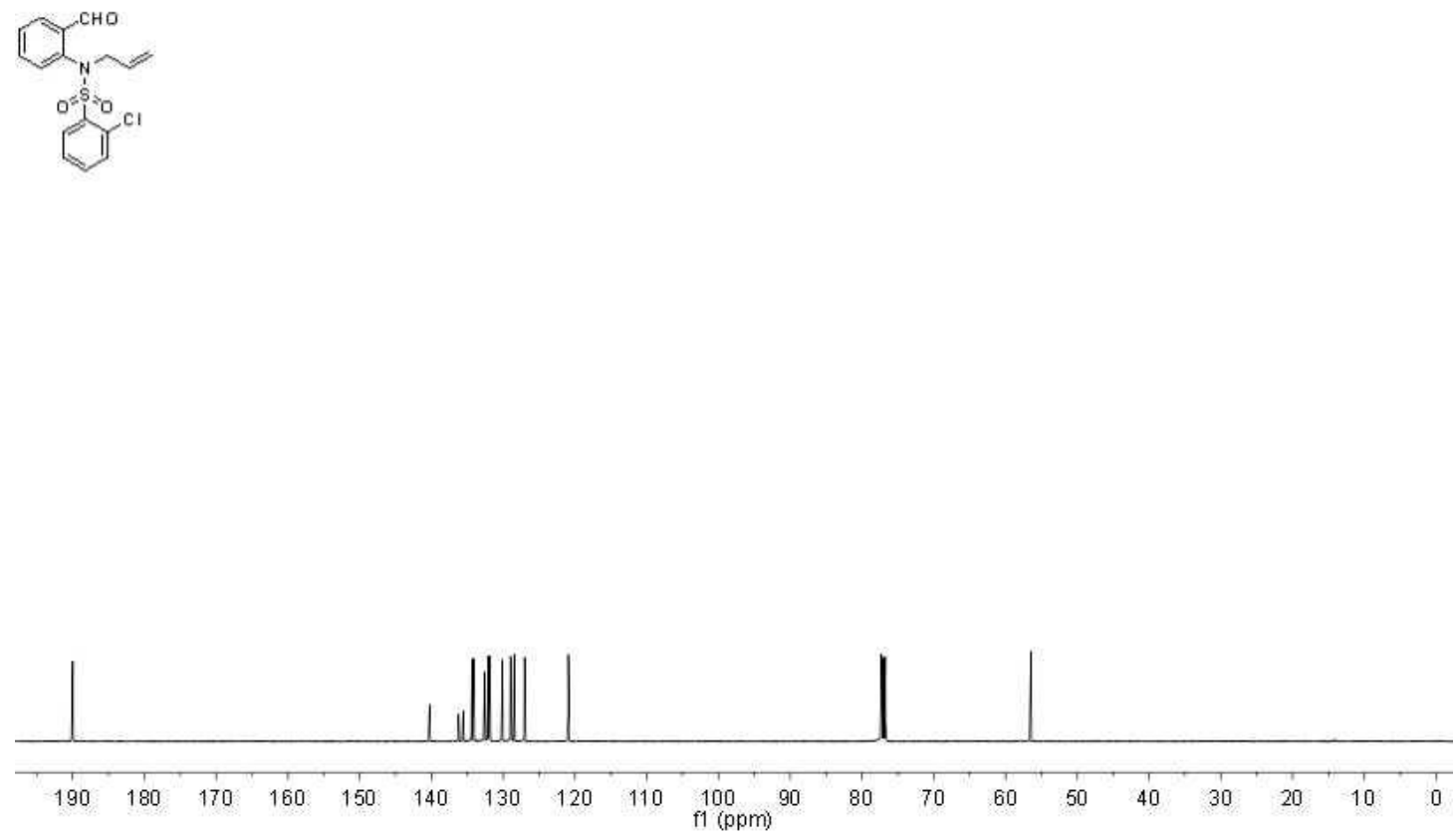

\section{1x NMR}

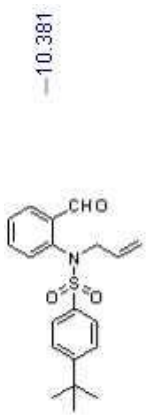

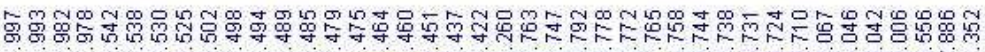

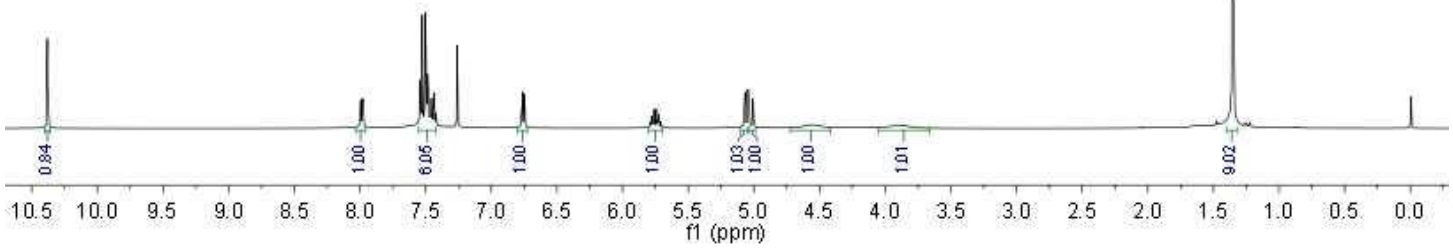




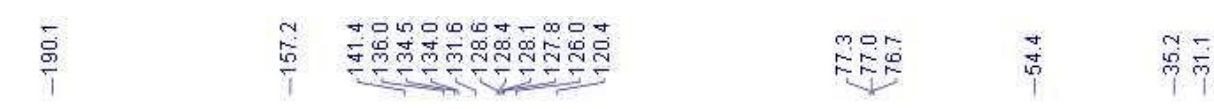
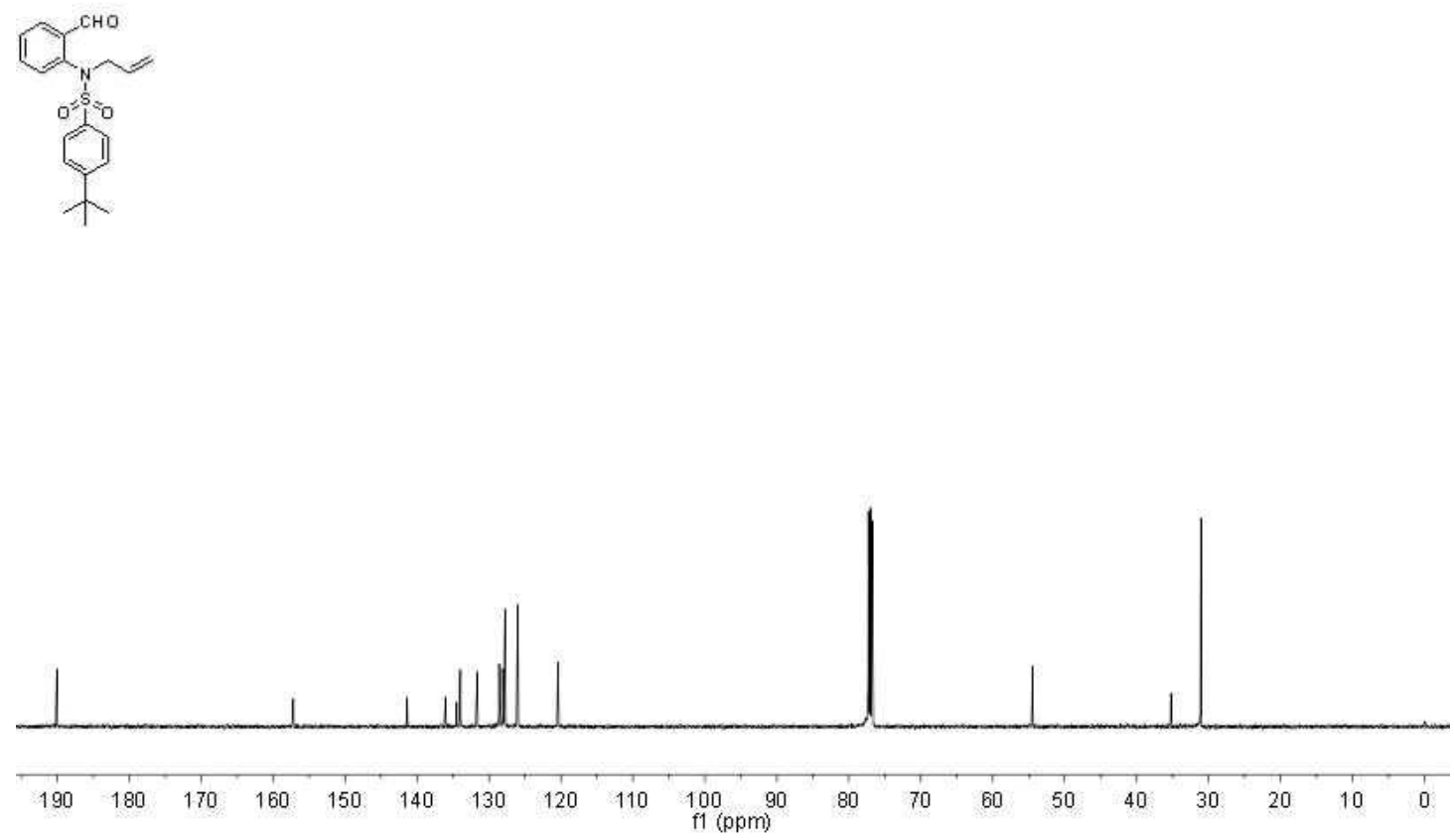

\section{1y NMR}

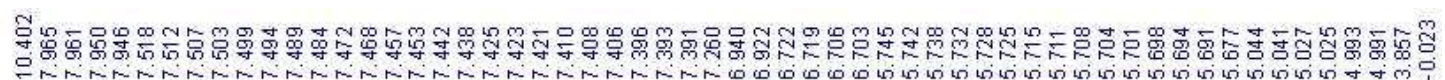

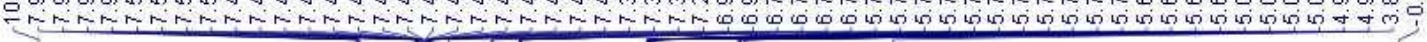<smiles></smiles>

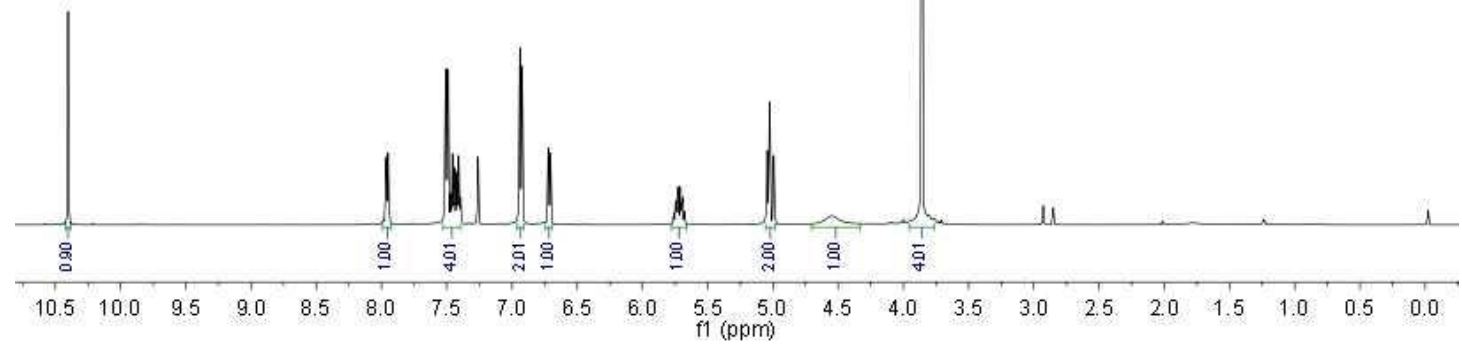




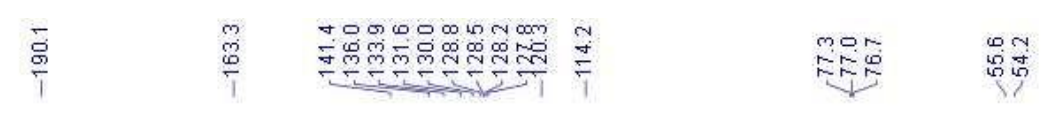
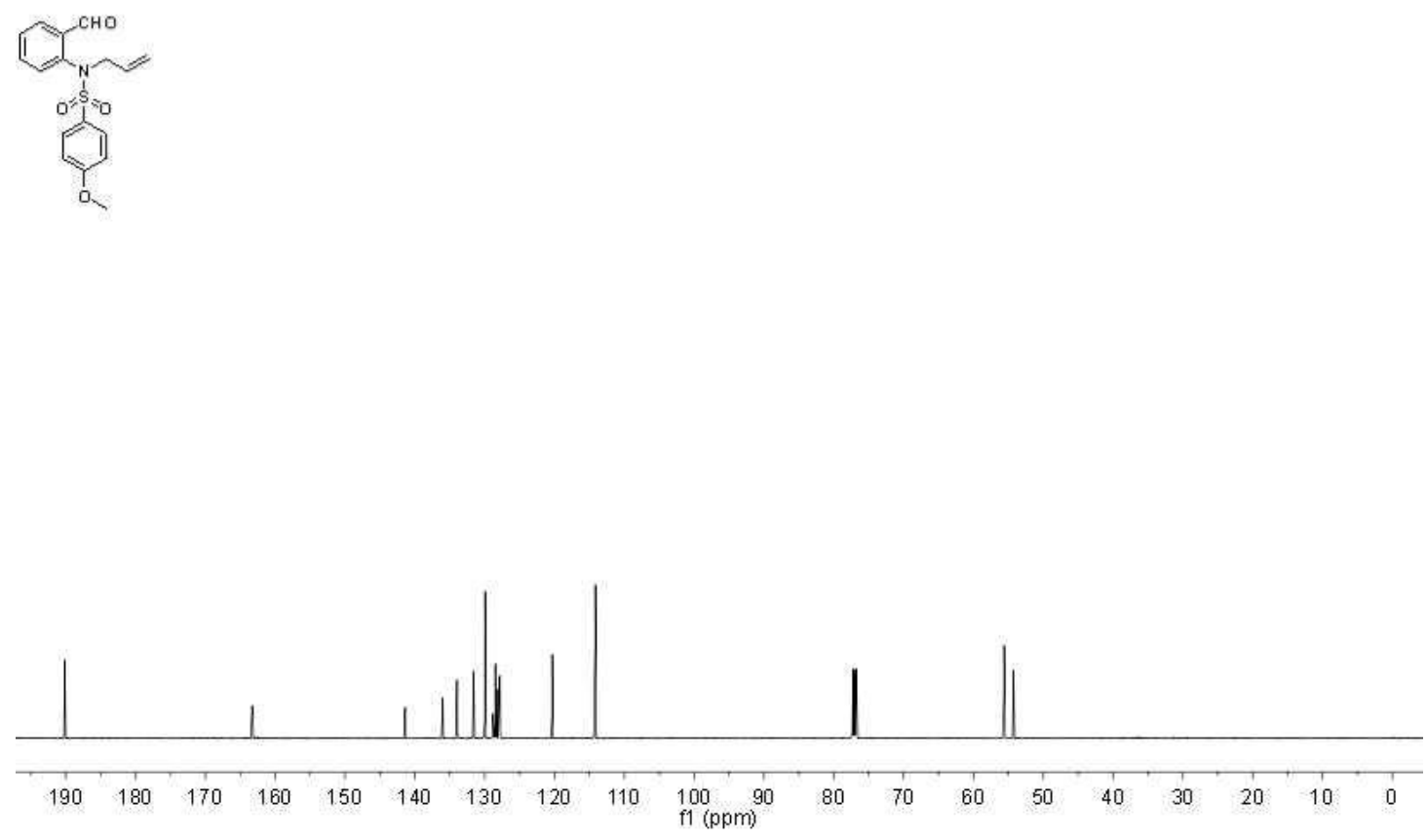

1z NMR

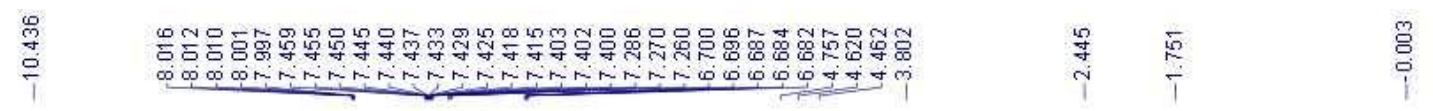

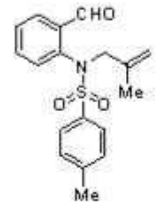

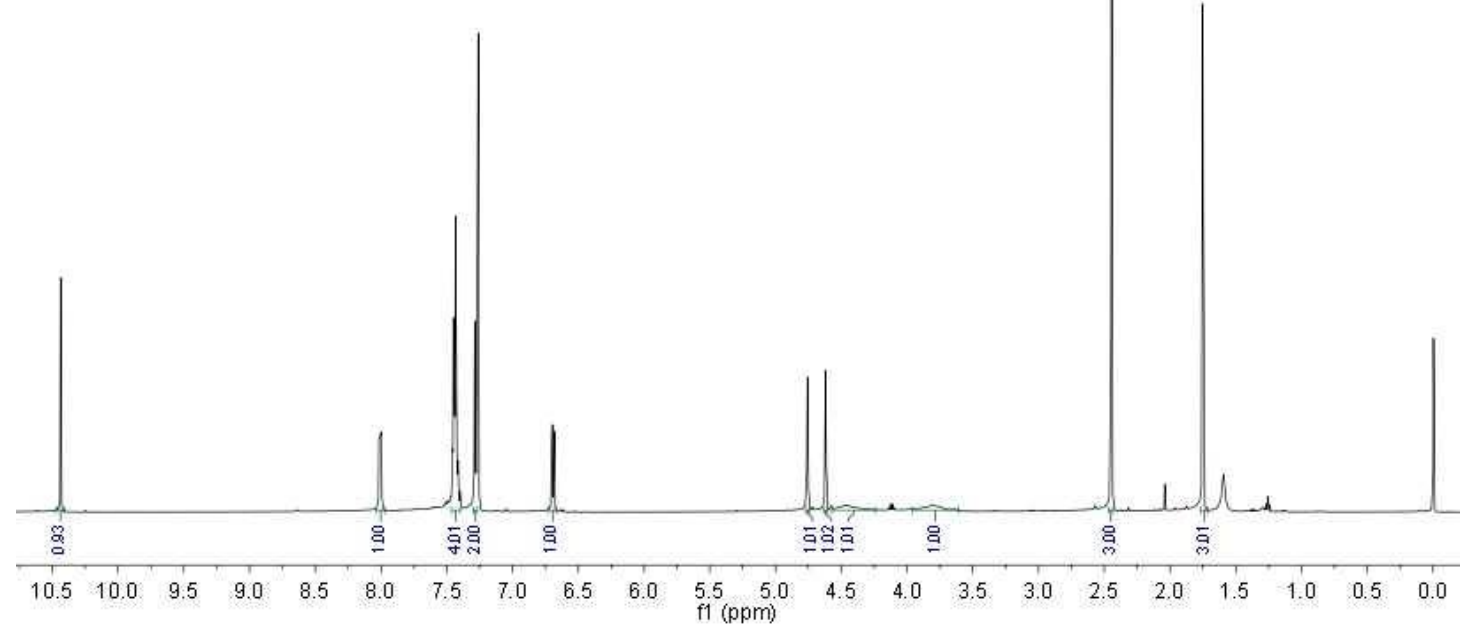




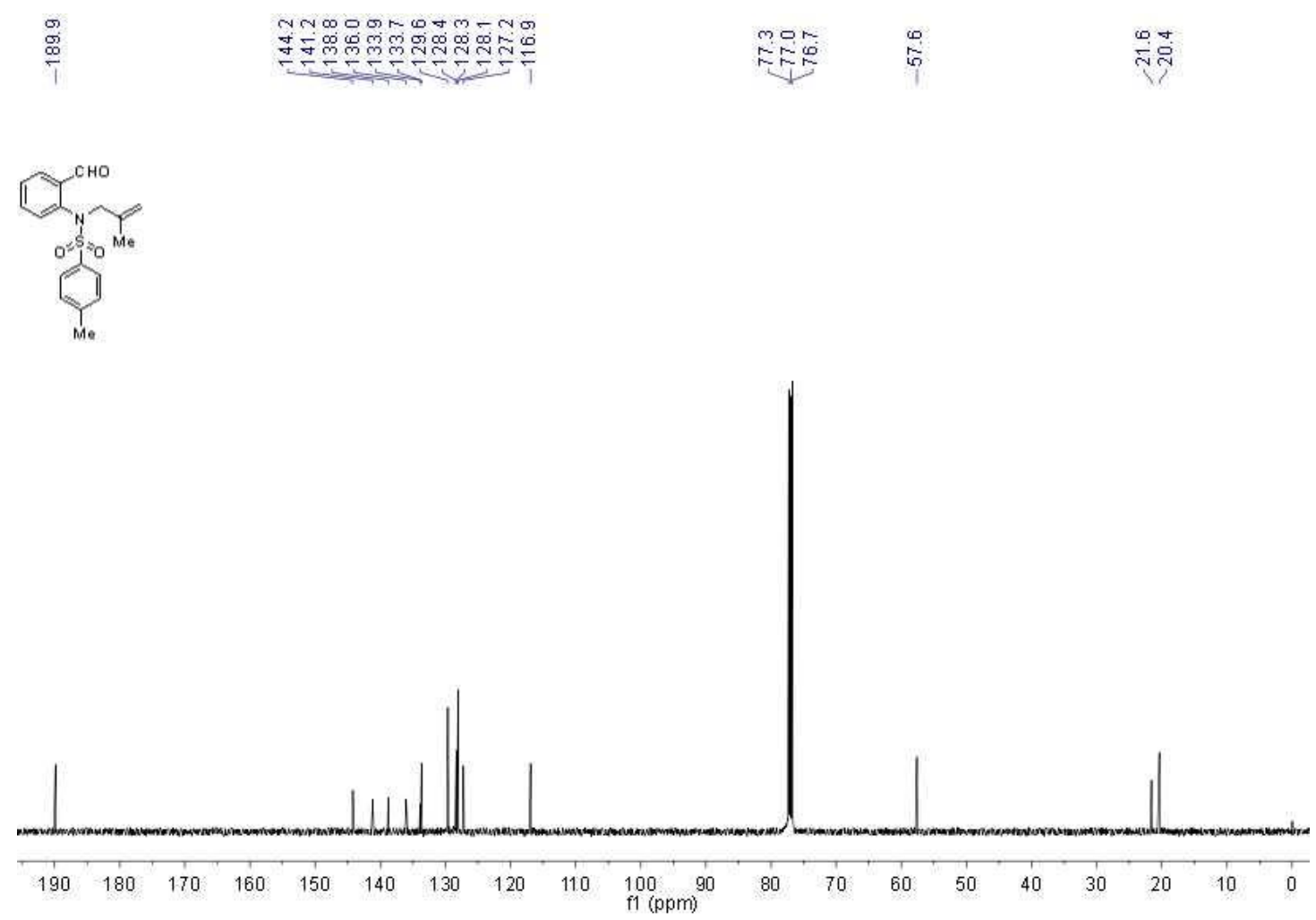

\section{3aa NMR}

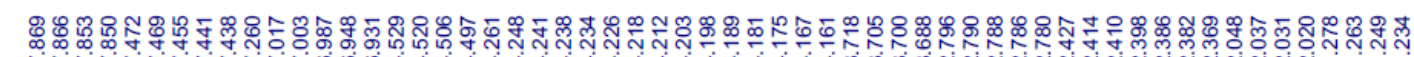

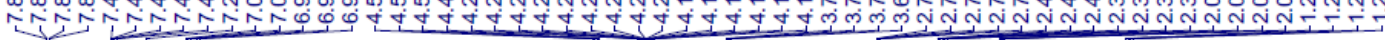

$\overbrace{0}^{\text {COOEt }}$

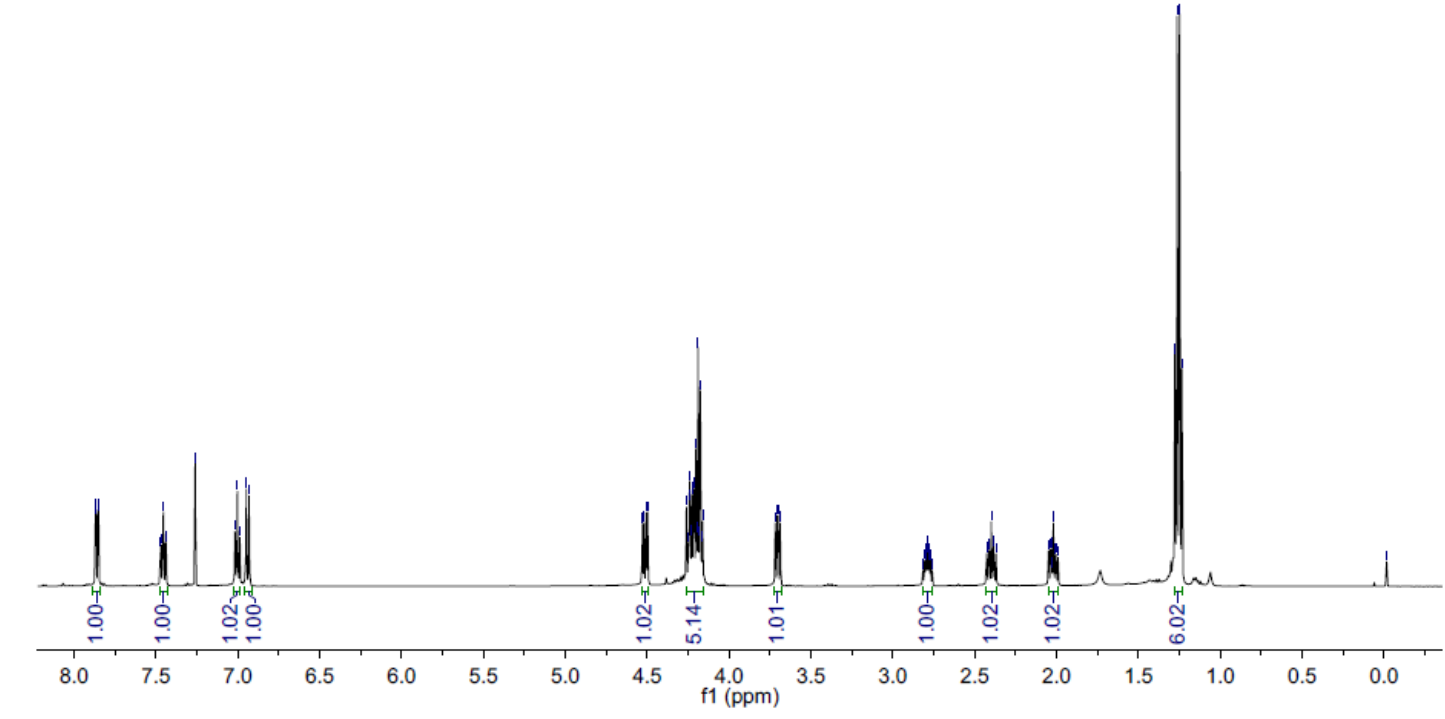




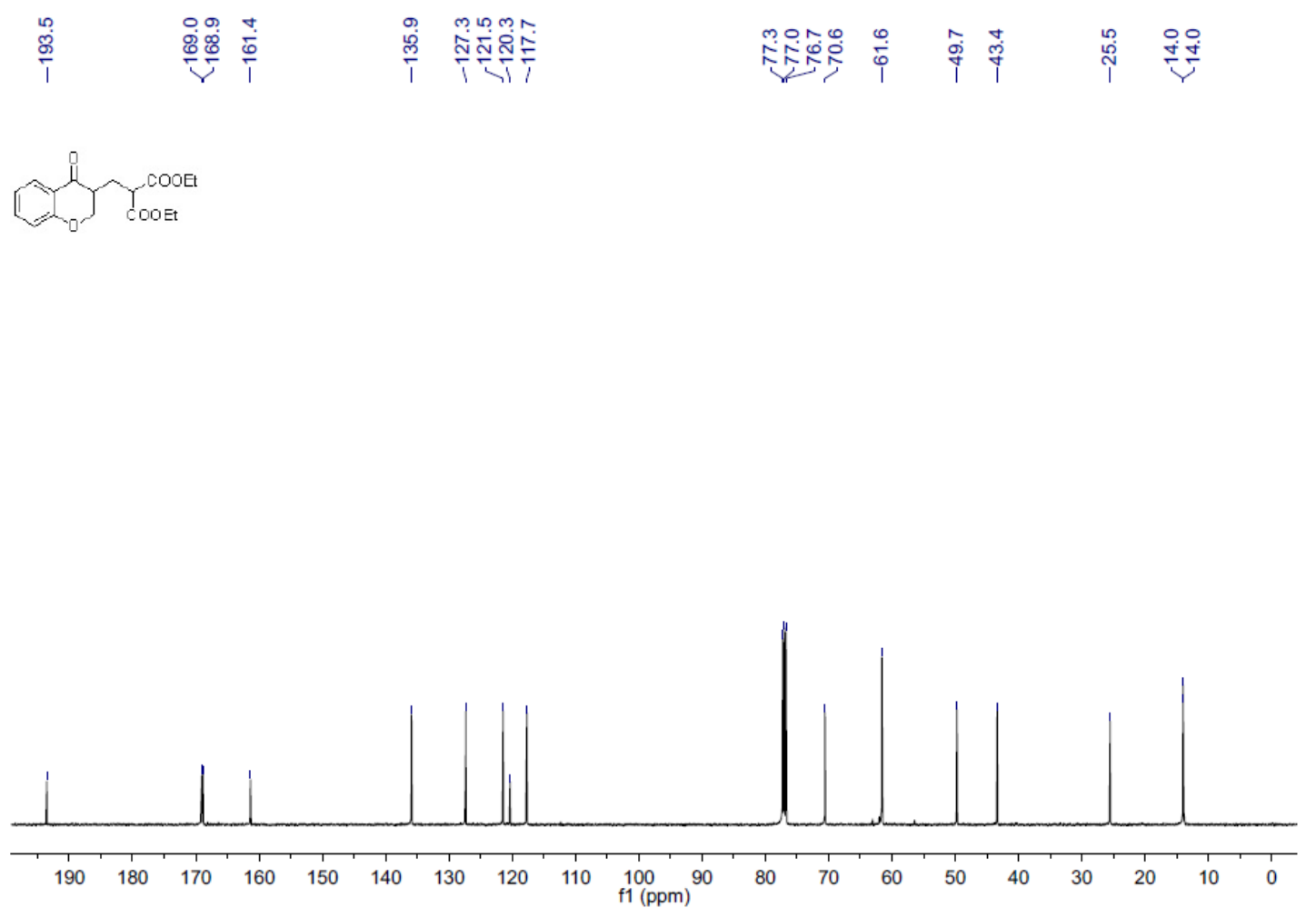

\section{3ba NMR}

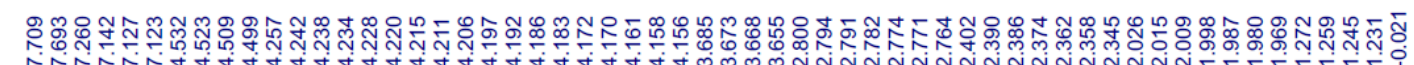

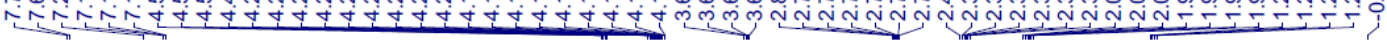

$\underbrace{\text { COOEt }}_{\text {COOEt }}$

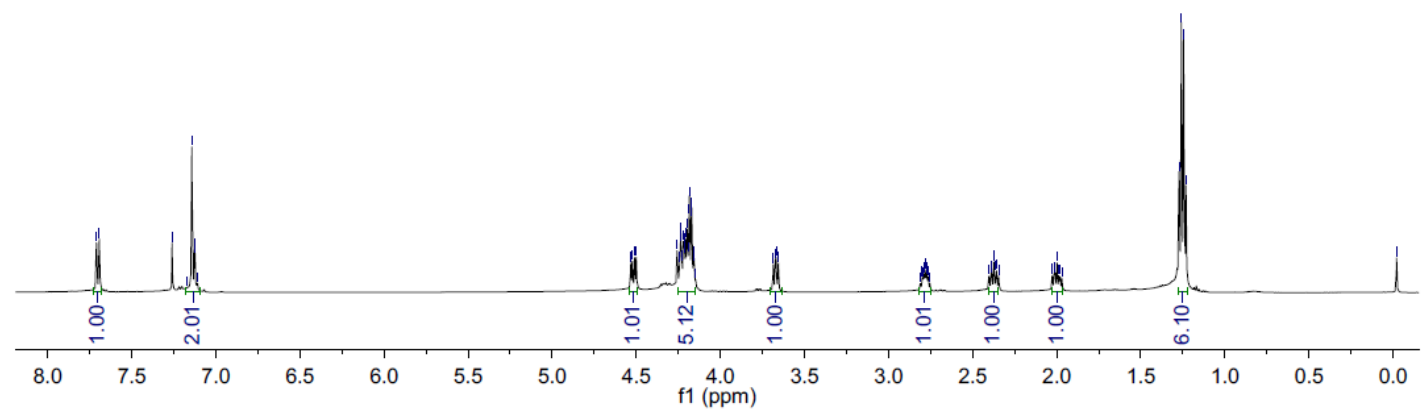



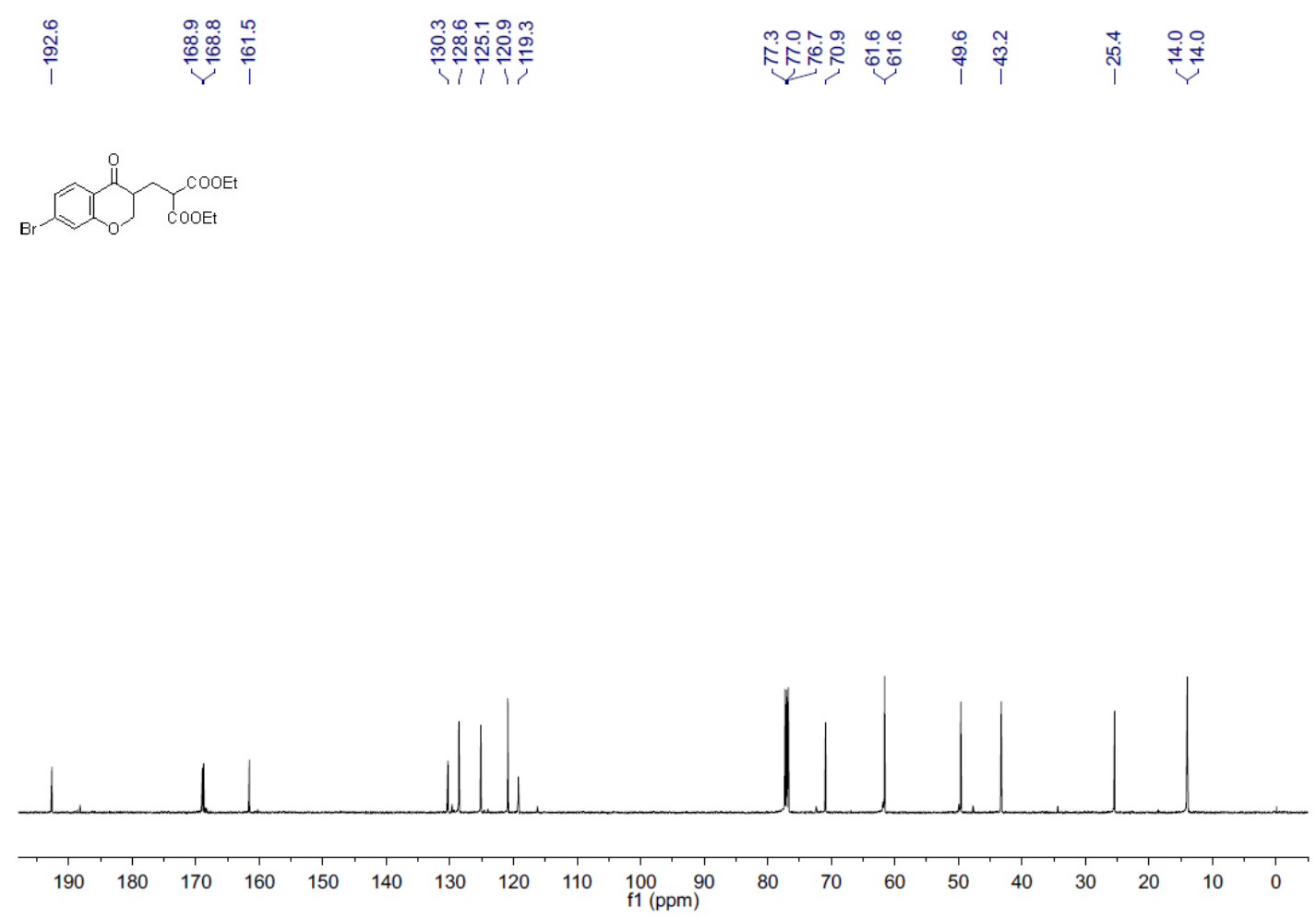

3ca NMR

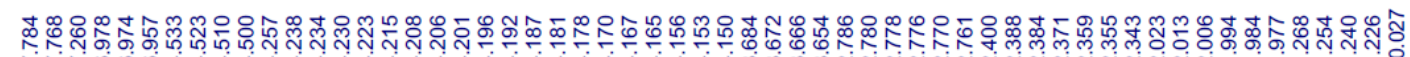

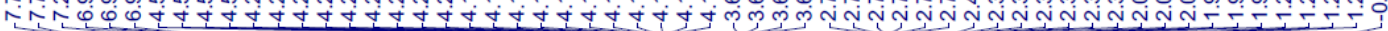

$\underbrace{0}_{0} \underbrace{C O O E t}_{C O O E t}$

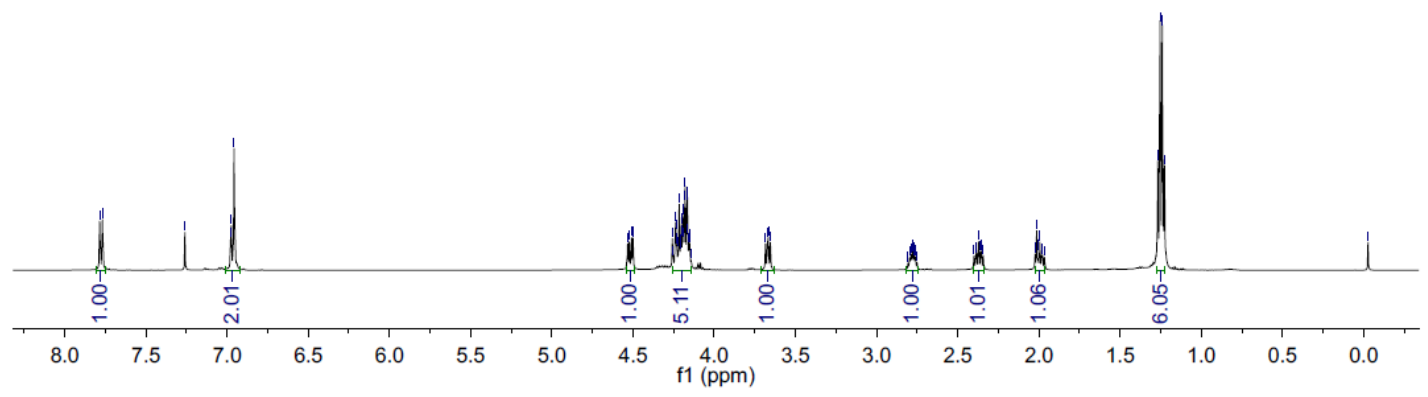



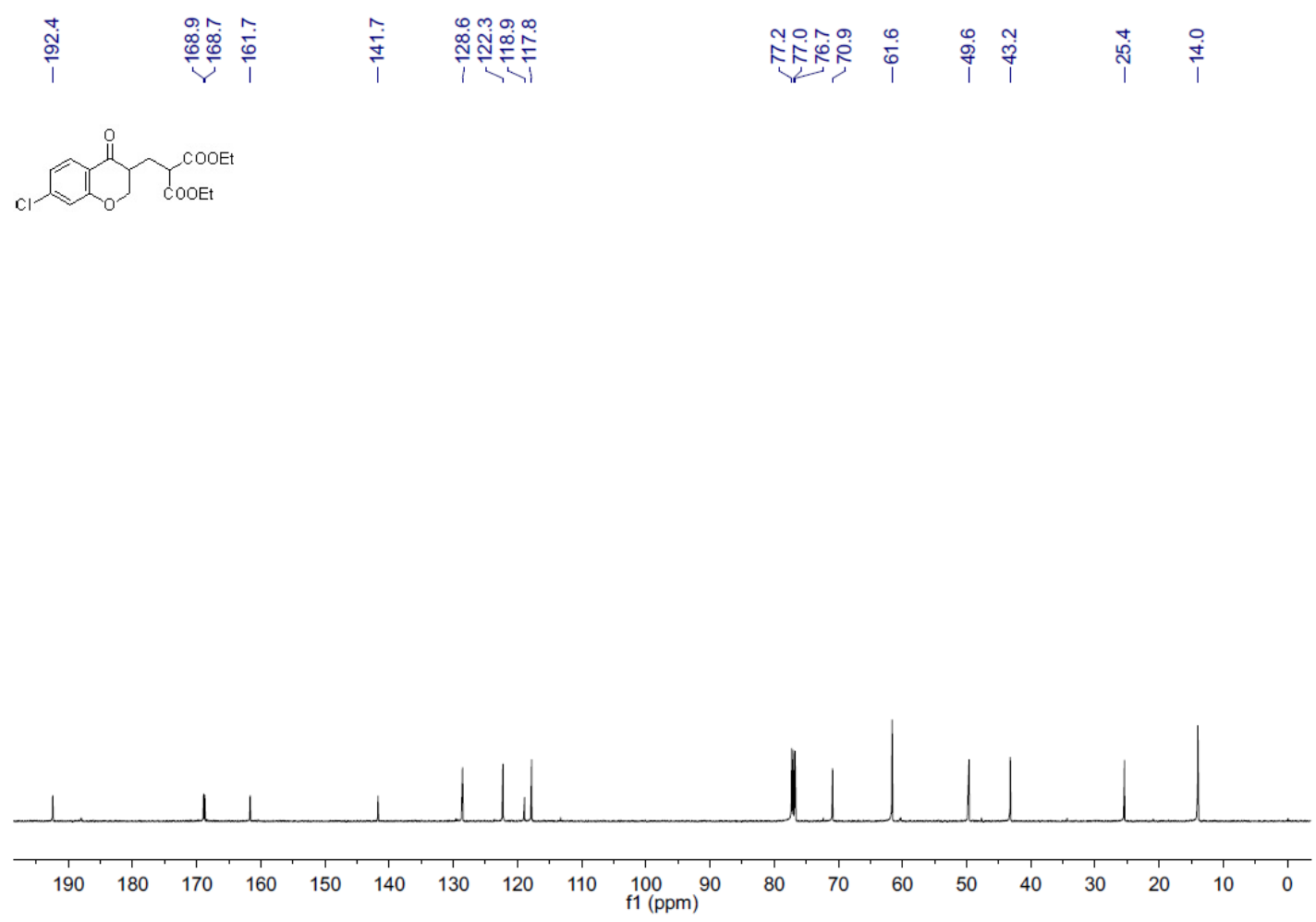

3da NMR

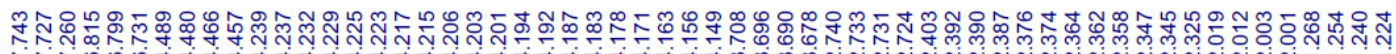

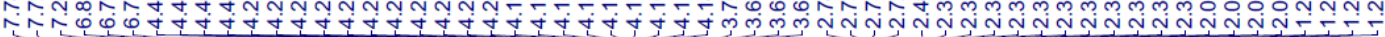

$\overbrace{C O E t}^{C O O E t}$

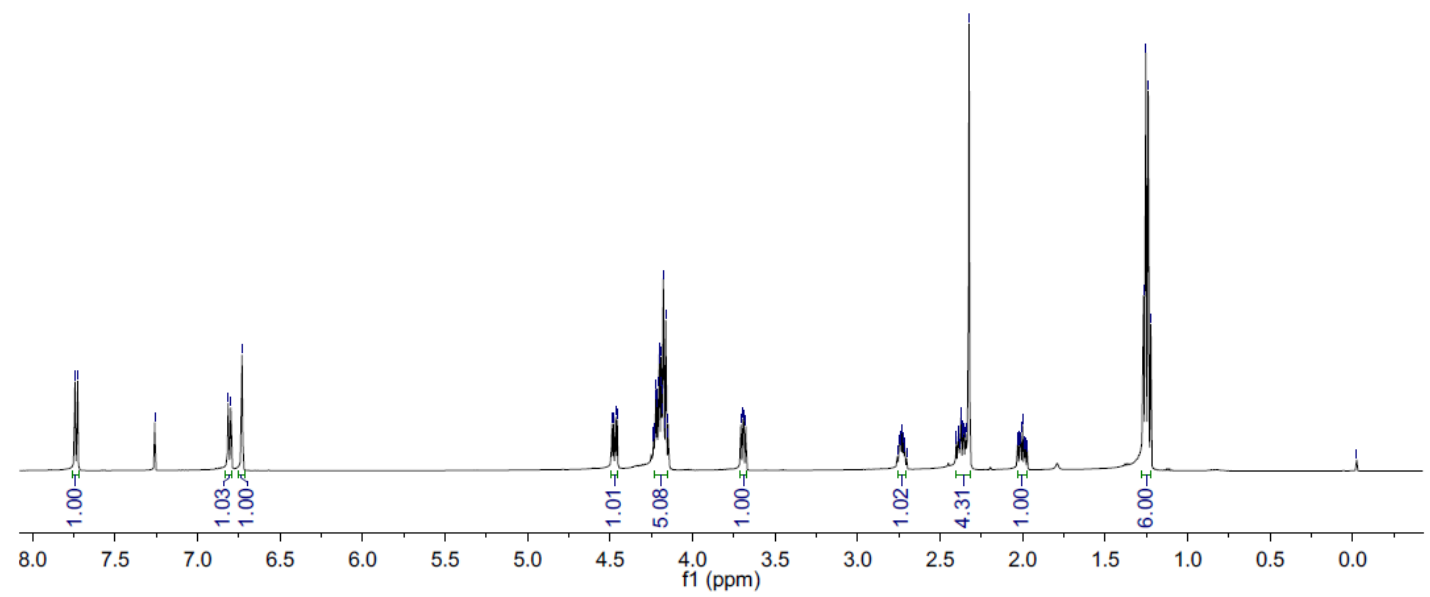




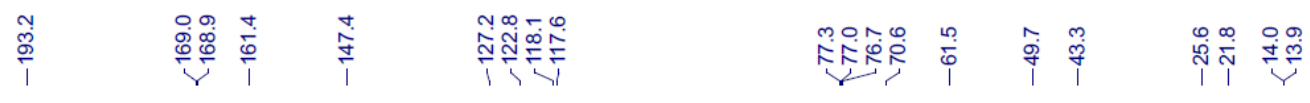<smiles>CCOC(=O)CC1COc2cc([N+](=O)[O-])ccc2C1=O</smiles>

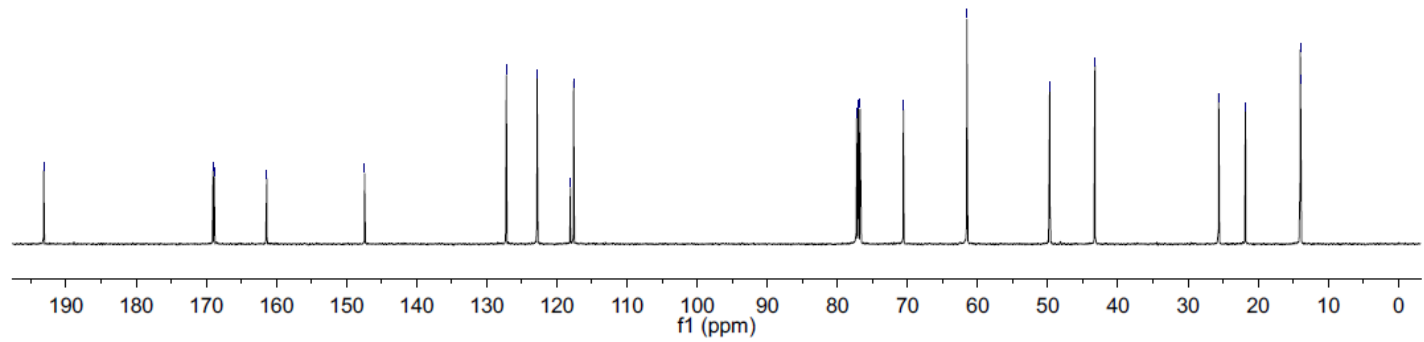

3ea NMR

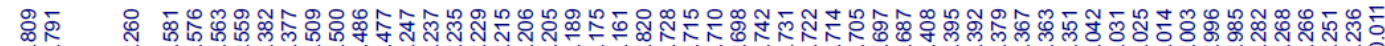

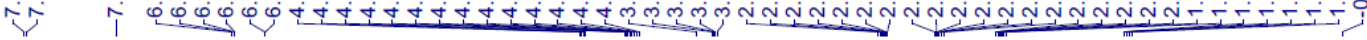

COOEt

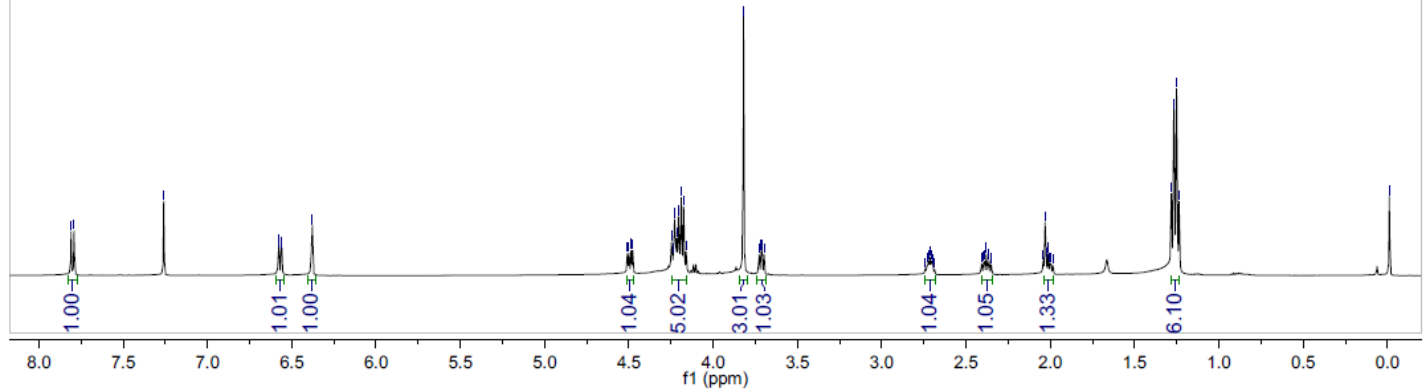




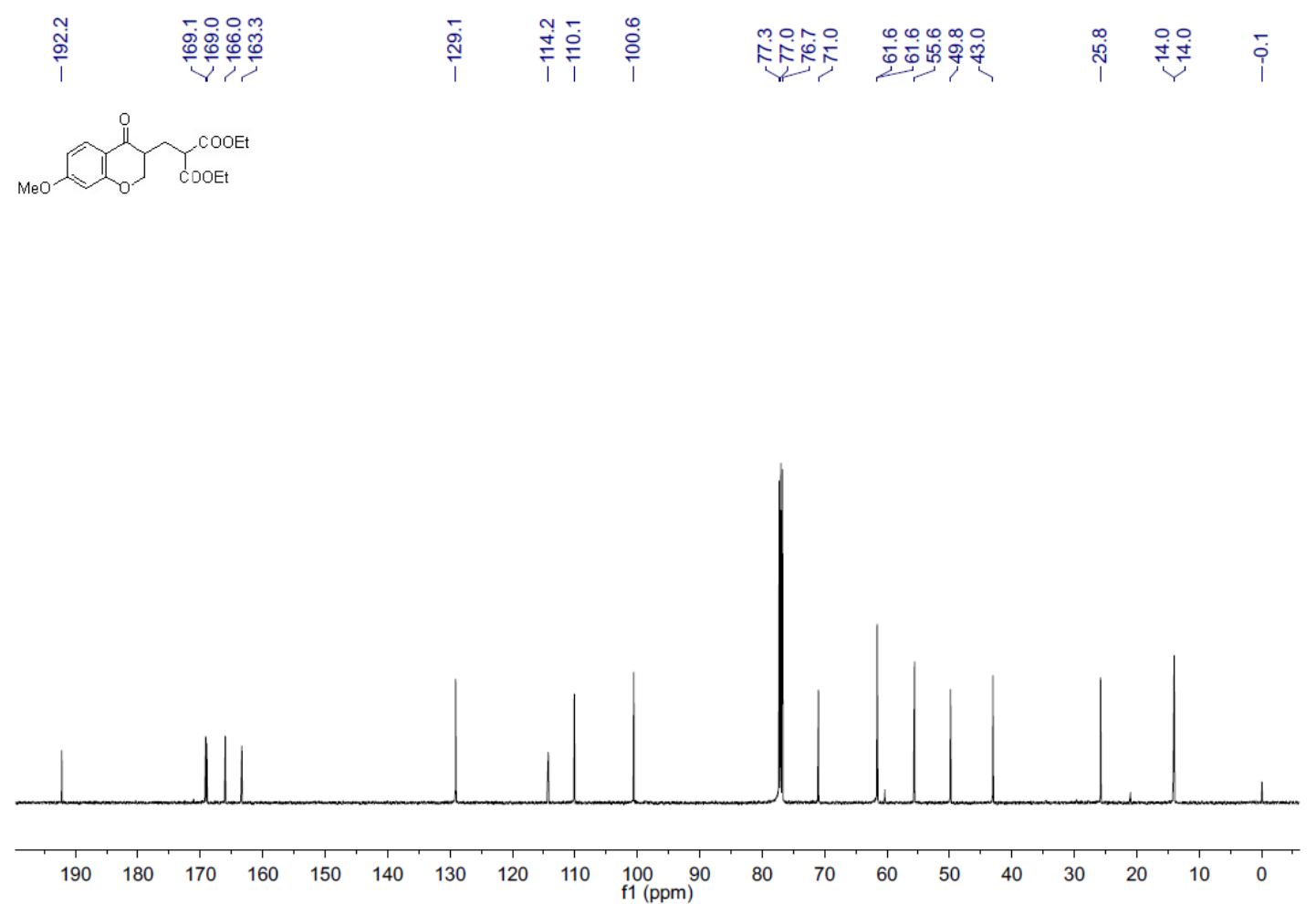

3fa NMR

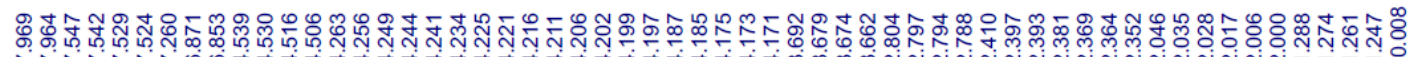

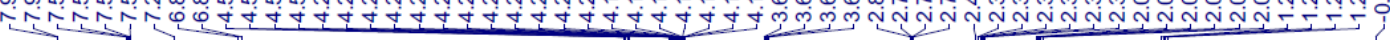

(1) COCOEt

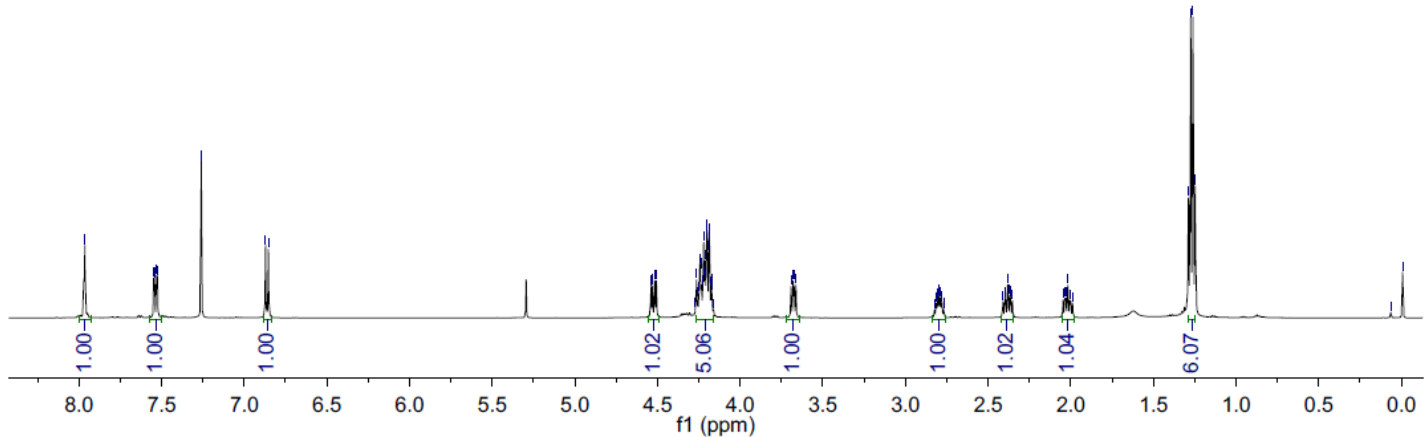



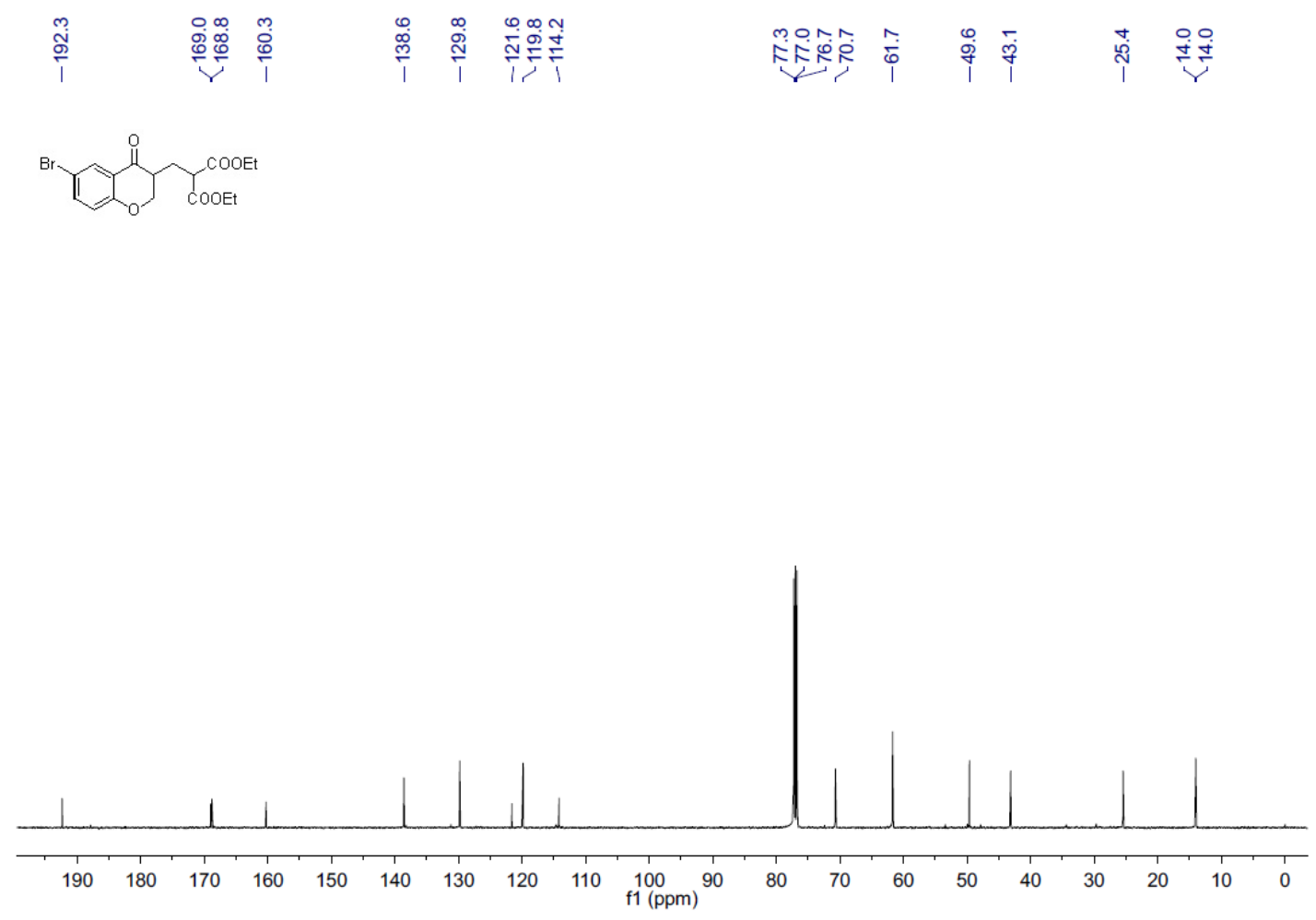

3ga NMR

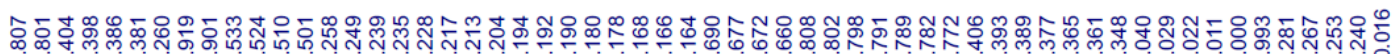

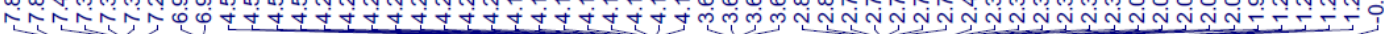
Cl

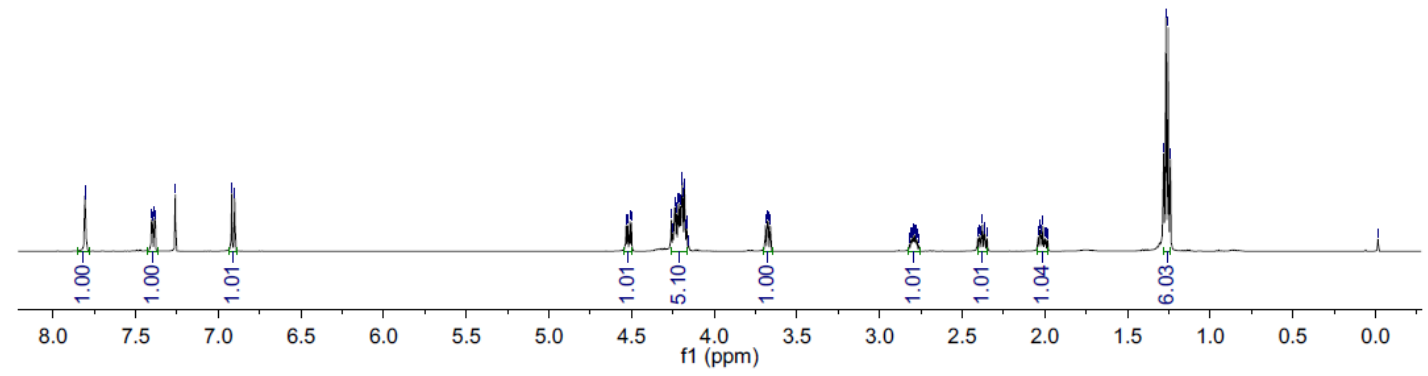




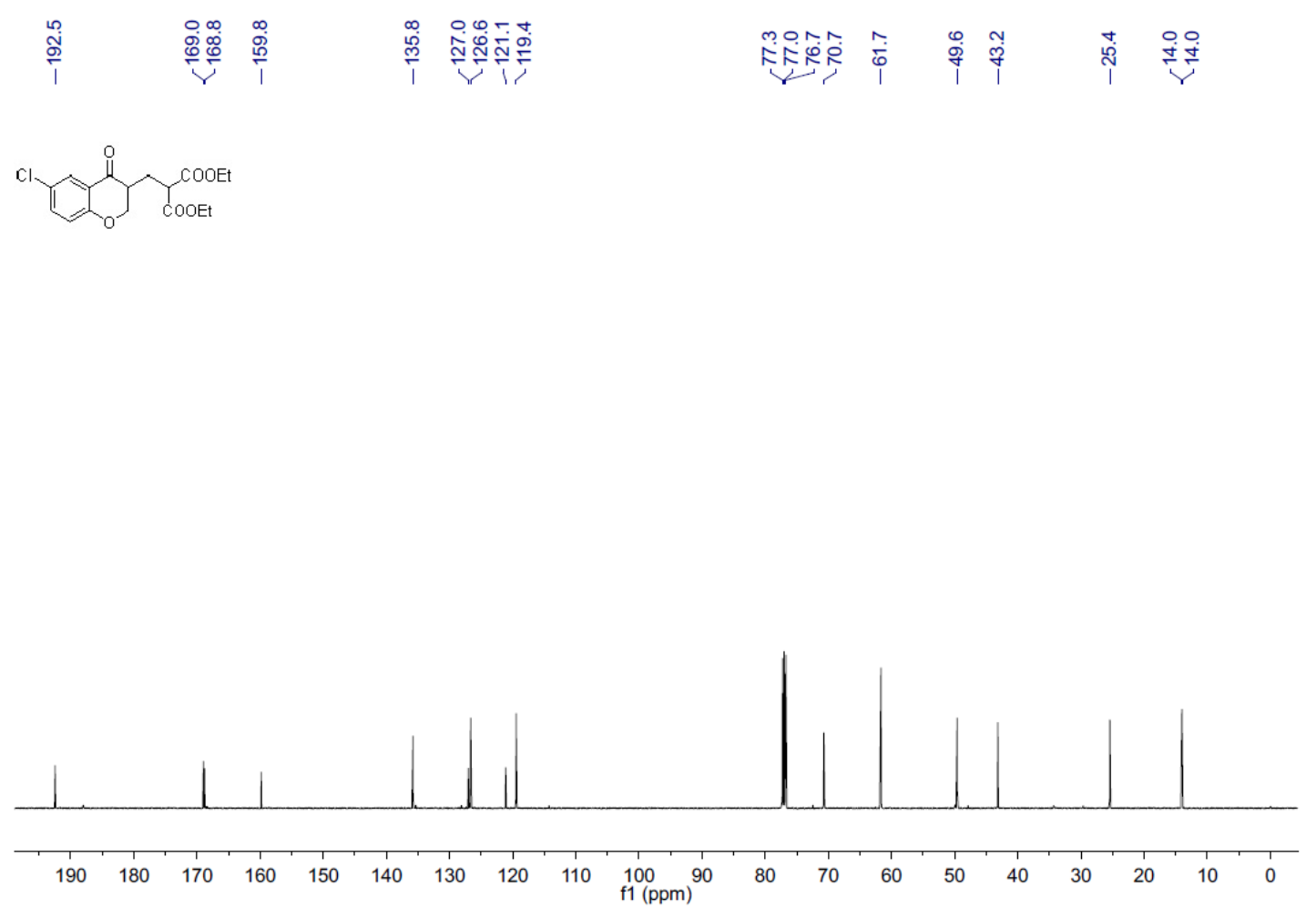

\section{3ha NMR}

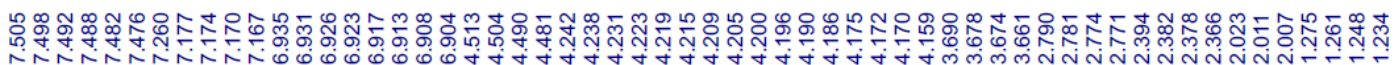

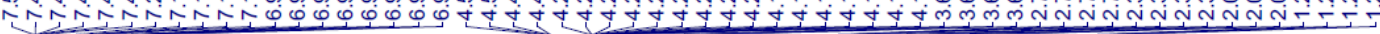

$\int_{0}^{\text {COOEt }}$

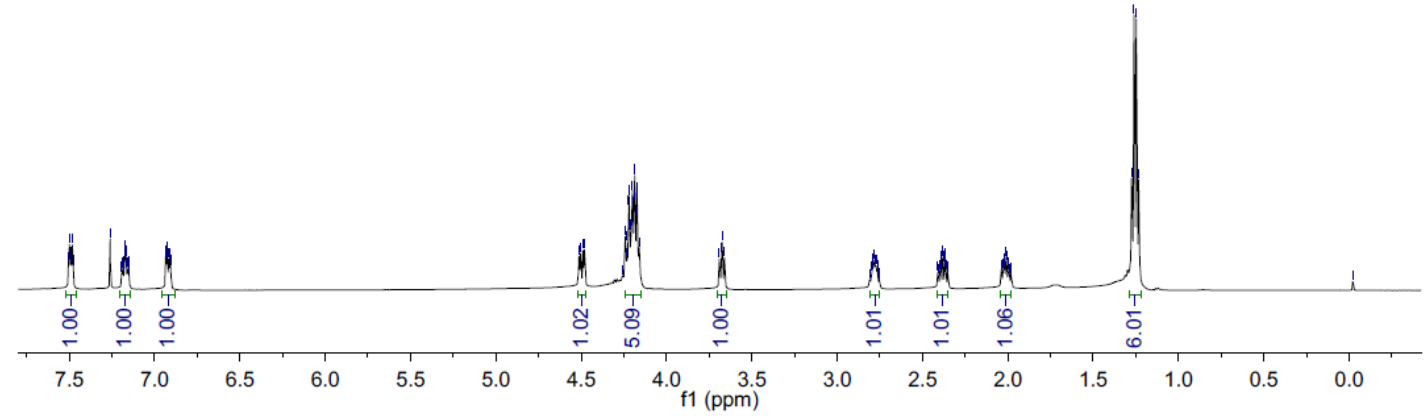



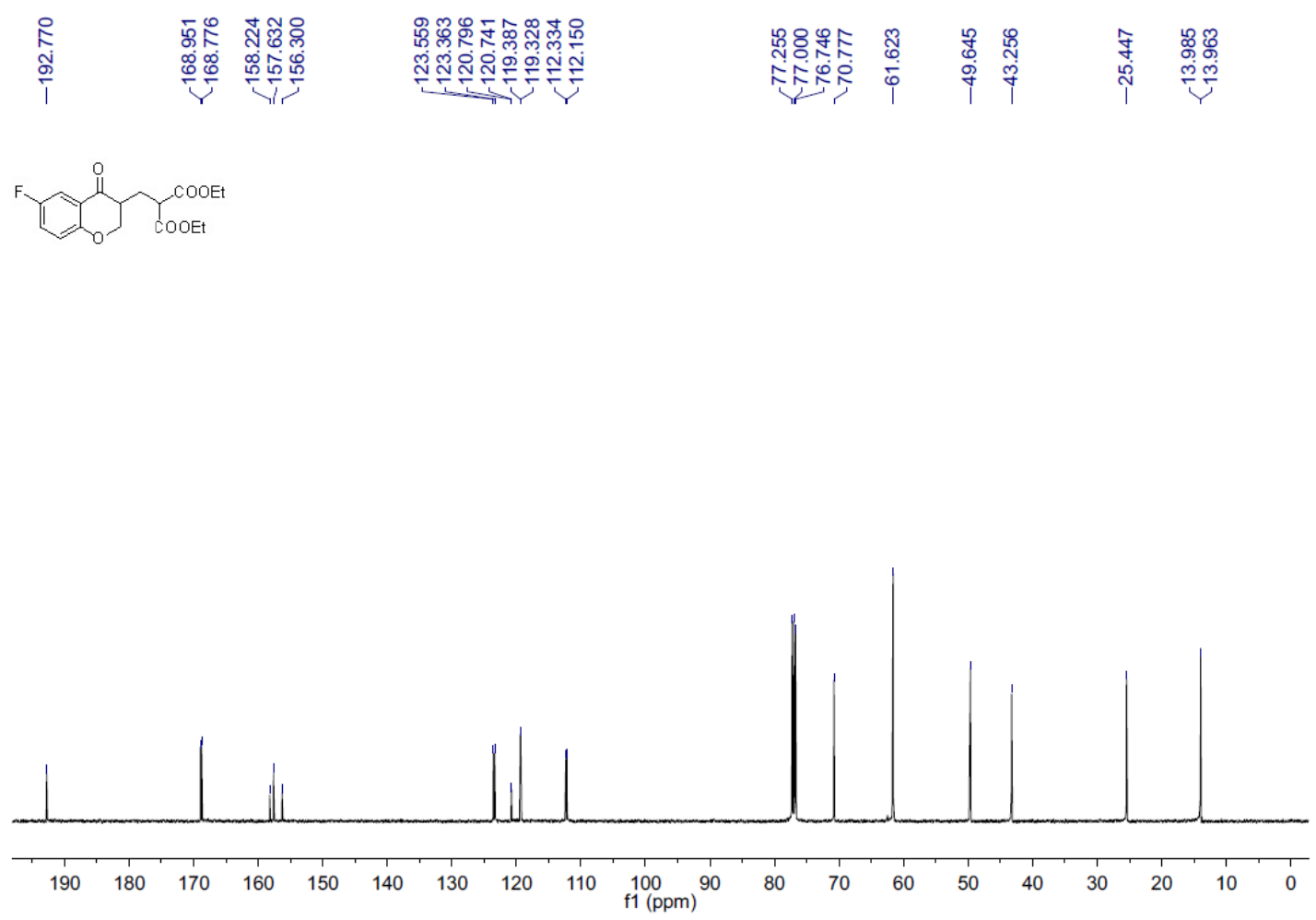

3ia NMR
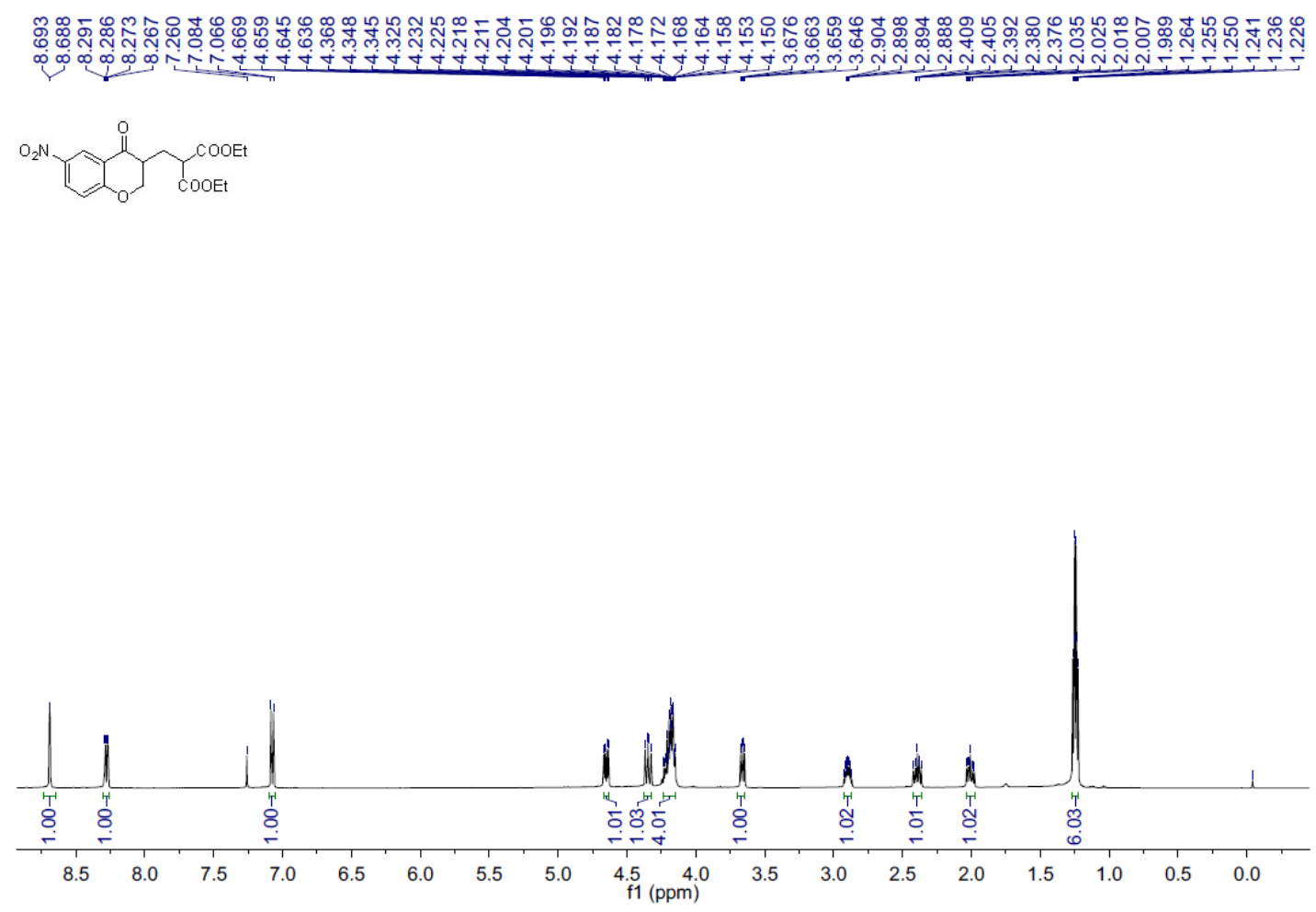

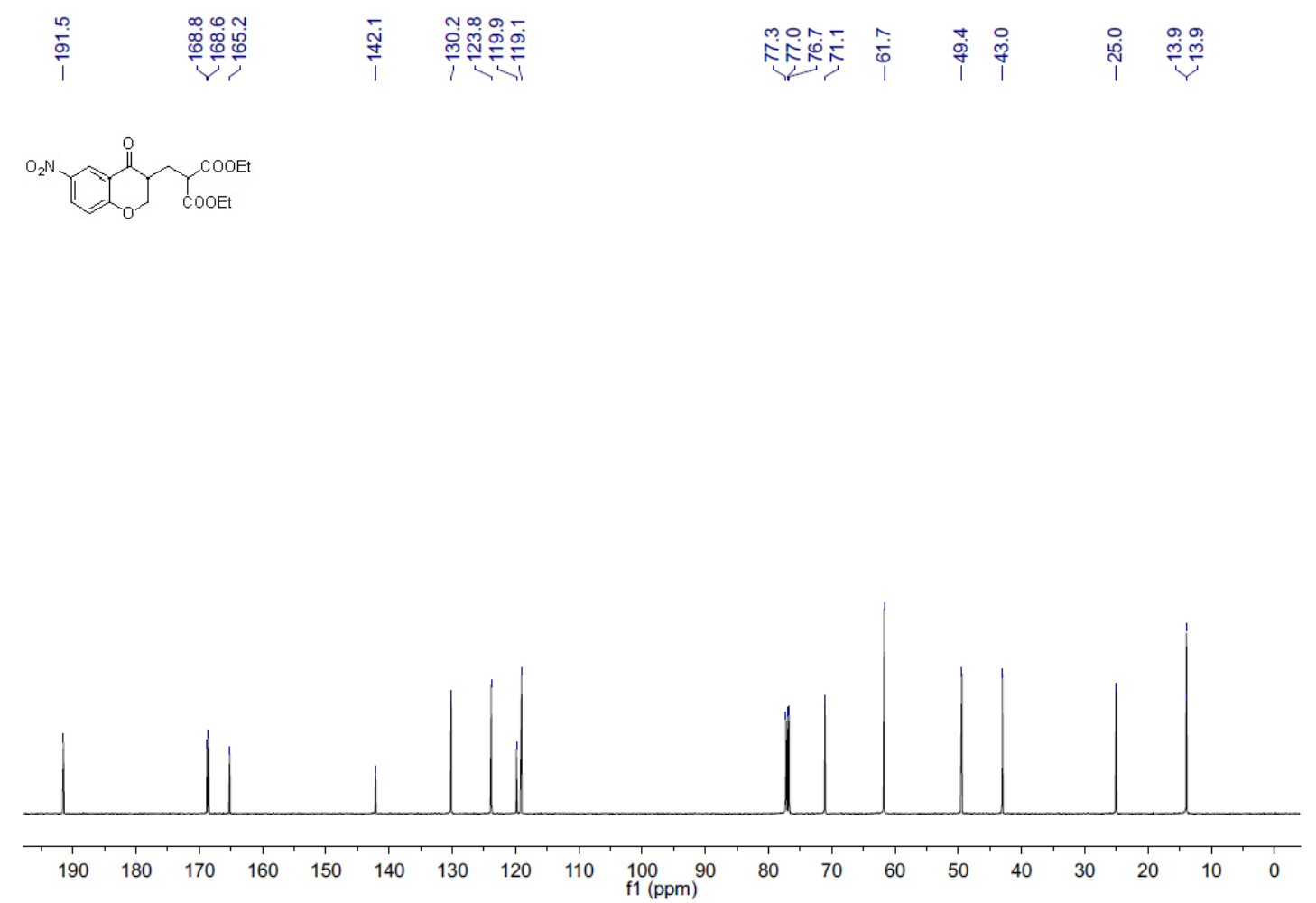

\section{3ja NMR}

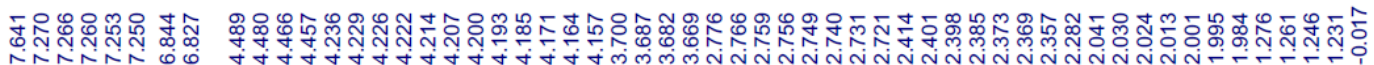

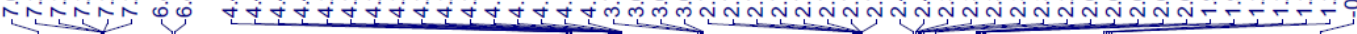

COCOEt

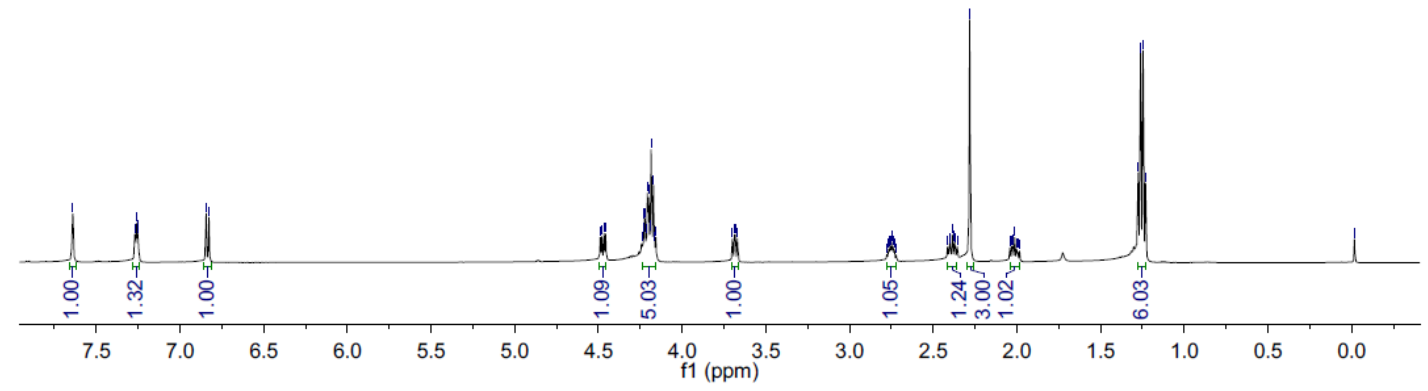




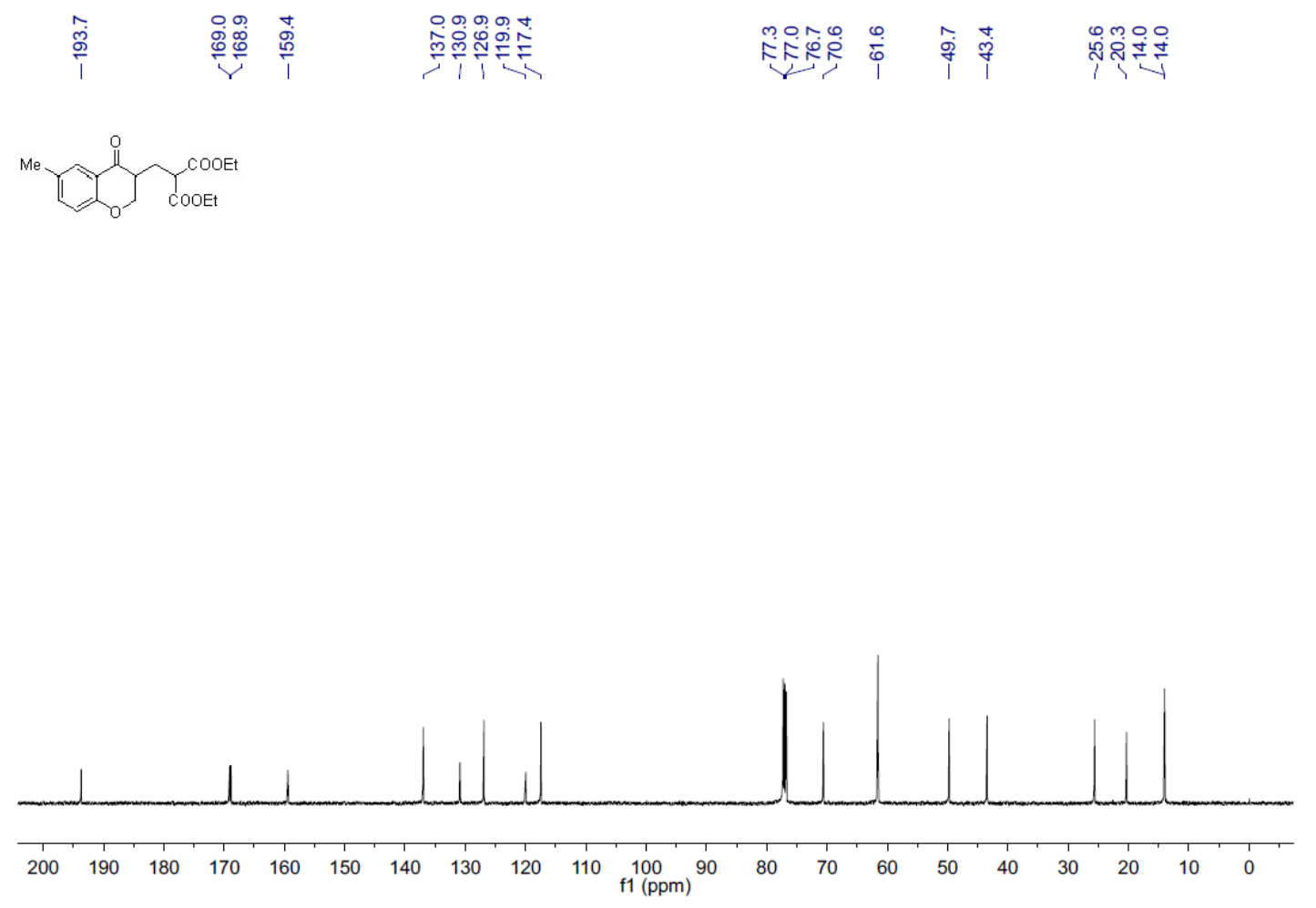

\section{3ka NMR}

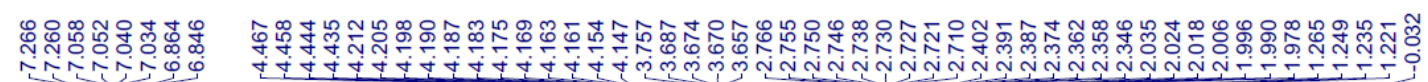<smiles>CCOC(CCC1COc2ccc(OC)cc2C1=O)C(=O)OC</smiles>

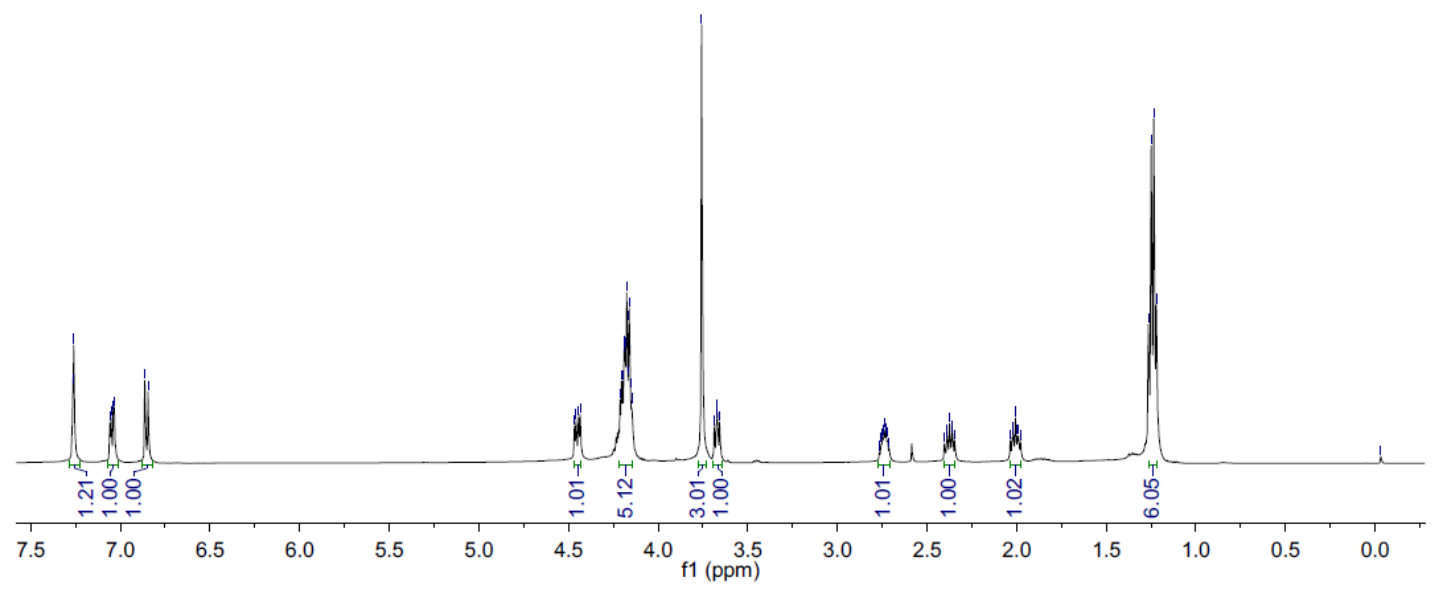



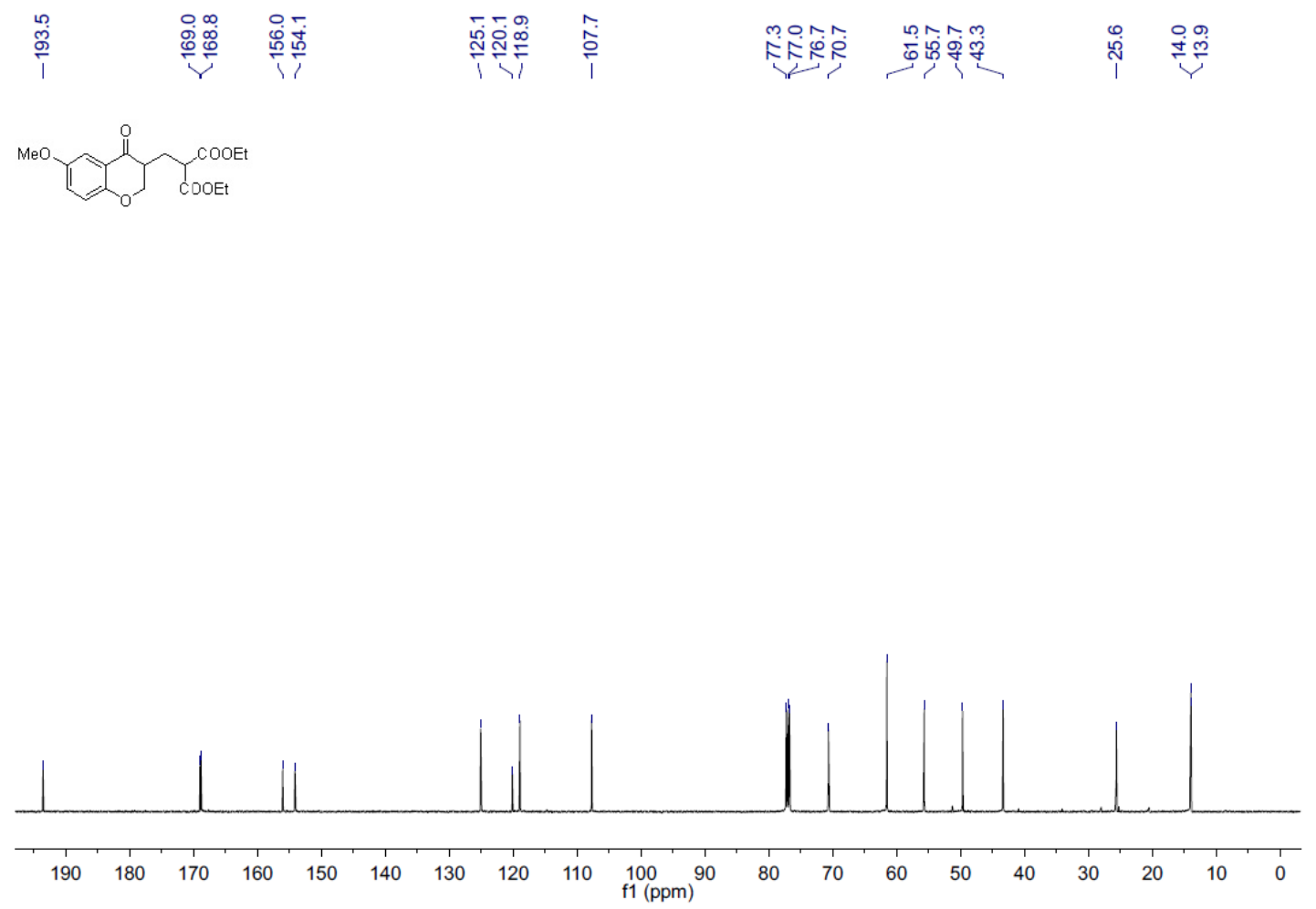

3la NMR

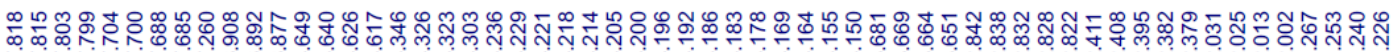

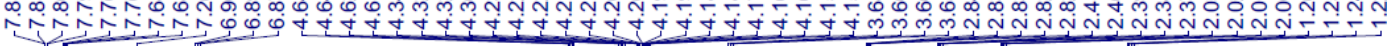

CODt

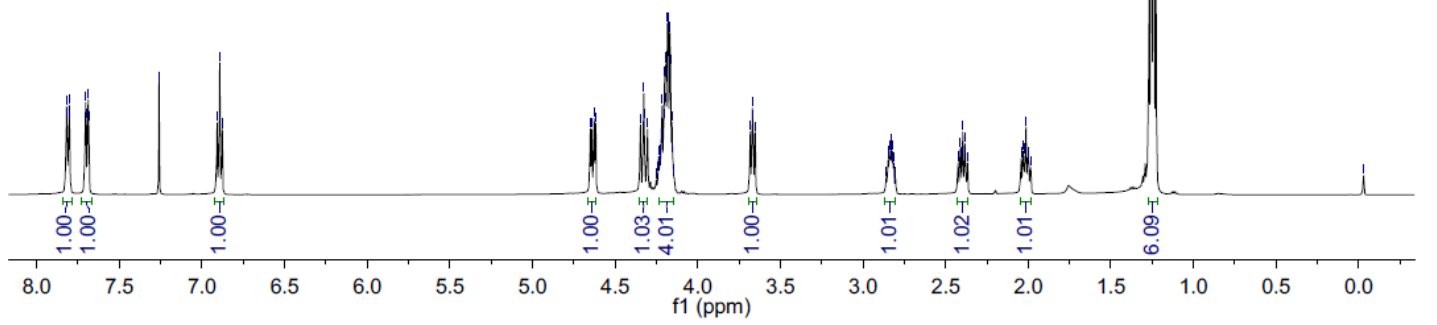




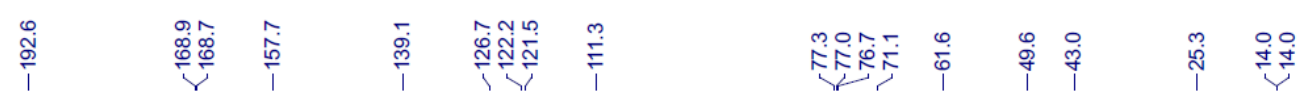<smiles>CCOC(CC(=O)c1coc2ccccc12)OCC</smiles>

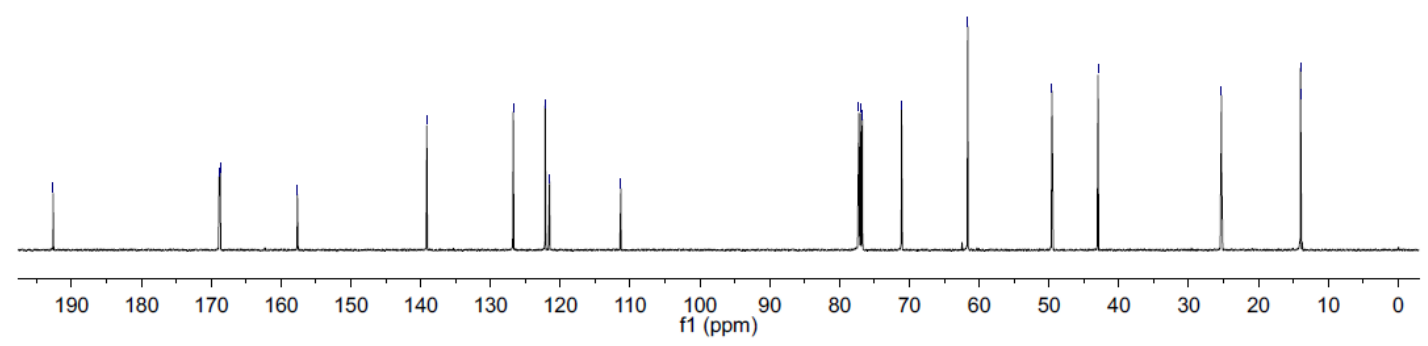

3ma NMR

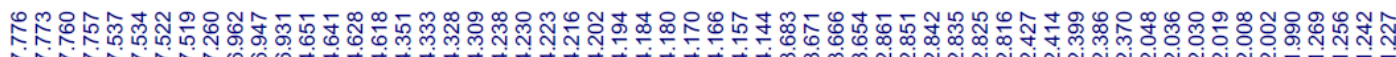

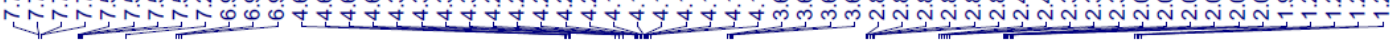

$\overbrace{C l}^{1} \int_{C O D E t}^{C O O E t}$

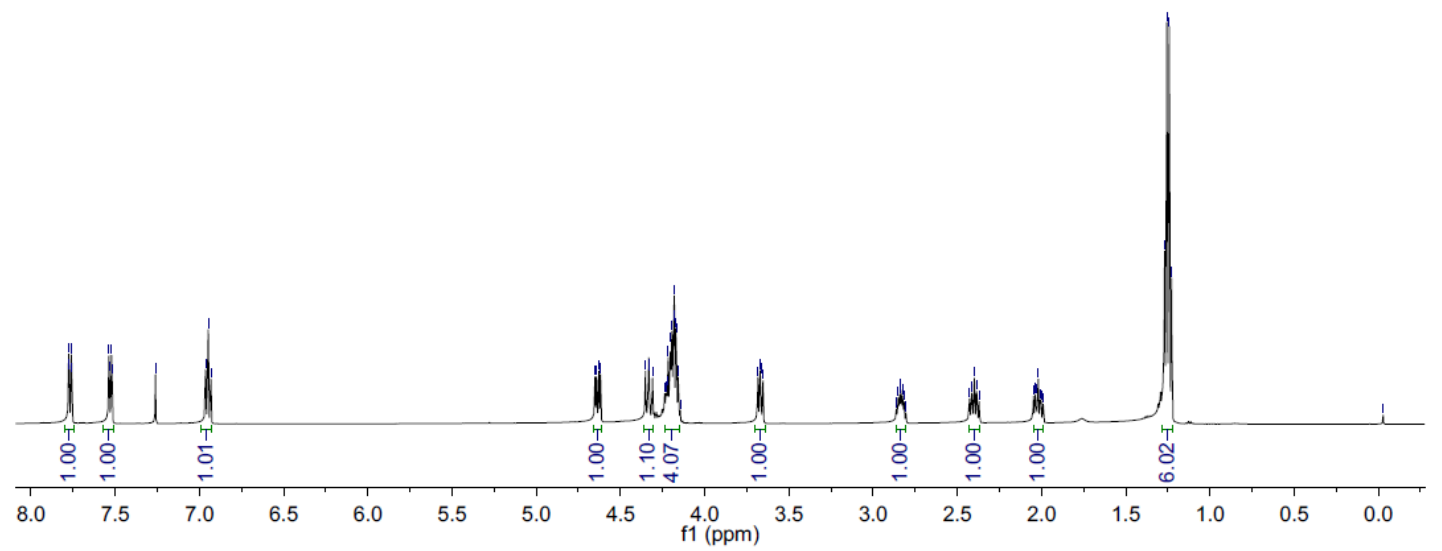




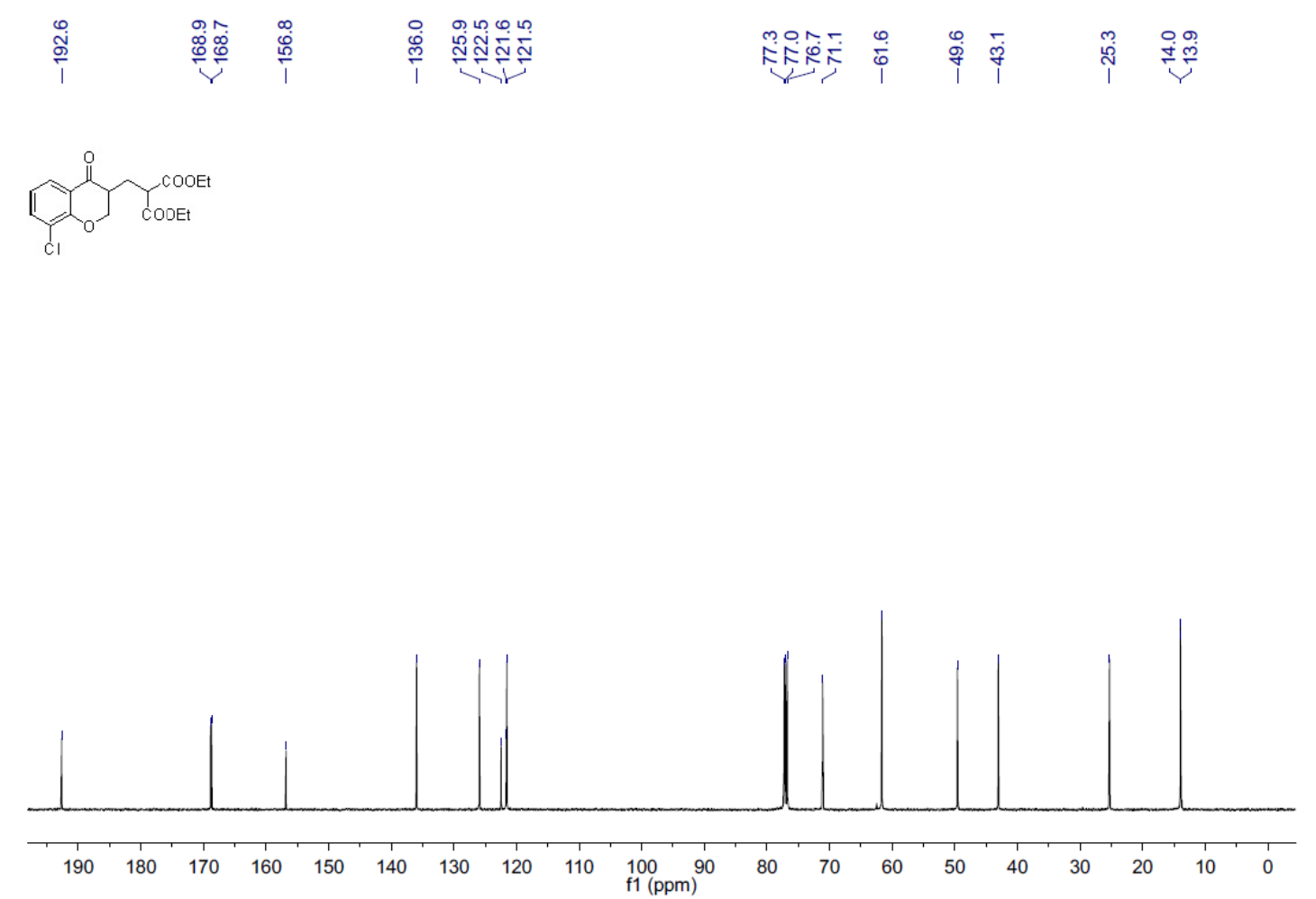

\section{3na NMR}

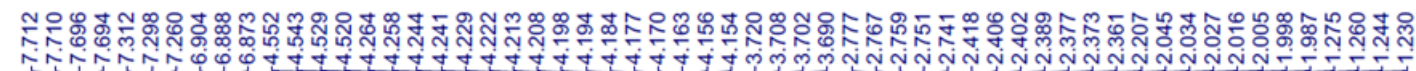
CODEt

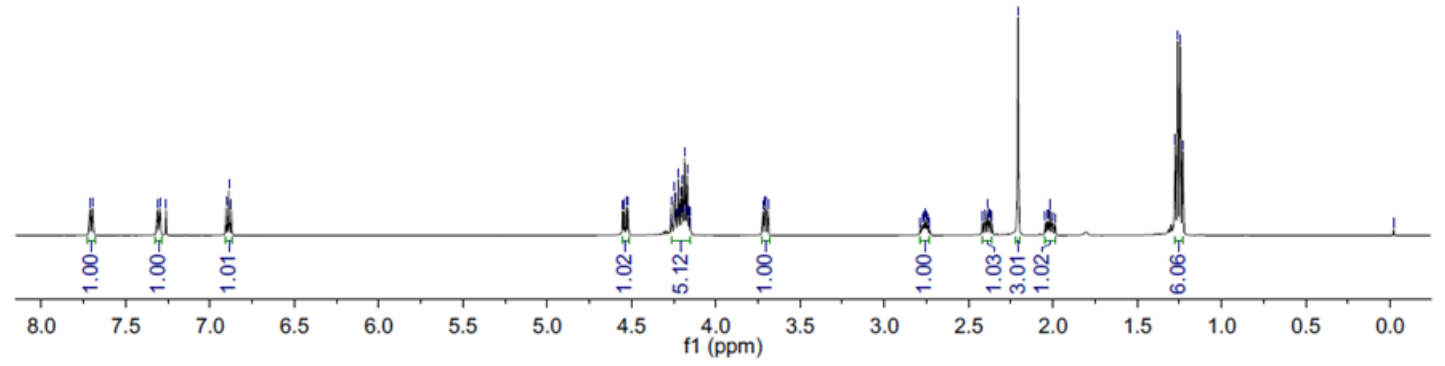




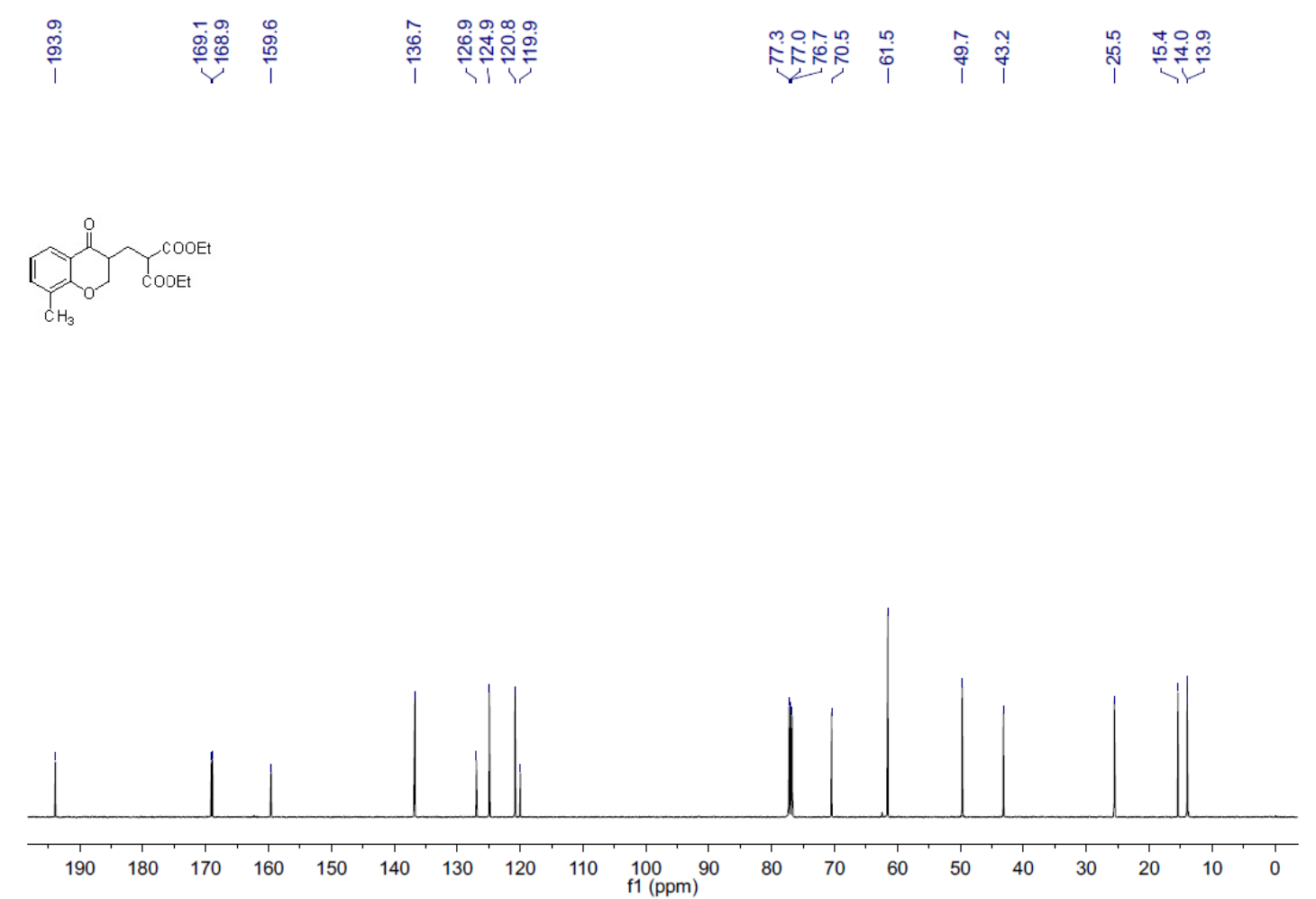

\section{3oa NMR}

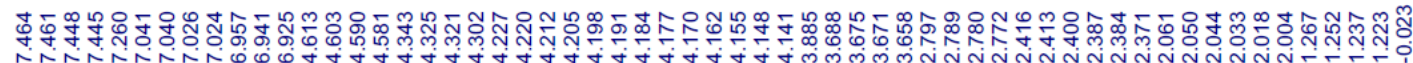

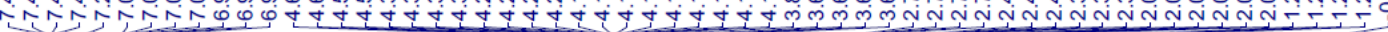
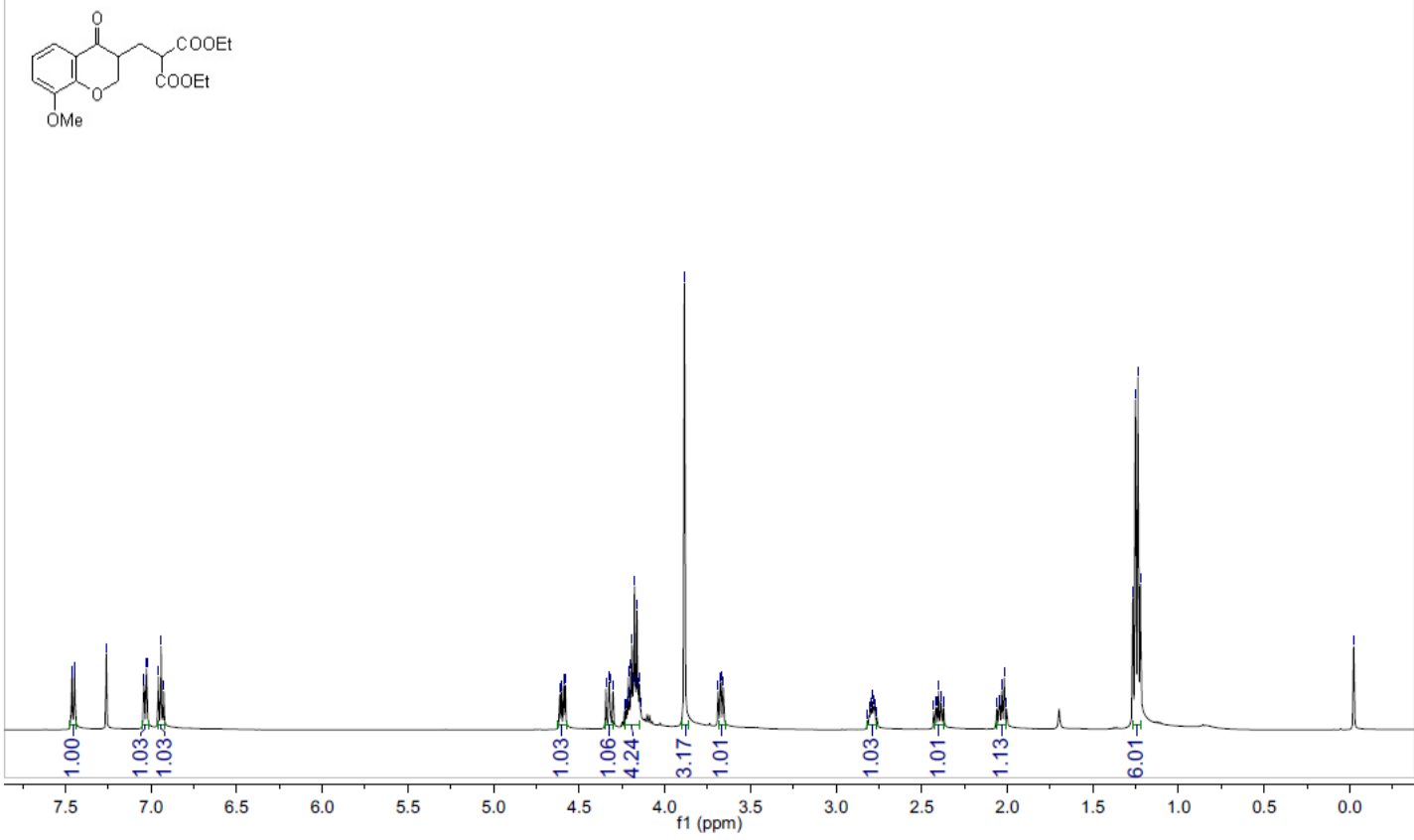

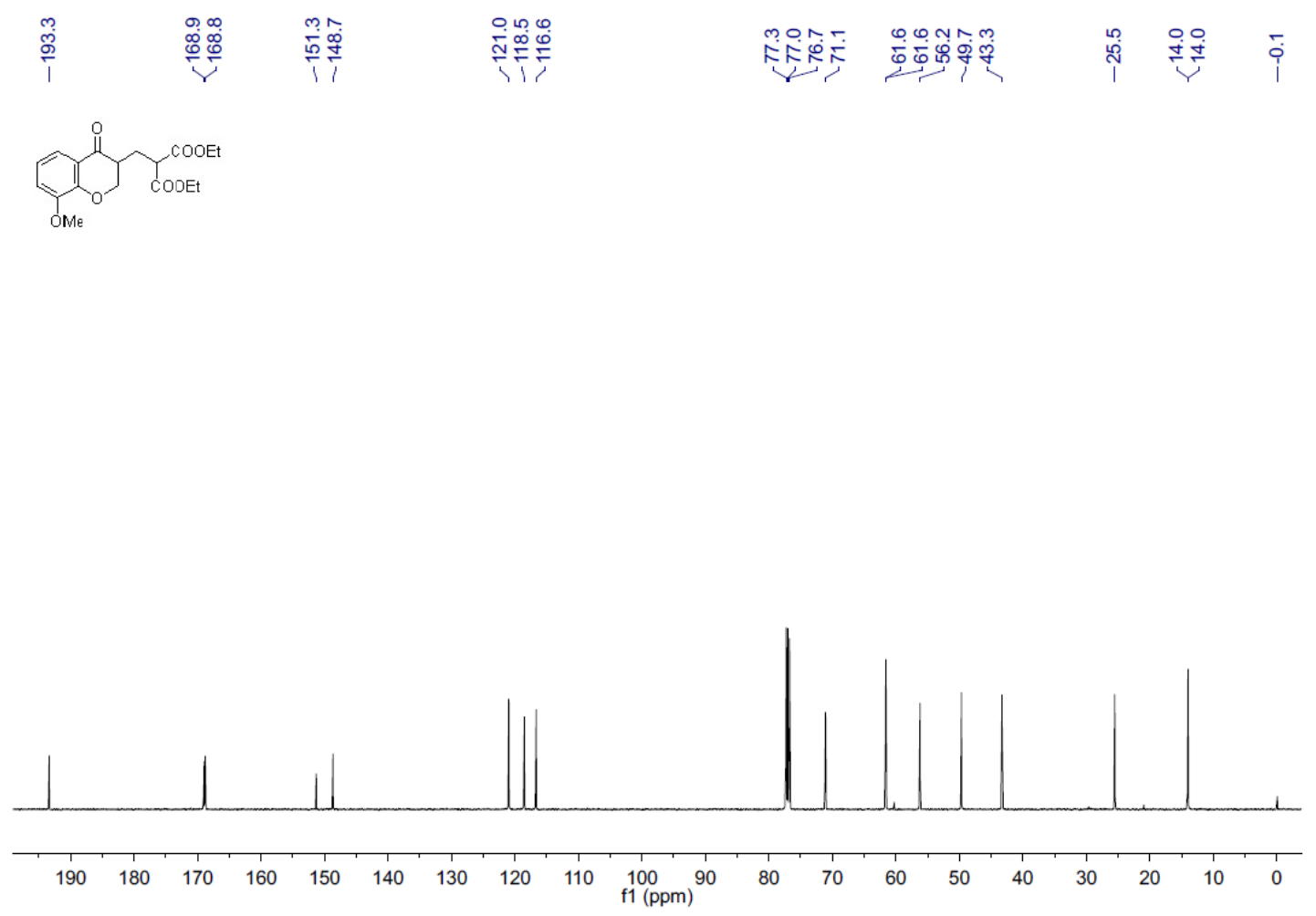

3pa NMR
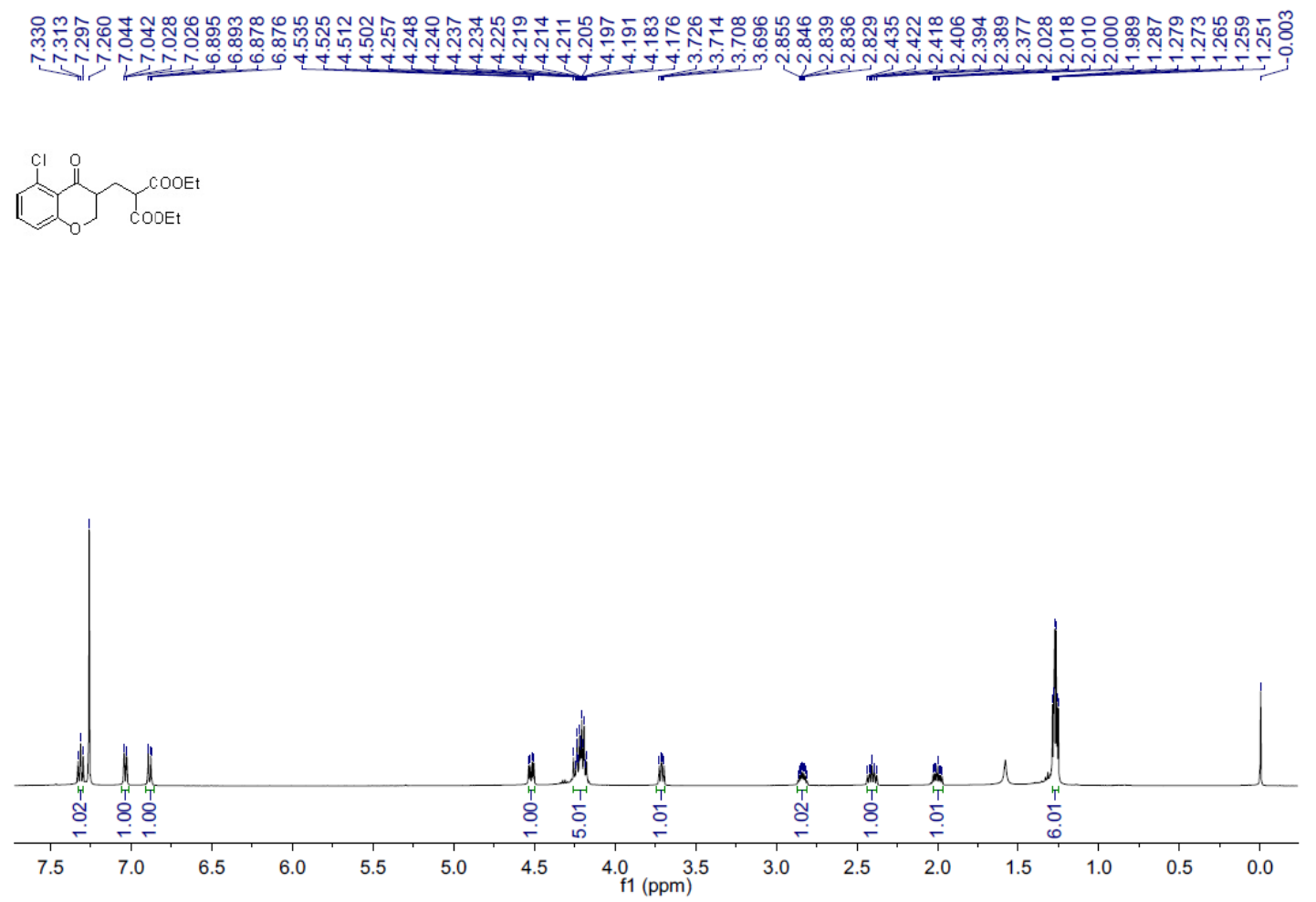


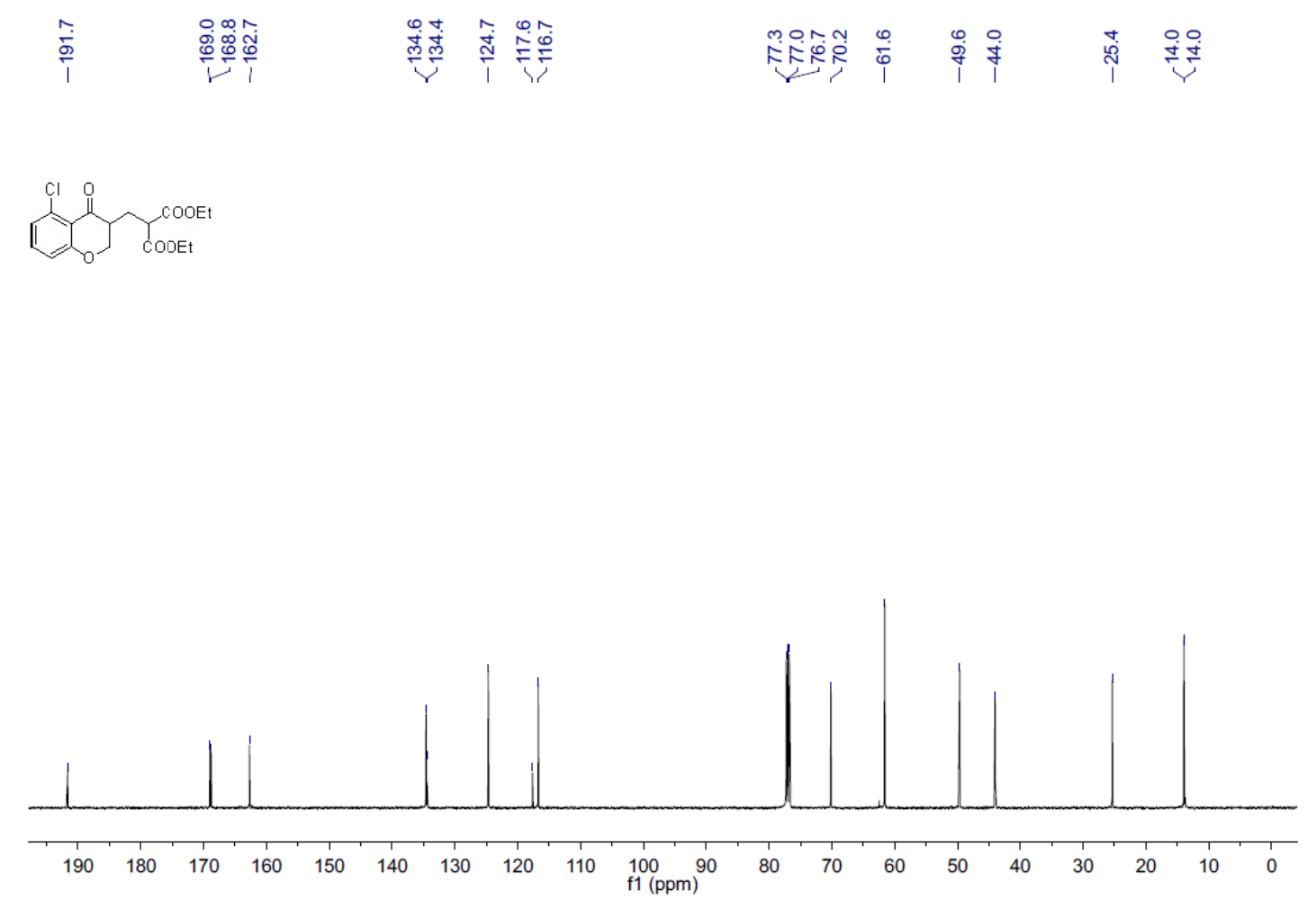

\section{3qa NMR}

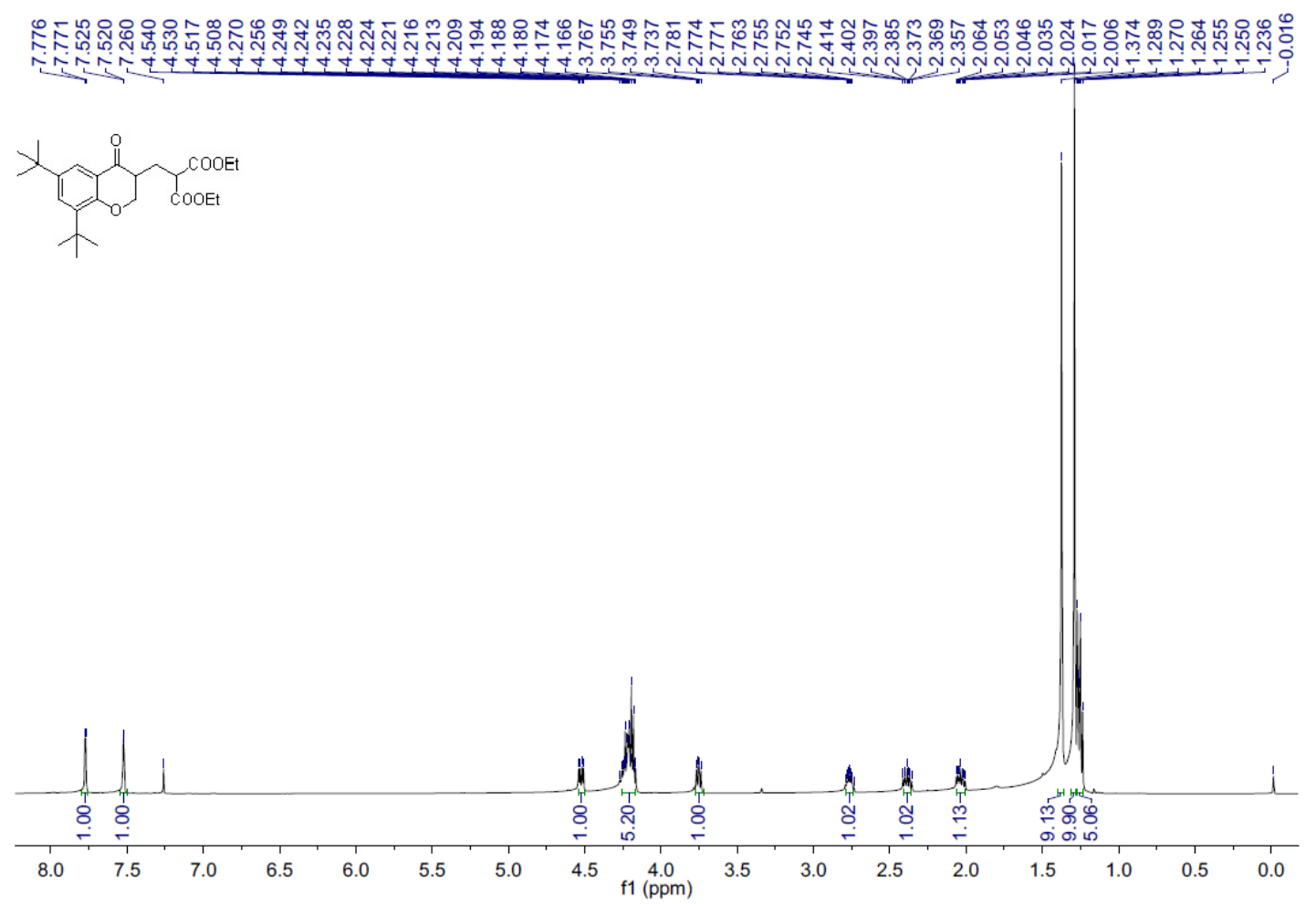




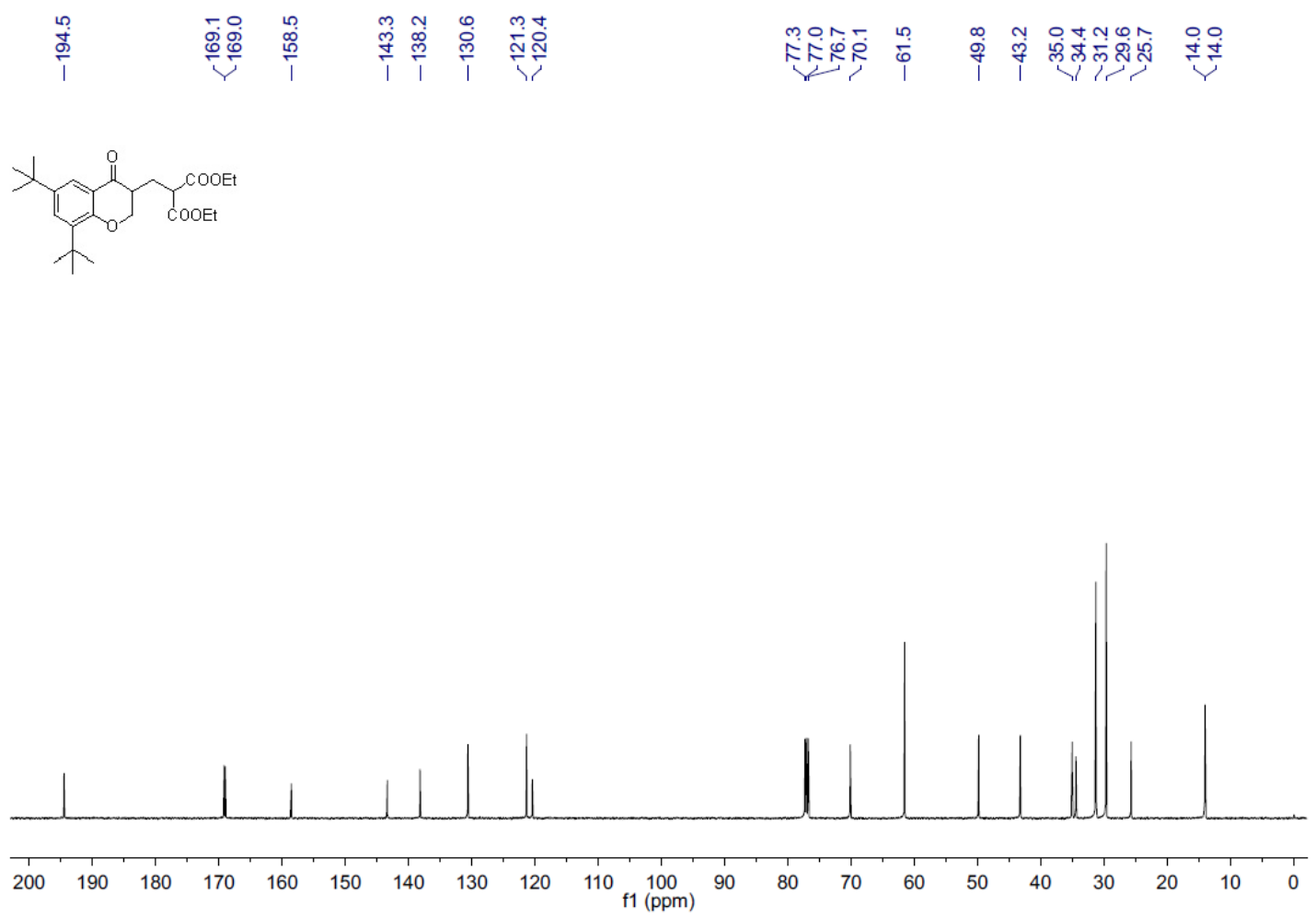

\section{3ra NMR}

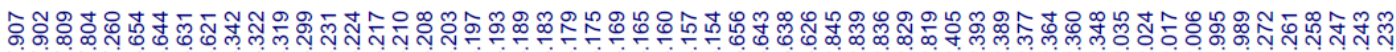

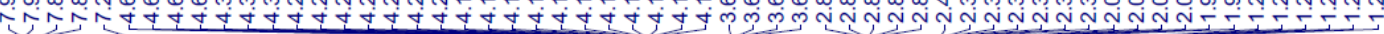<smiles>CCOC(=O)C(CC1COc2c(Br)cc(Br)cc2C1=O)C(=O)OCC</smiles>

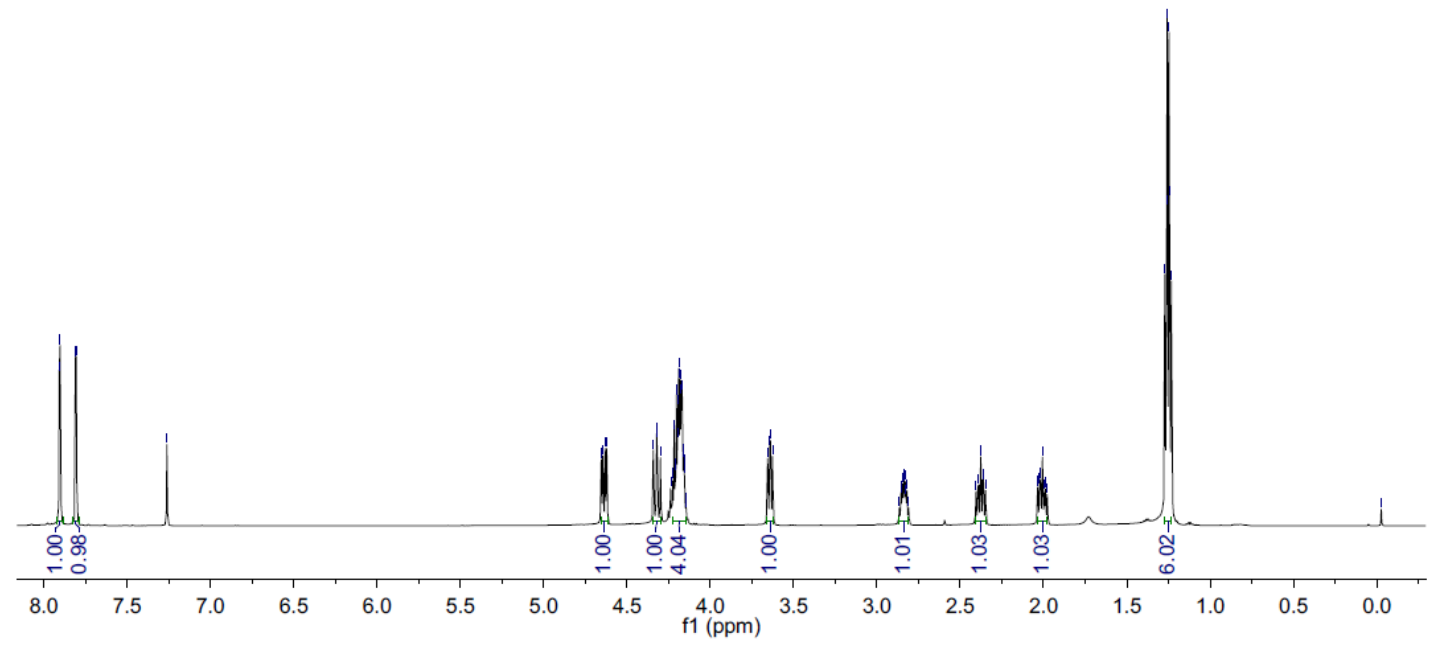




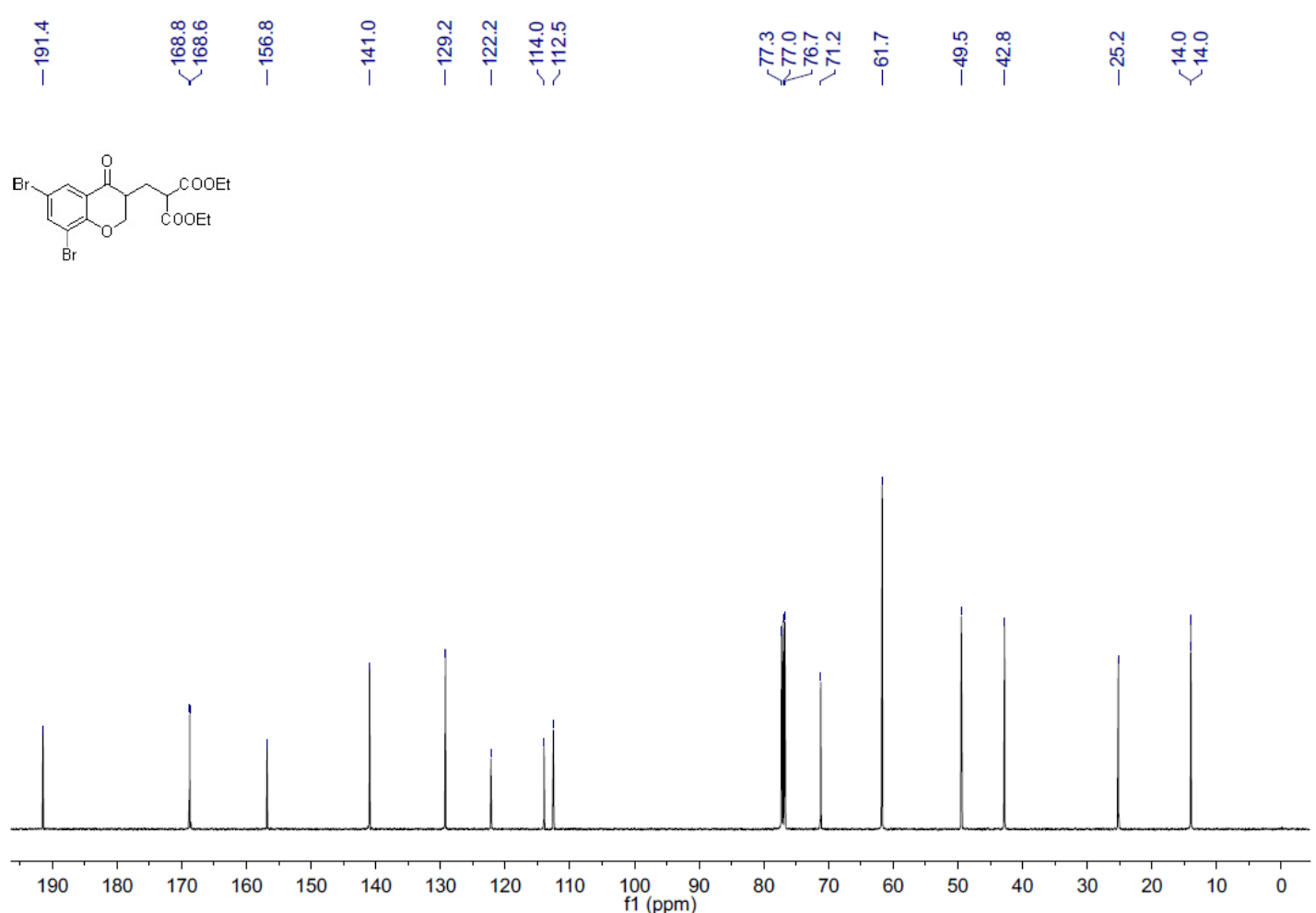

\section{3sa NMR}

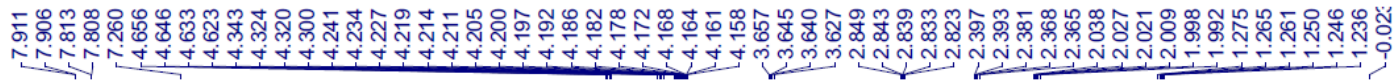

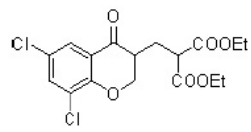

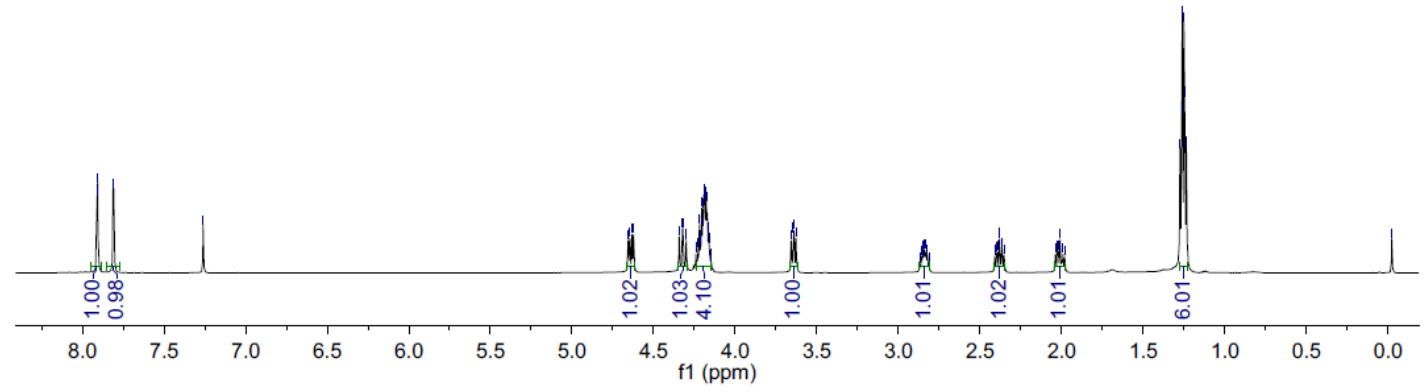




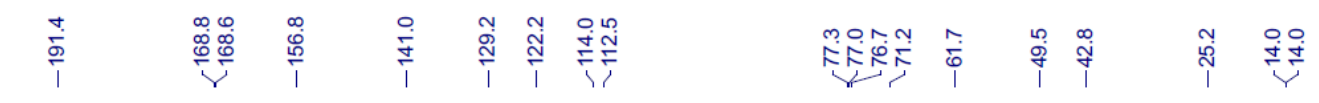<smiles>CCOC(=O)CC1COc2c(Cl)cc(Cl)cc2C1=O</smiles>

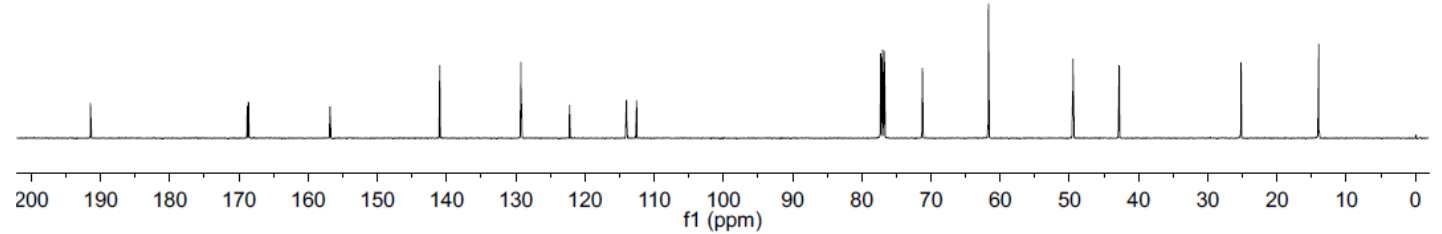

3ta NMR

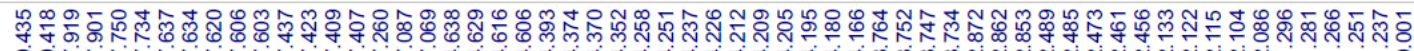

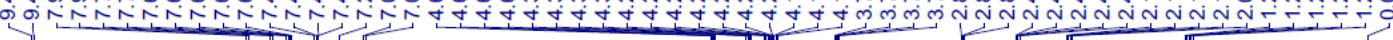
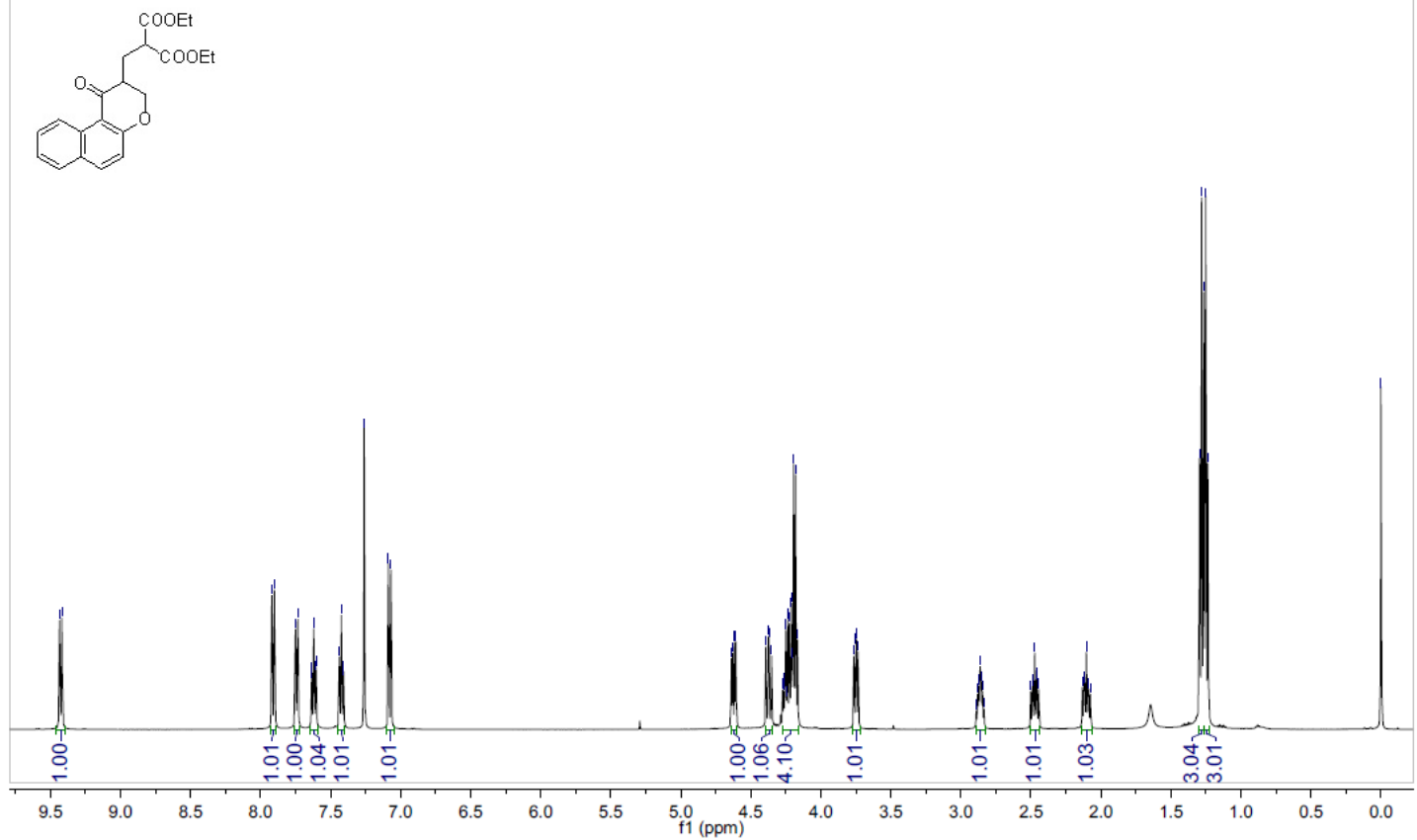


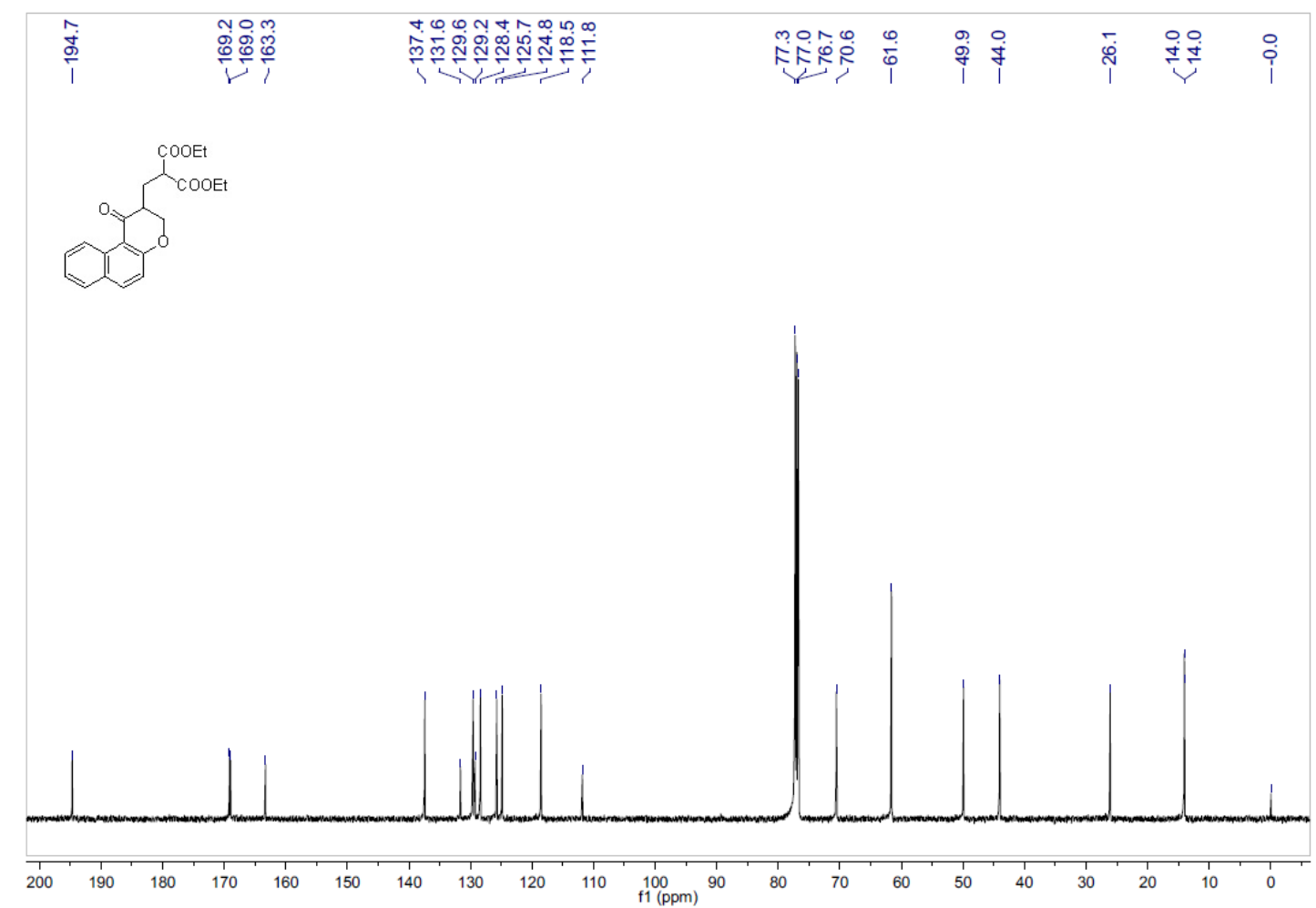

3ua NMR
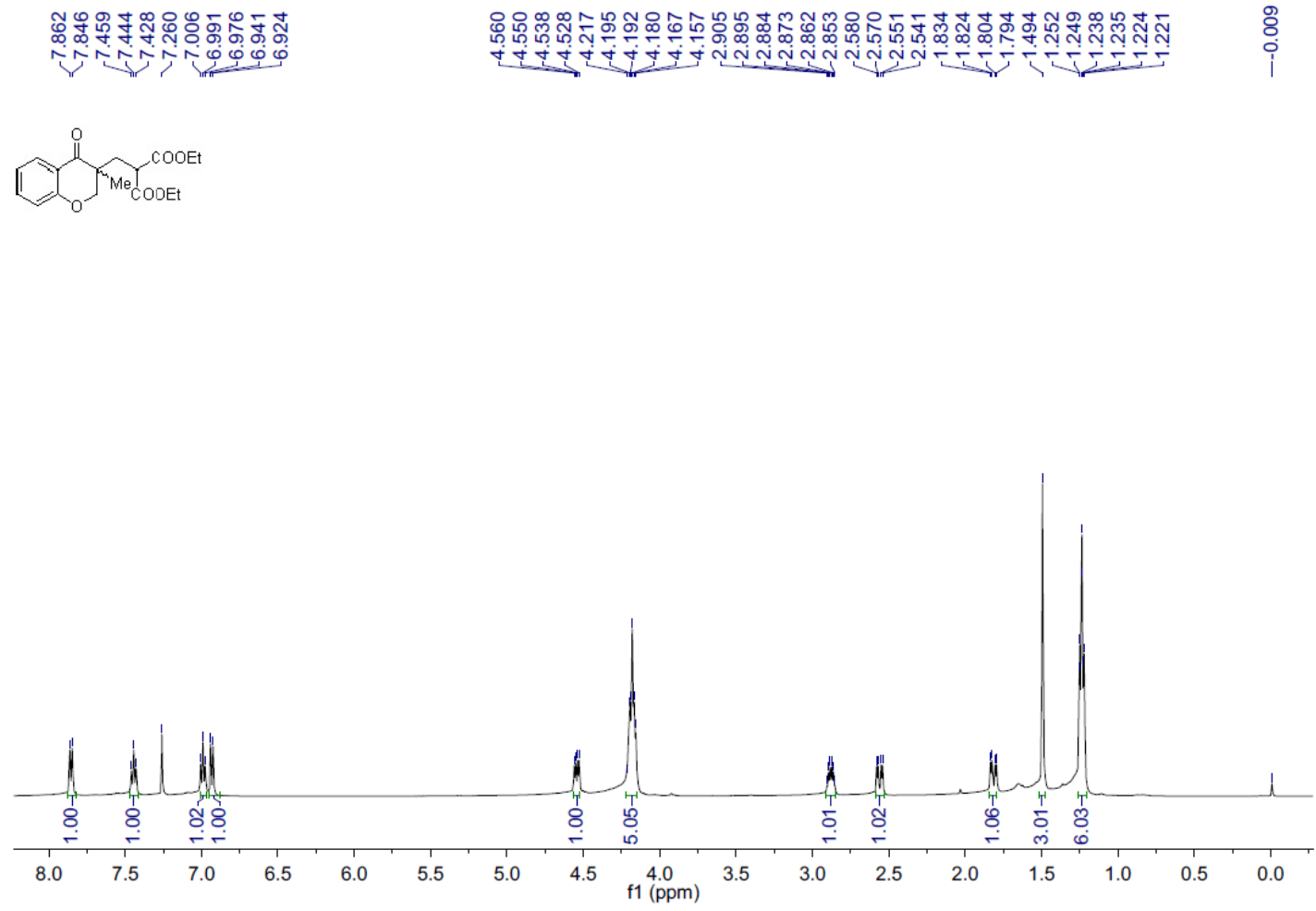


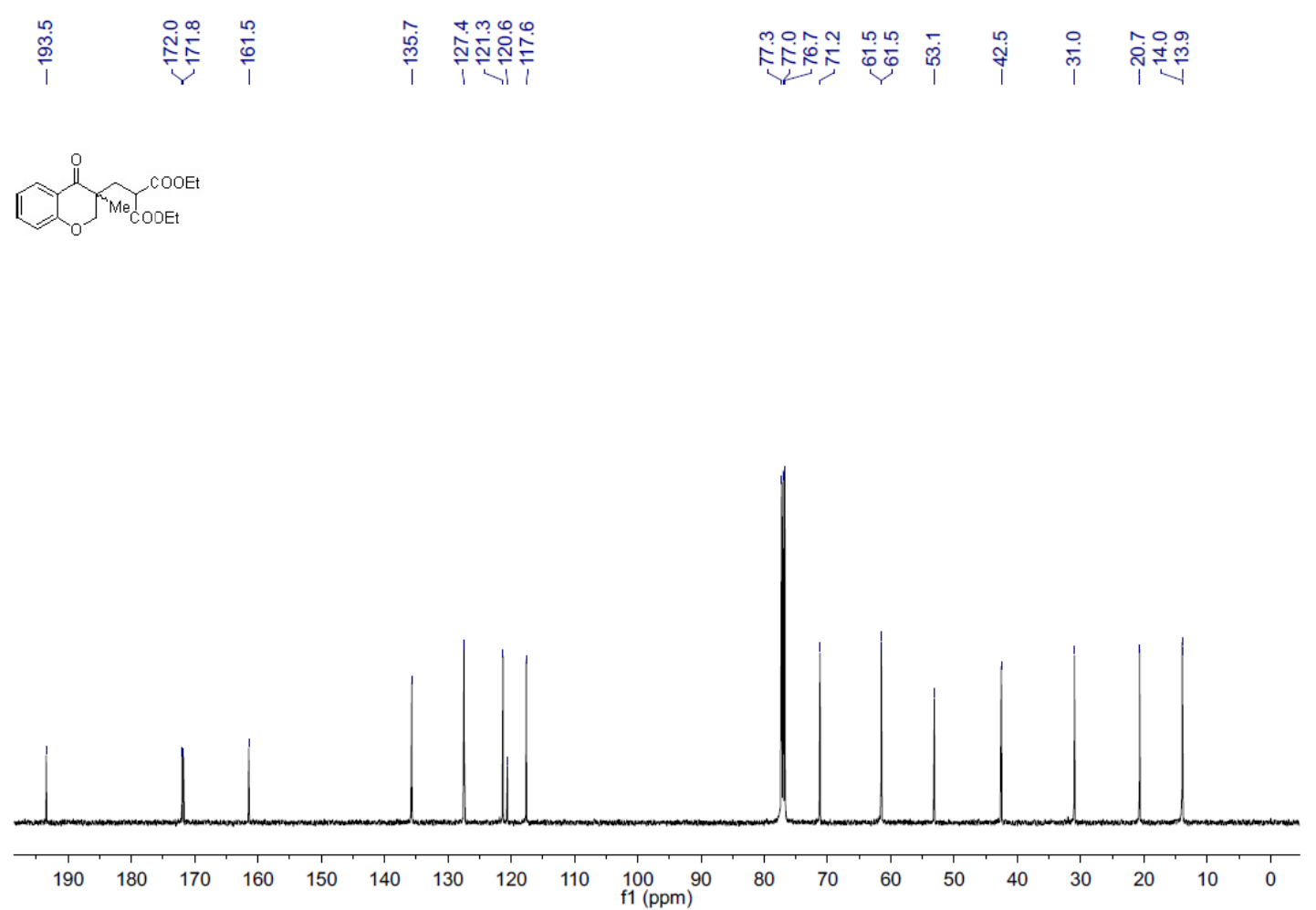

\section{3va NMR}

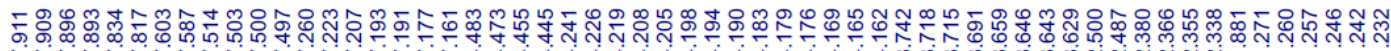

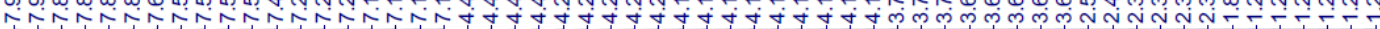<smiles>CCOC(COc1ccccc1)CC1CN(c2ccc(C)cc2)c2ccccc2C1=O</smiles>

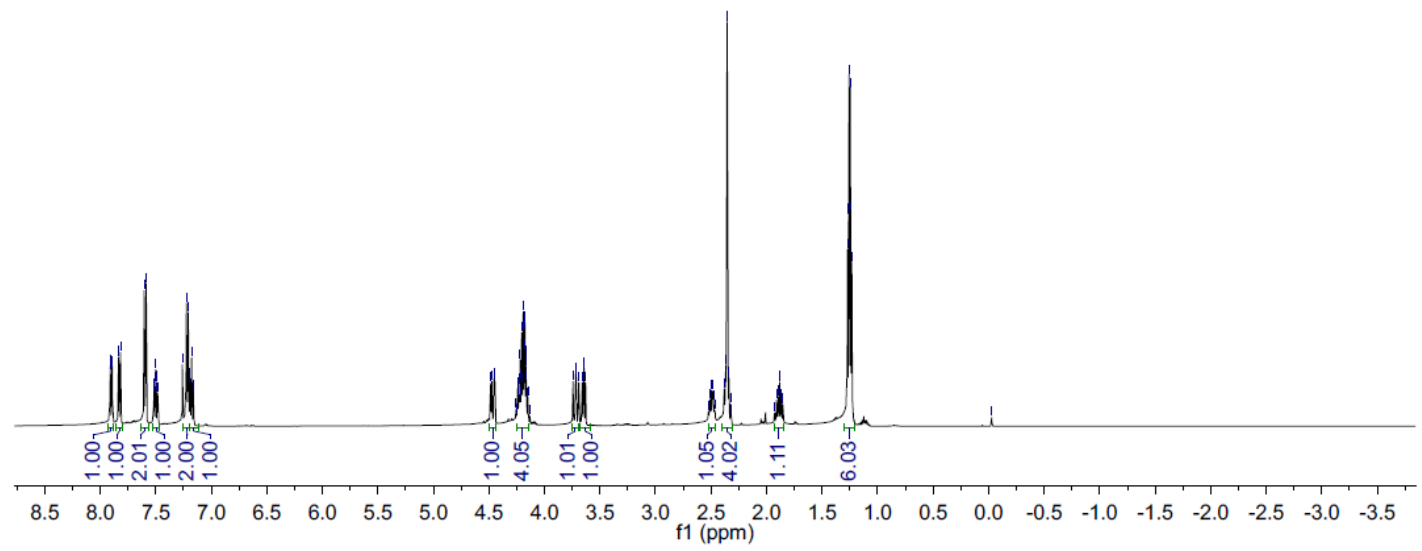



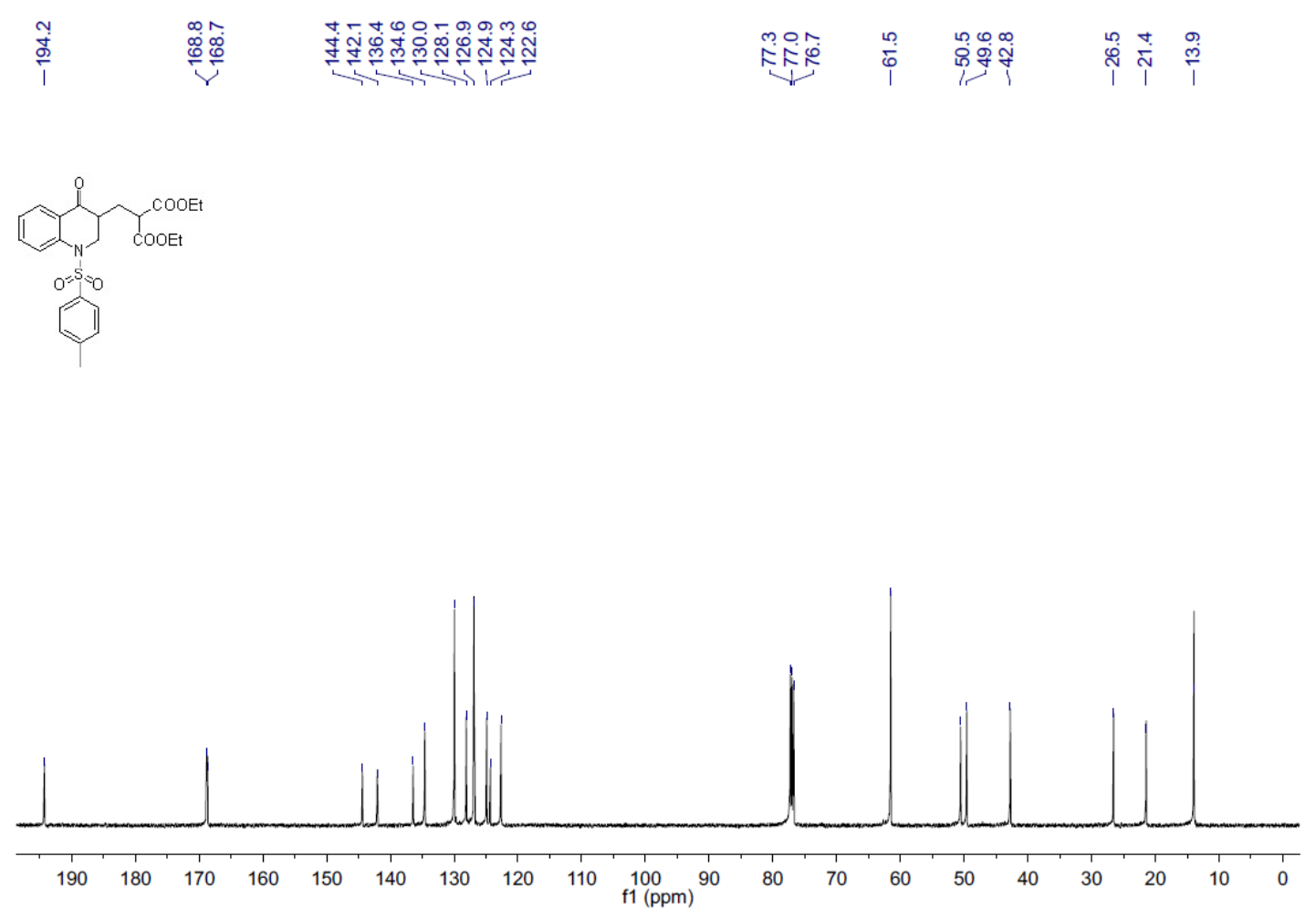

\section{3wa NMR}

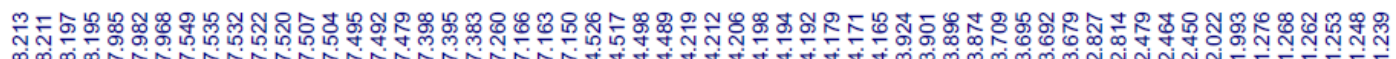

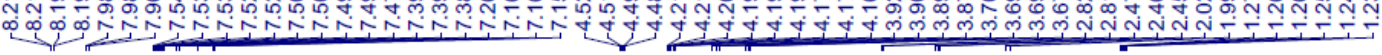

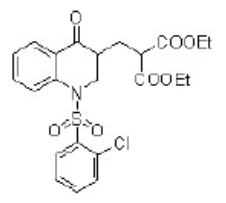

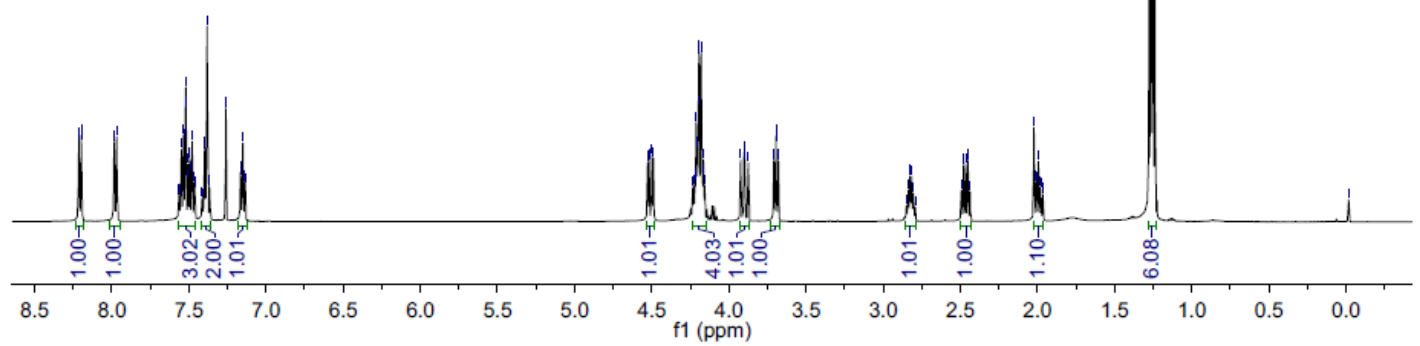




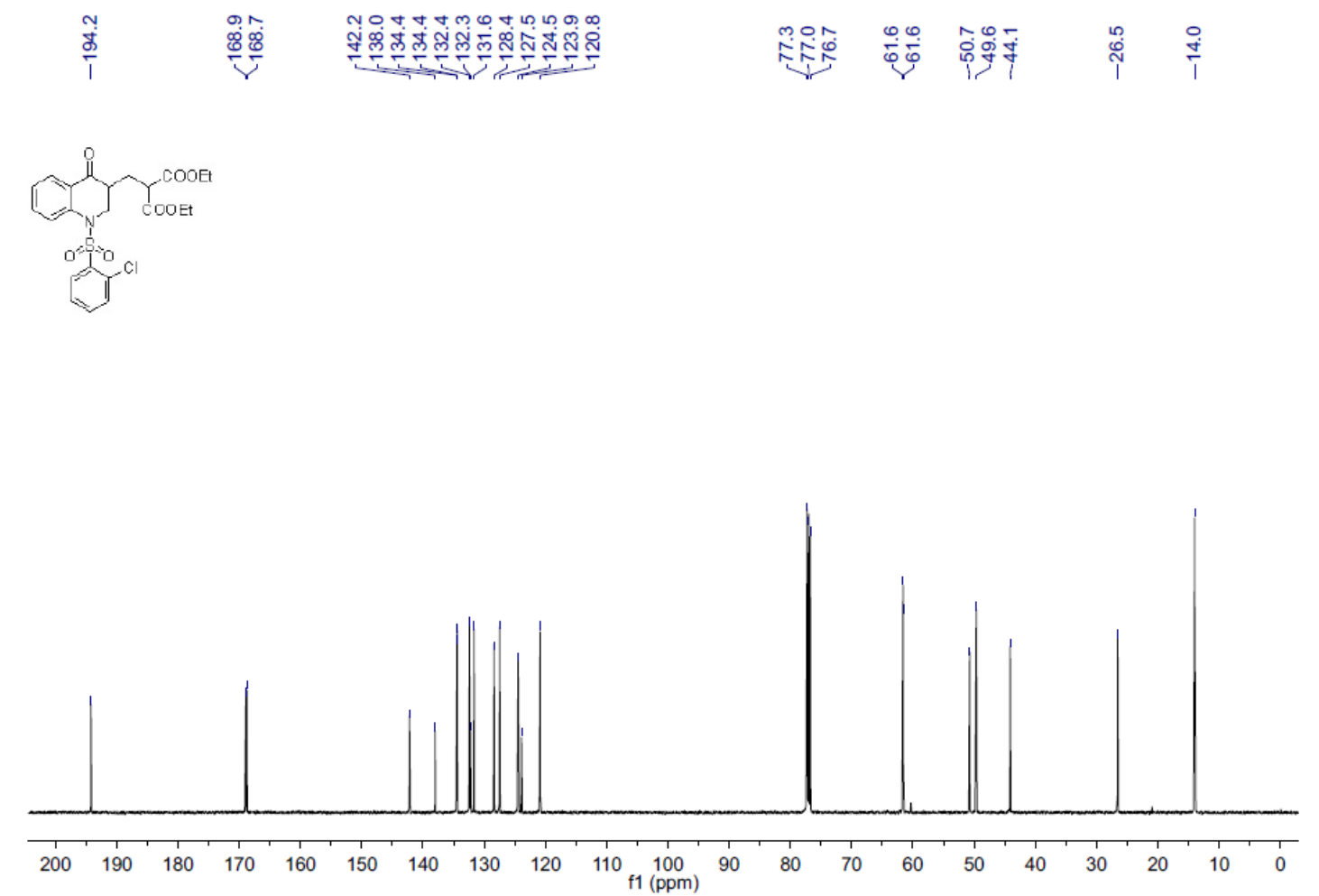

\section{3xa NMR}

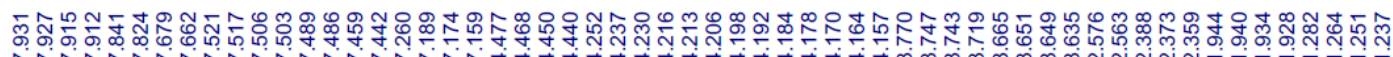

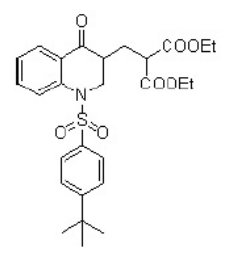

$\|$ U.

80808

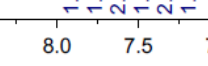

$6.5 \quad 6.0$

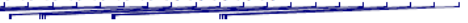




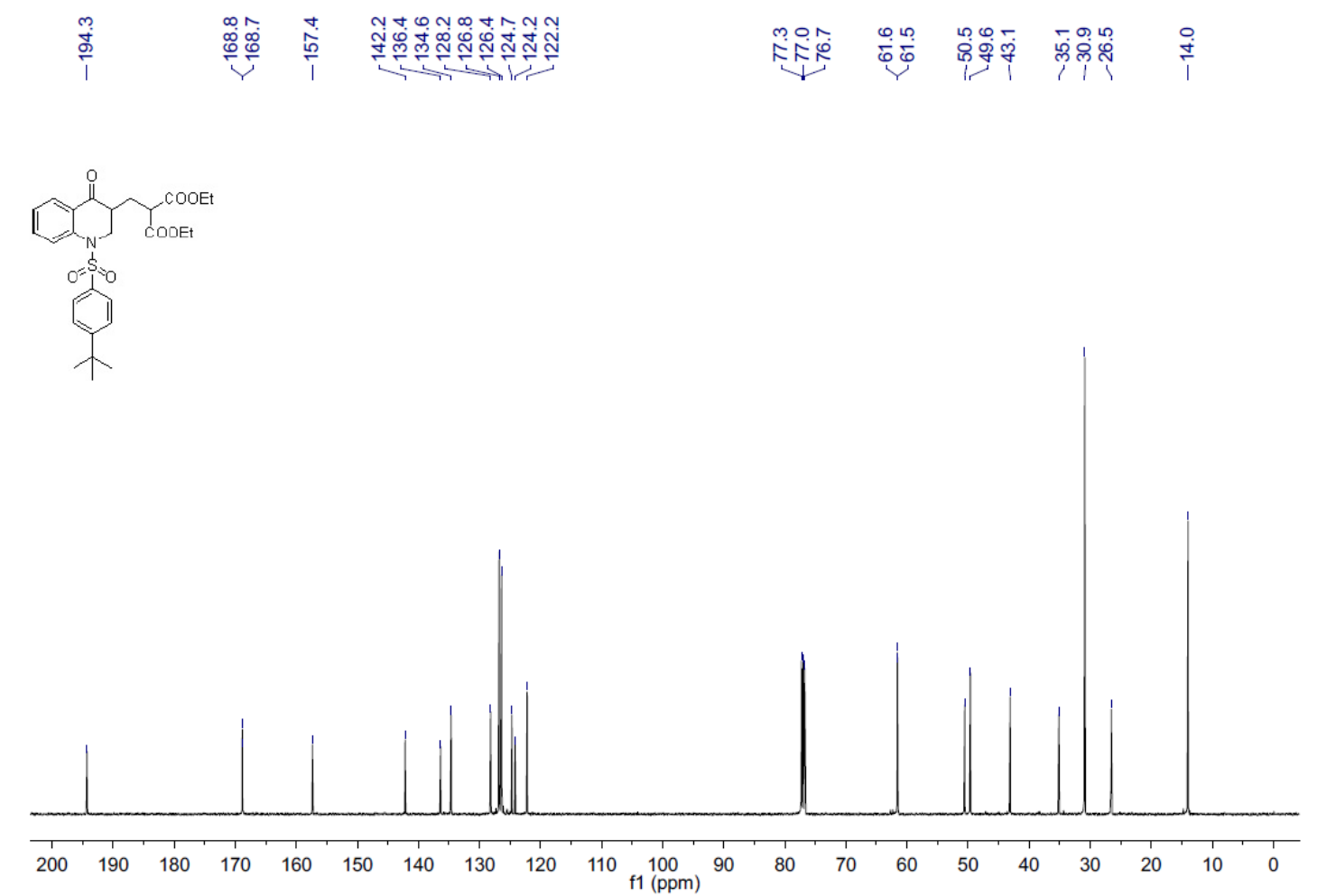

3ya NMR

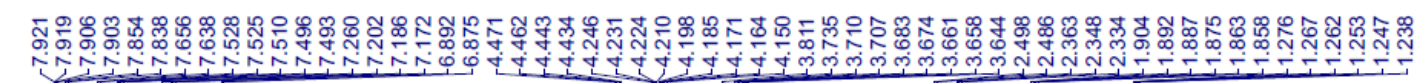

conct

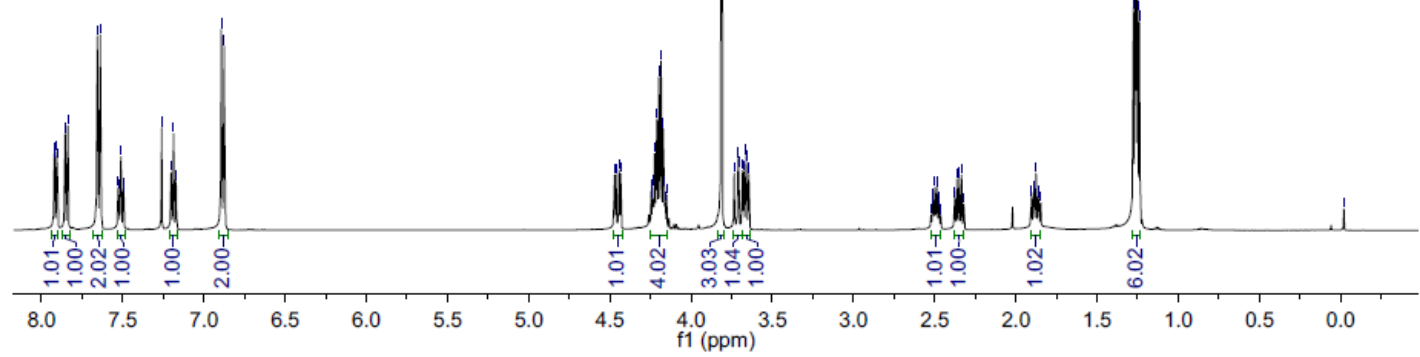




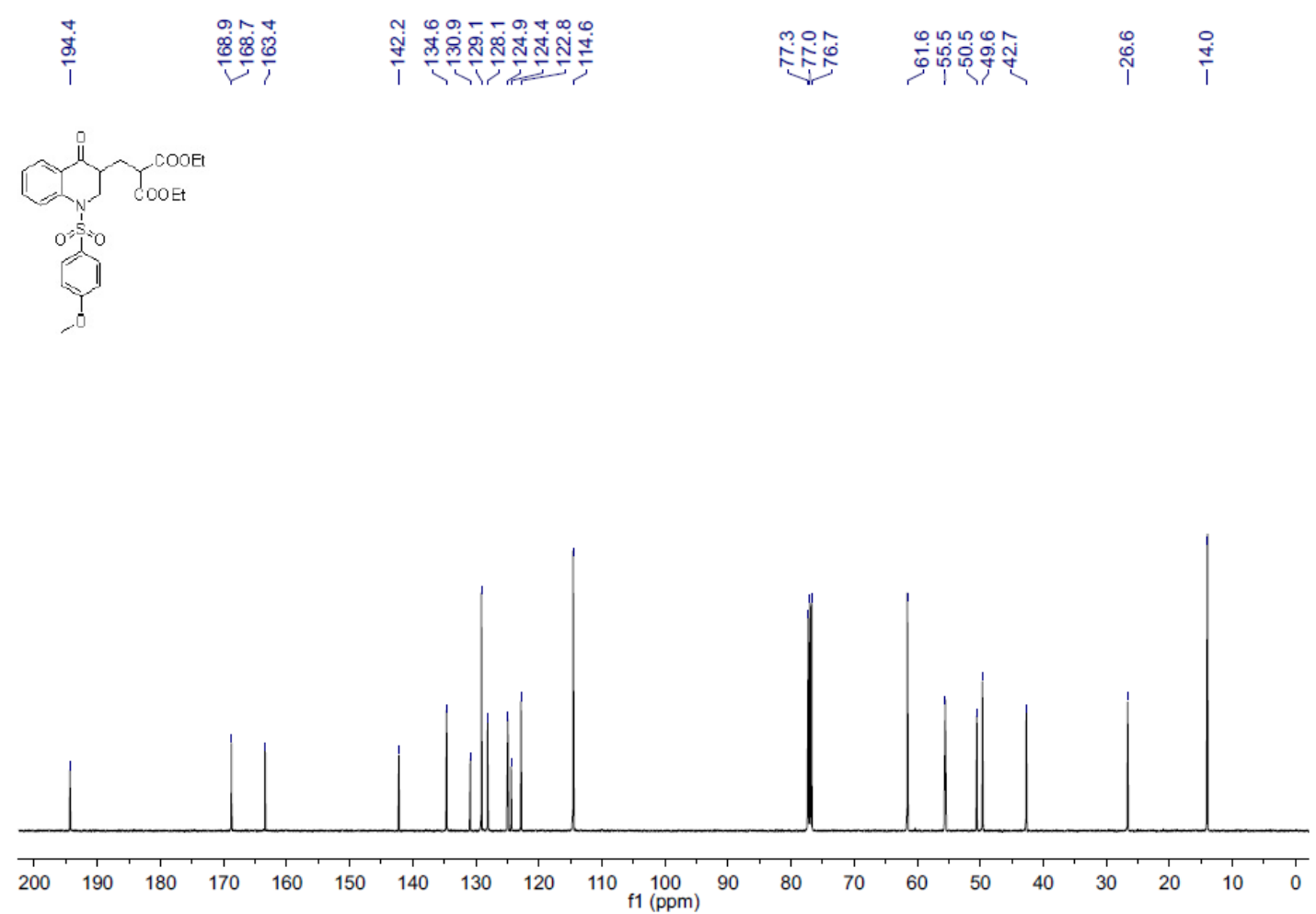

\section{3za NMR}

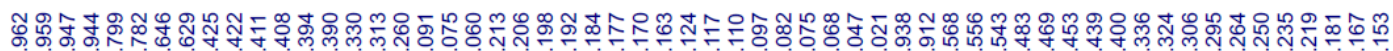

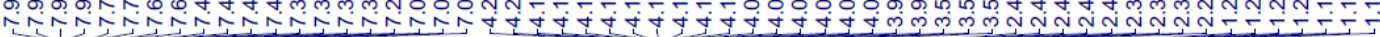<smiles>CCOC(=O)CC1(CC(C)C(=O)OCC)CN(S(=O)(=O)c2ccc(C)cc2)c2ccccc2C1=O</smiles>

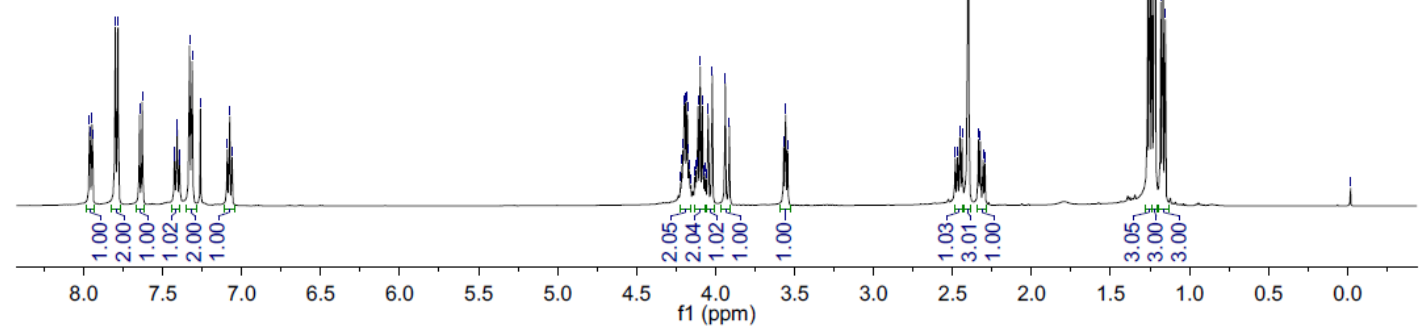




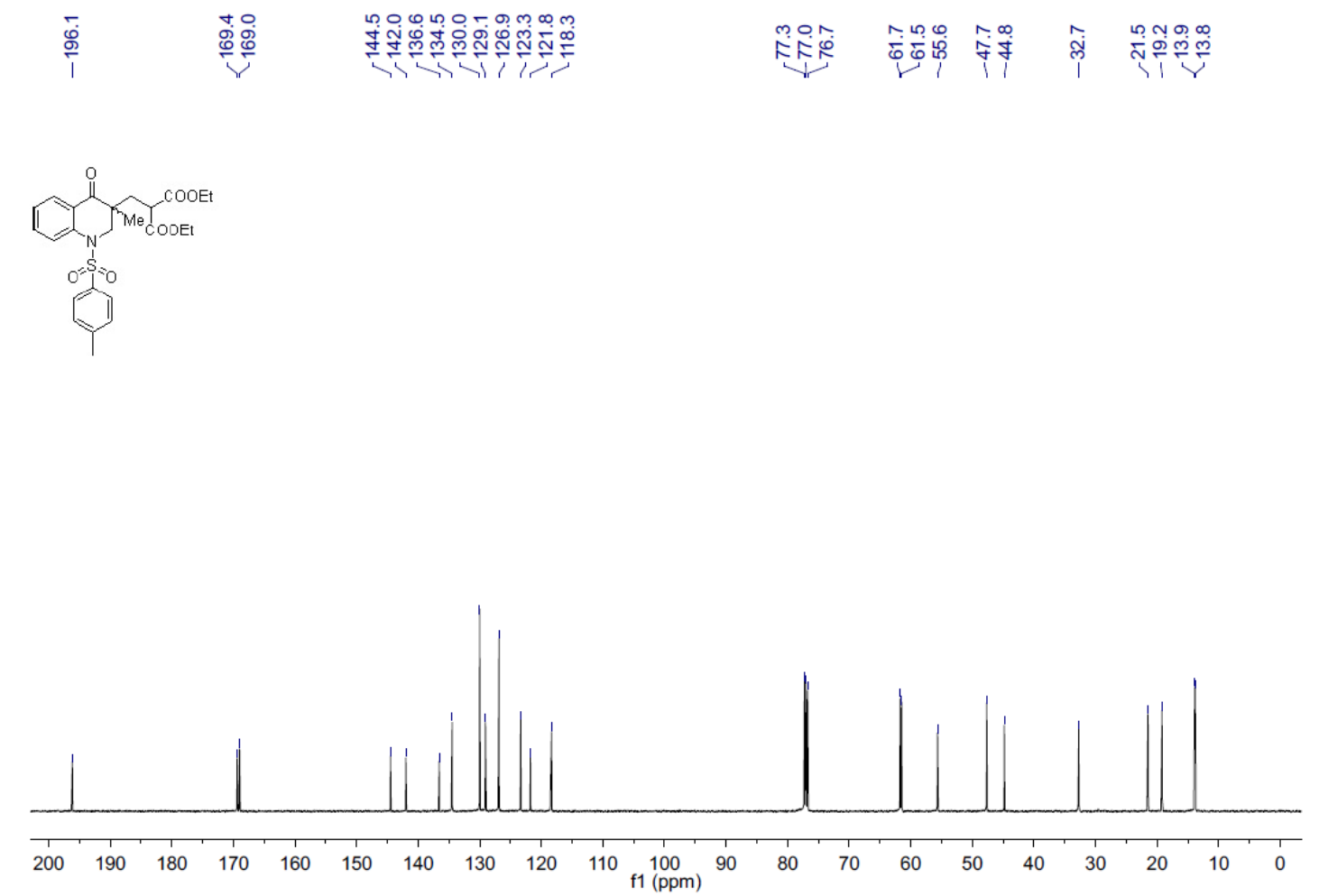

3ab NMR
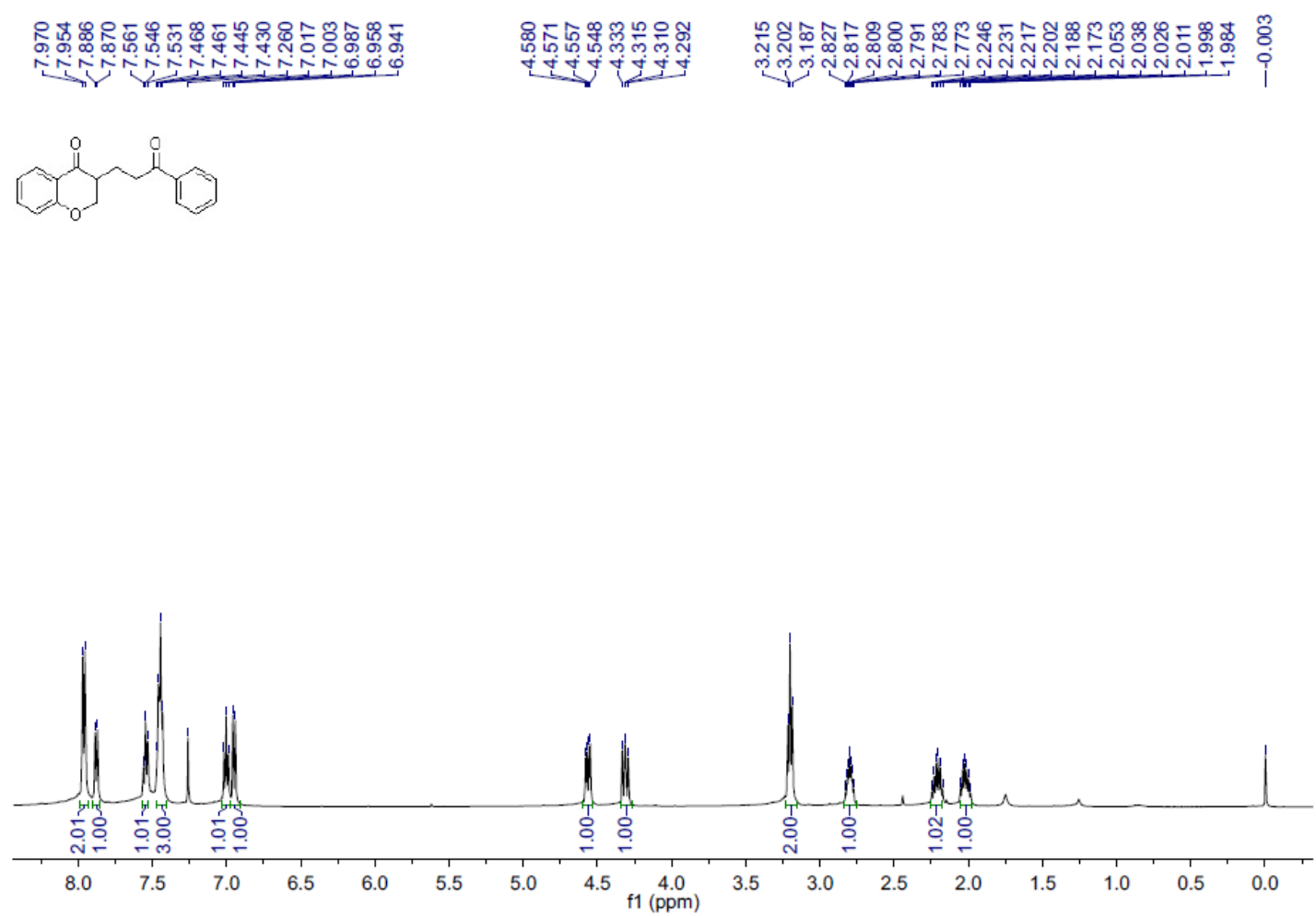
<smiles>O=C(CCC1CC2CCCC21)C1CCCC1</smiles>

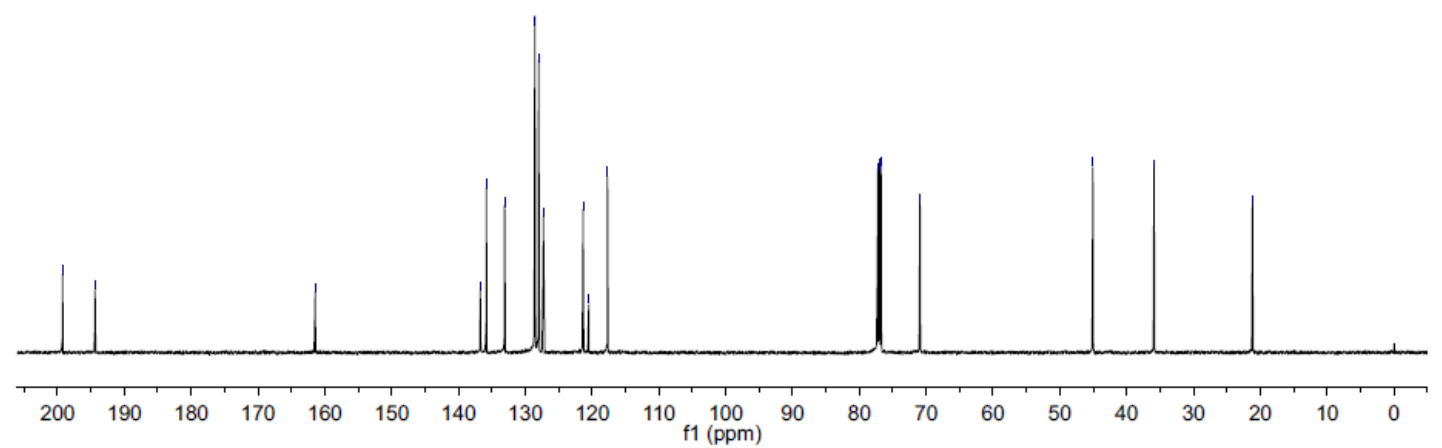

\section{3ac NMR}

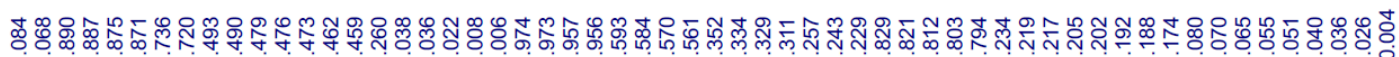
m.<smiles>Cc1ccc(C(=O)CCC2CC3CCCC3O2)cc1</smiles>

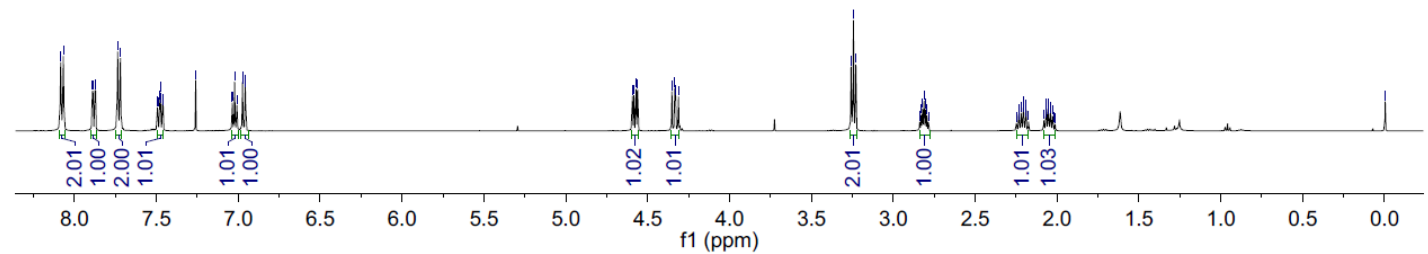




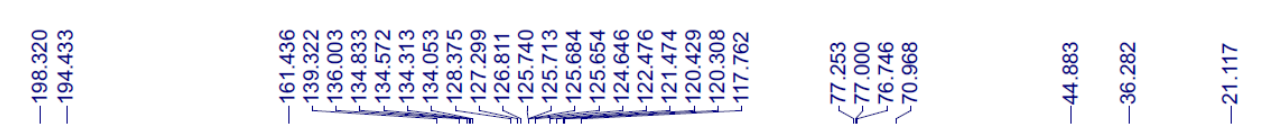
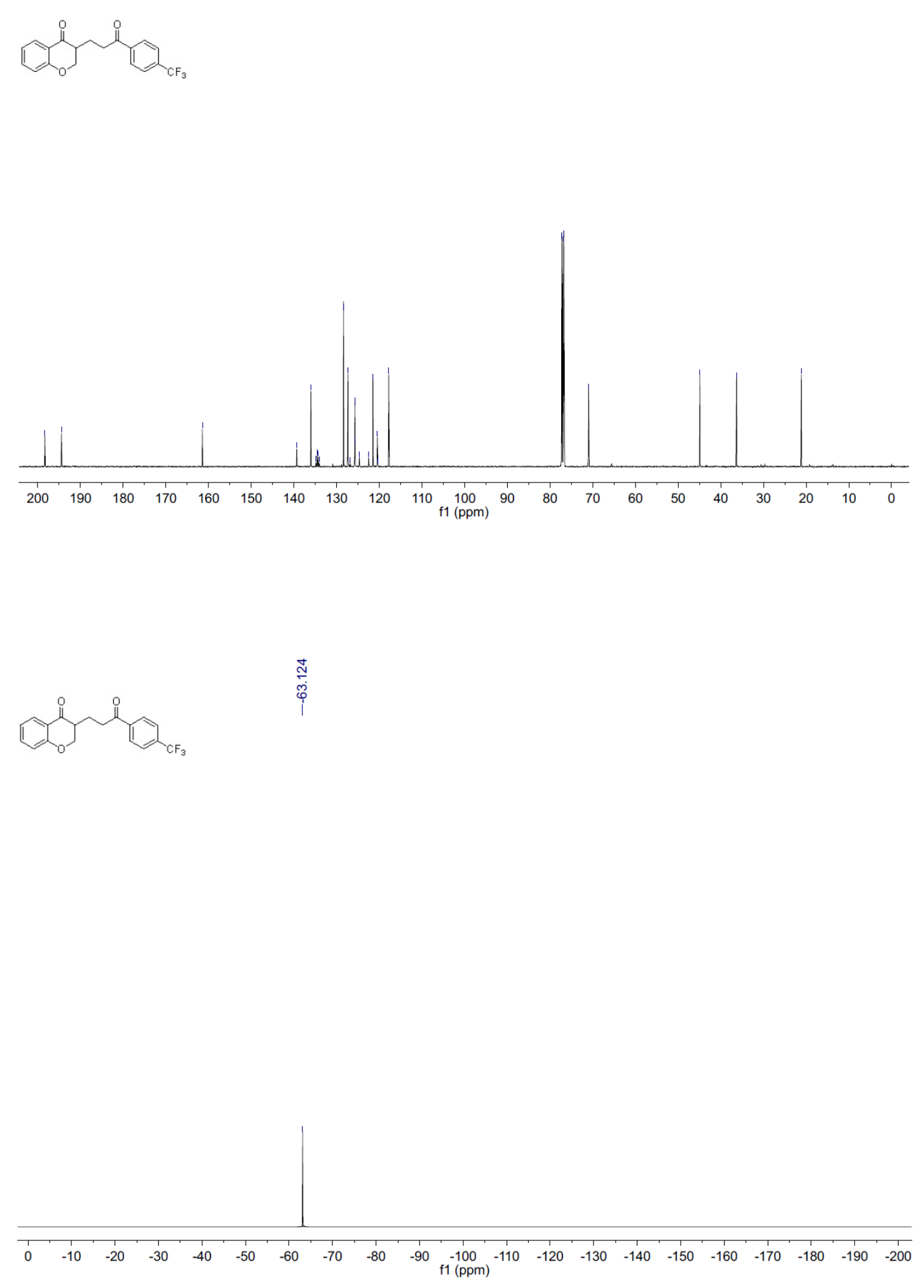

S35 


\section{3ad NMR}

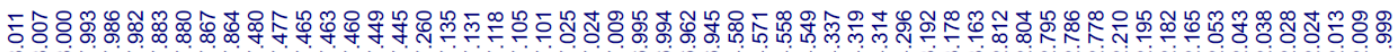

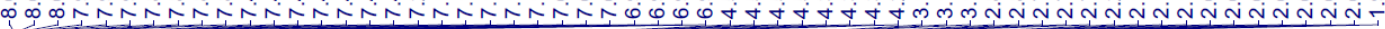<smiles>O=C(CCC1COc2ccccc2C1=O)c1ccc(F)cc1</smiles>

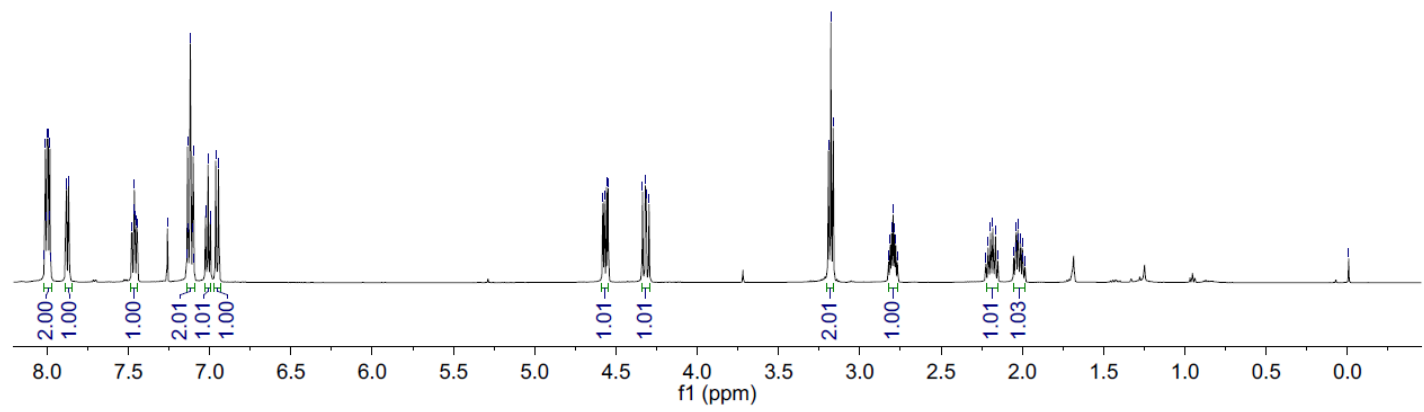

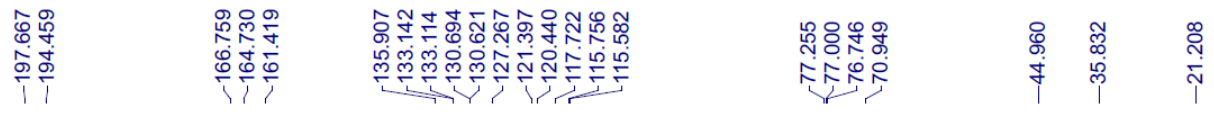<smiles>O=C(CCC1CC2CCCC2C1)C1CCCC1</smiles>

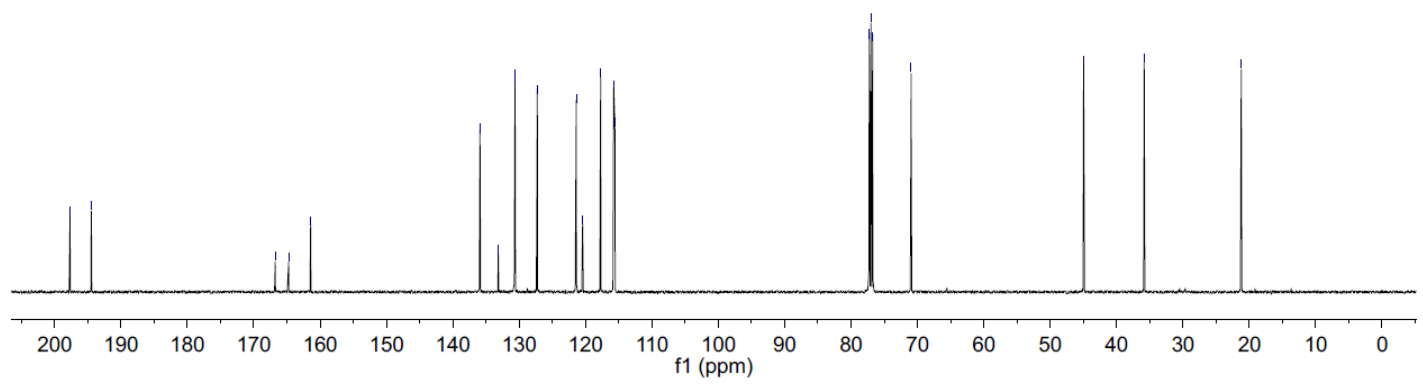



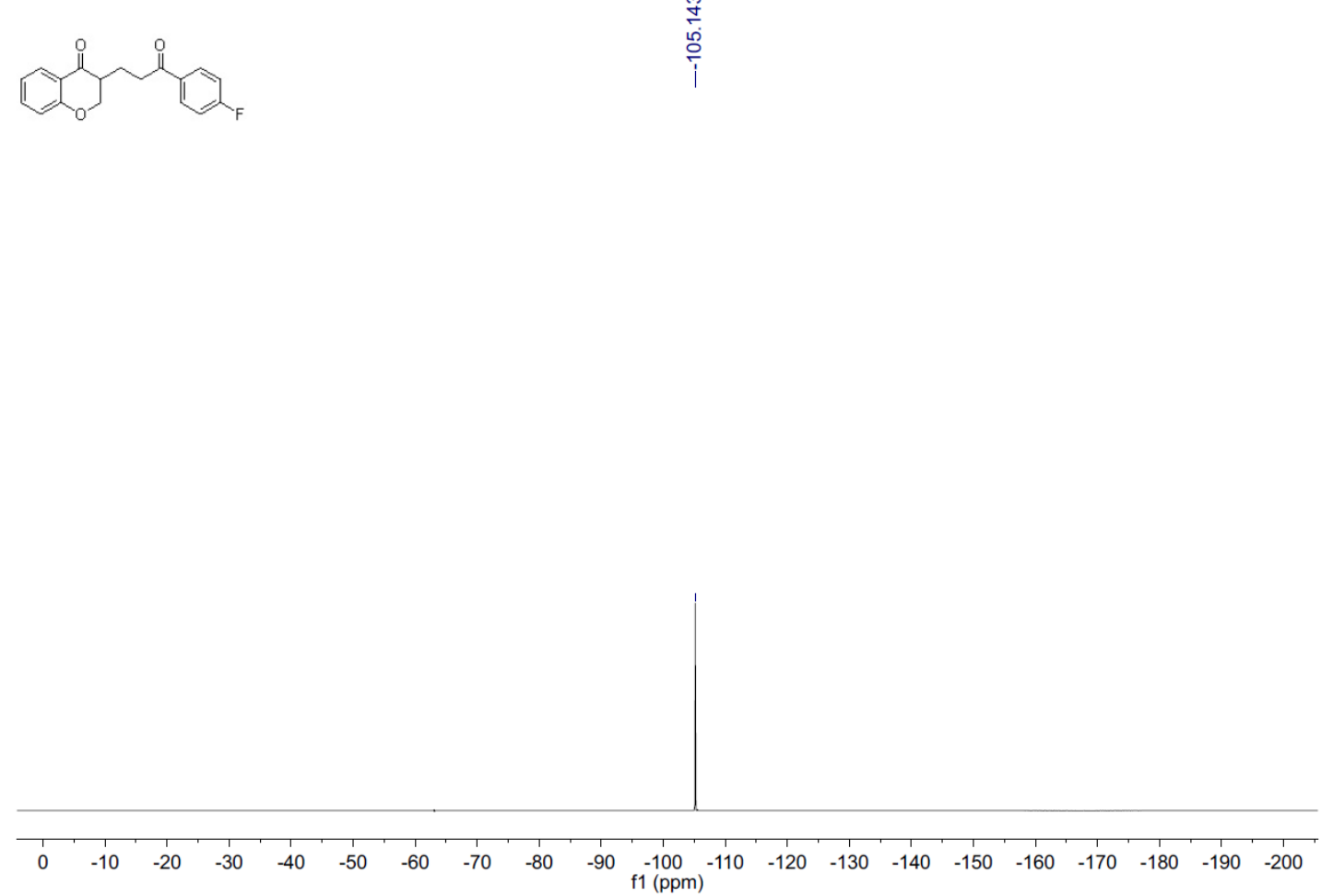

\section{3ae NMR}

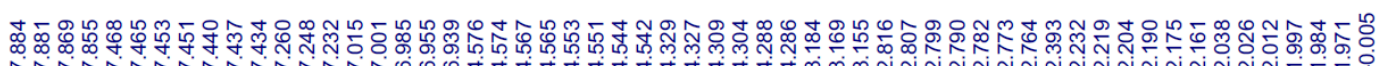

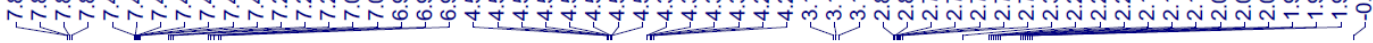<smiles>CC1CCC(CCC(=O)C2CC3CCCC3O2)C1</smiles>

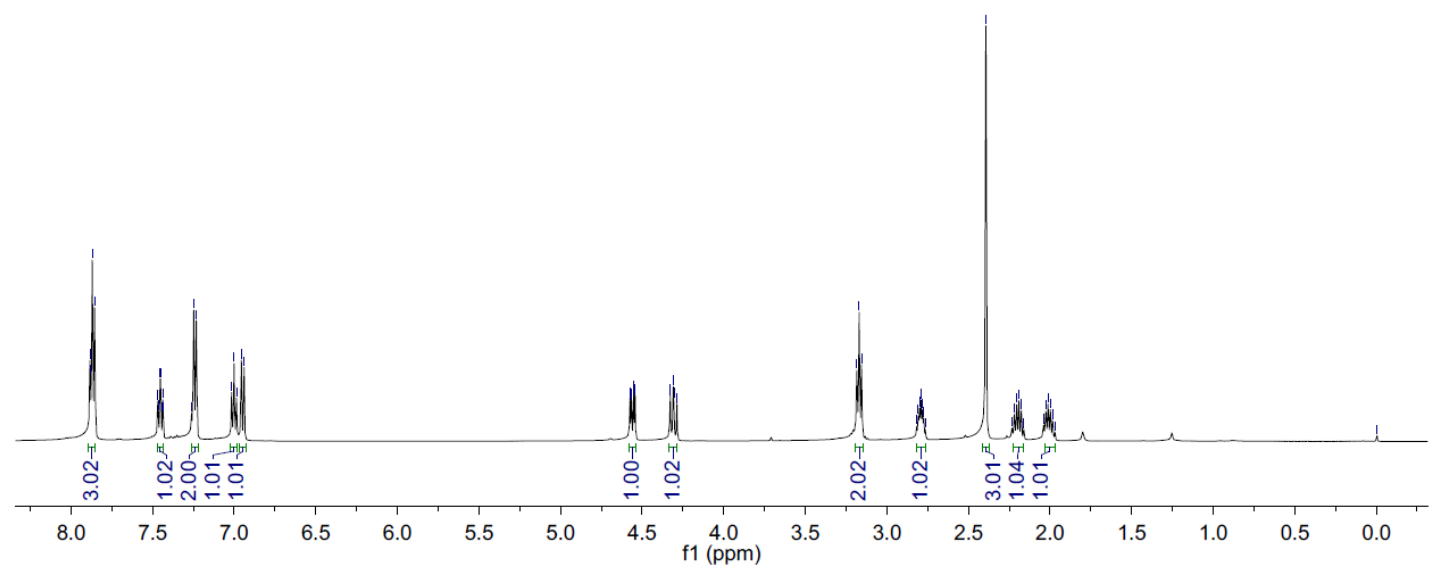




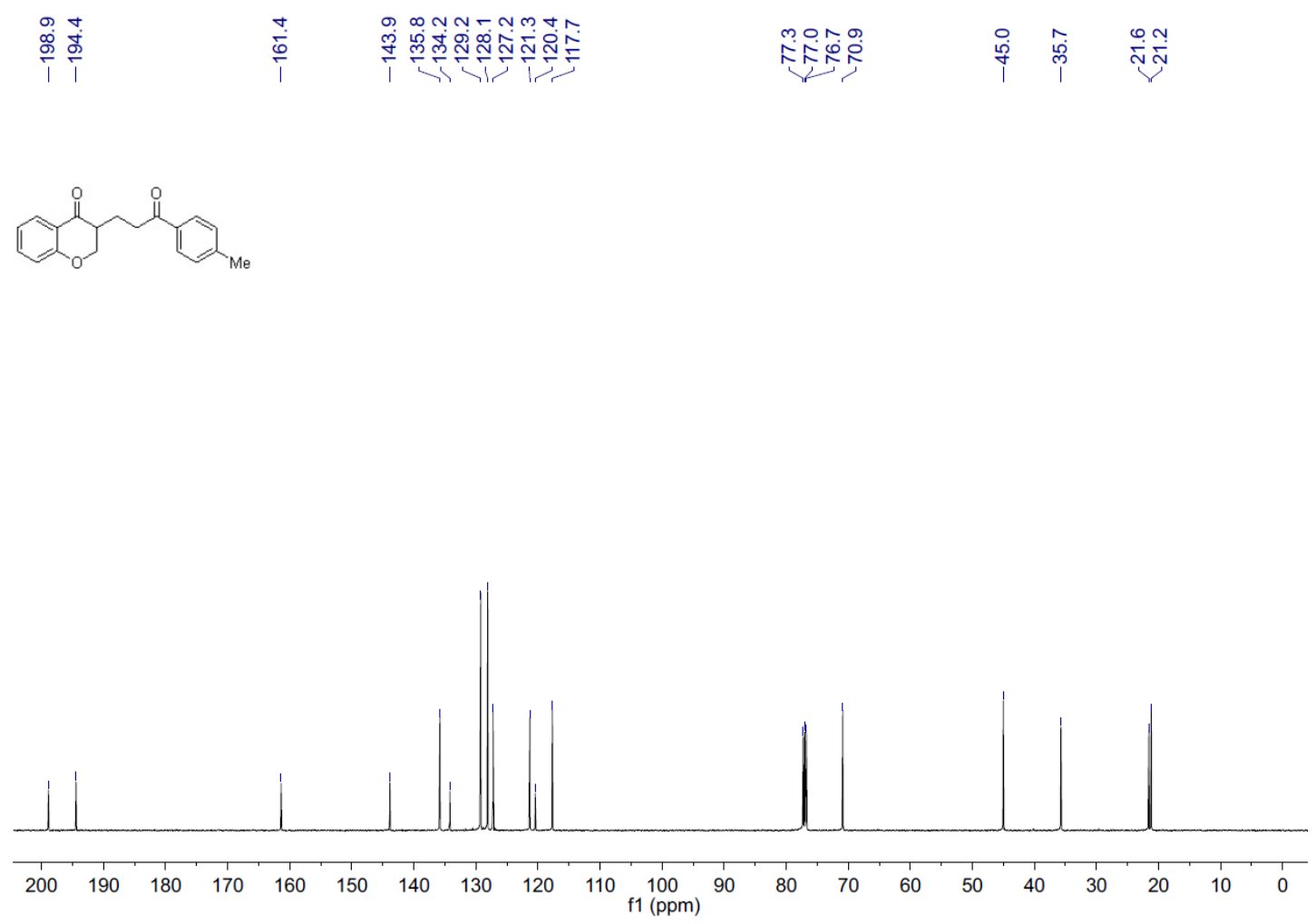

\section{3af NMR}

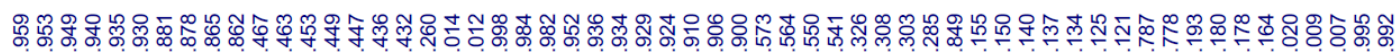

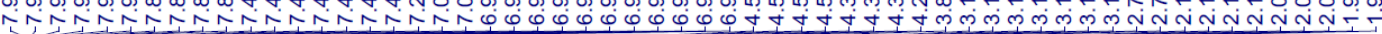<smiles>COc1ccc(C(=O)CCC2COc3ccccc3C2=O)cc1</smiles>

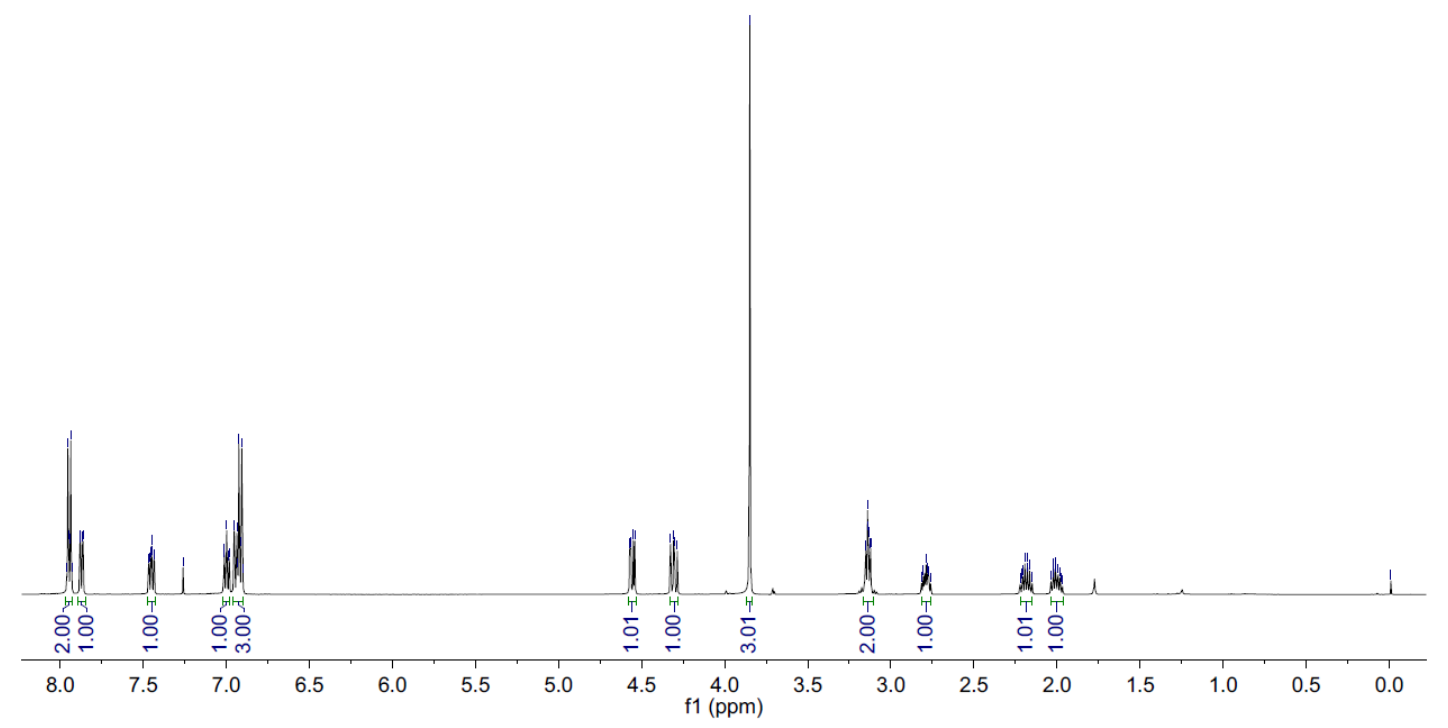




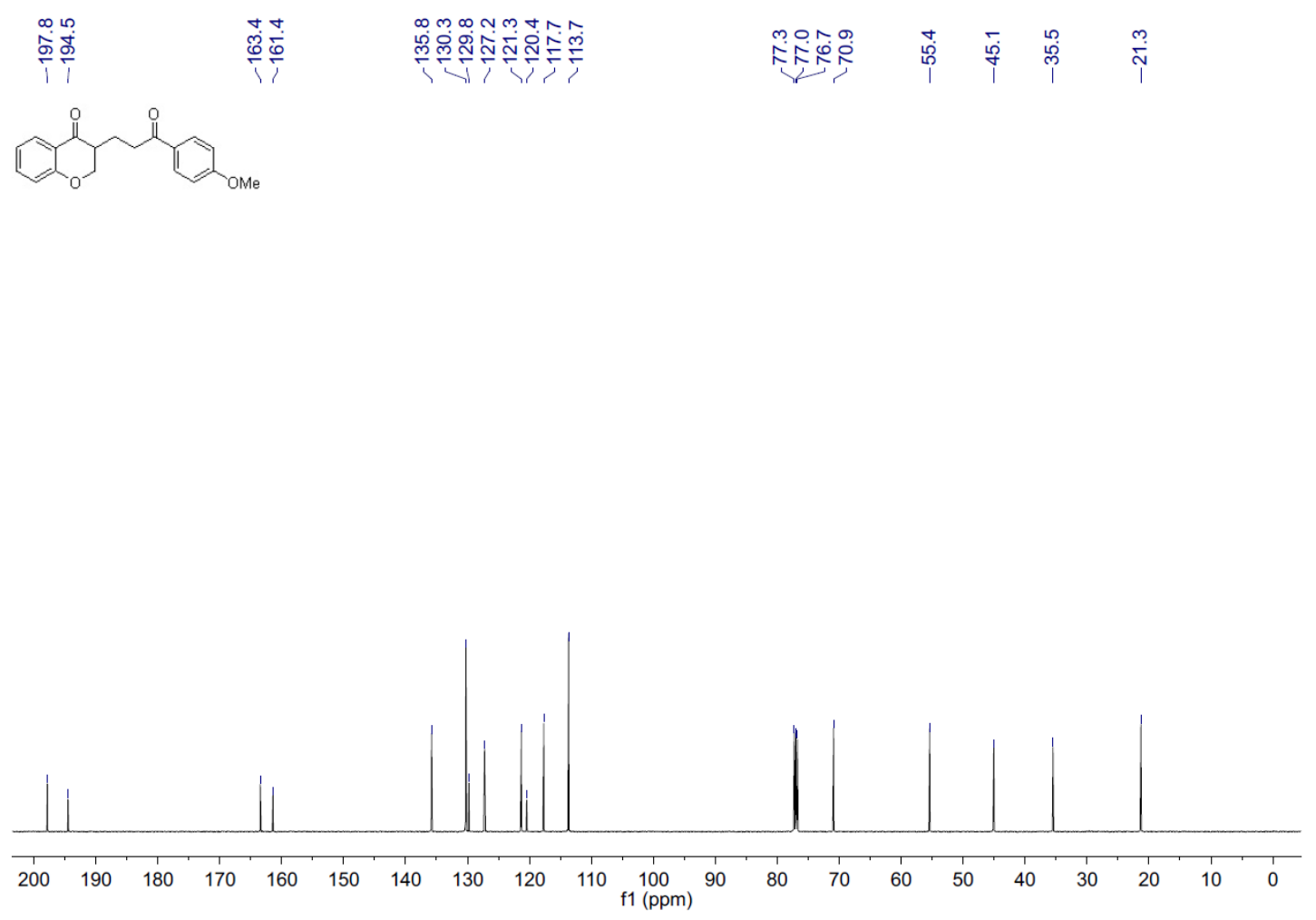

\section{3ag NMR}

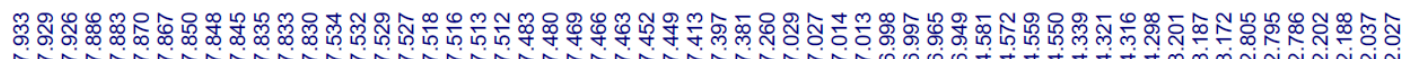

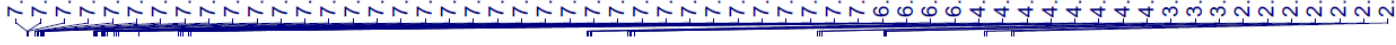<smiles>O=C(CCC1COc2ccccc2C1=O)c1cccc(Cl)c1</smiles>

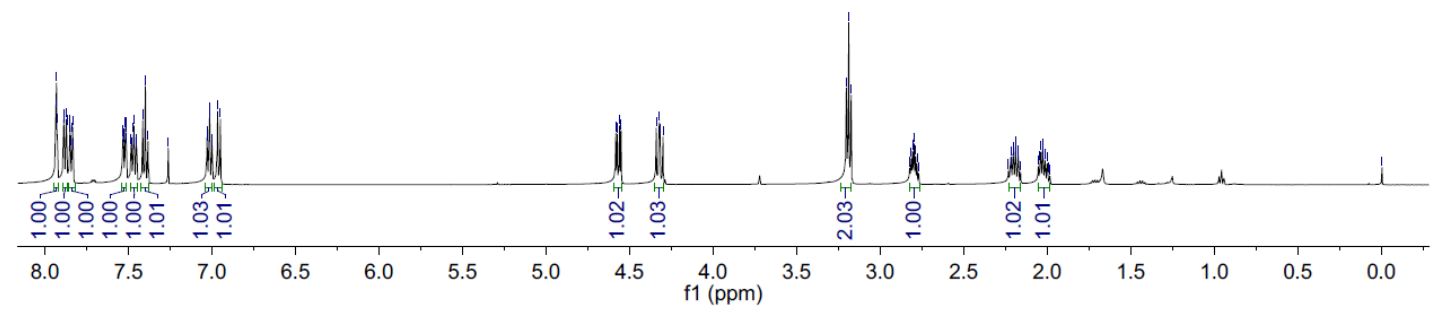




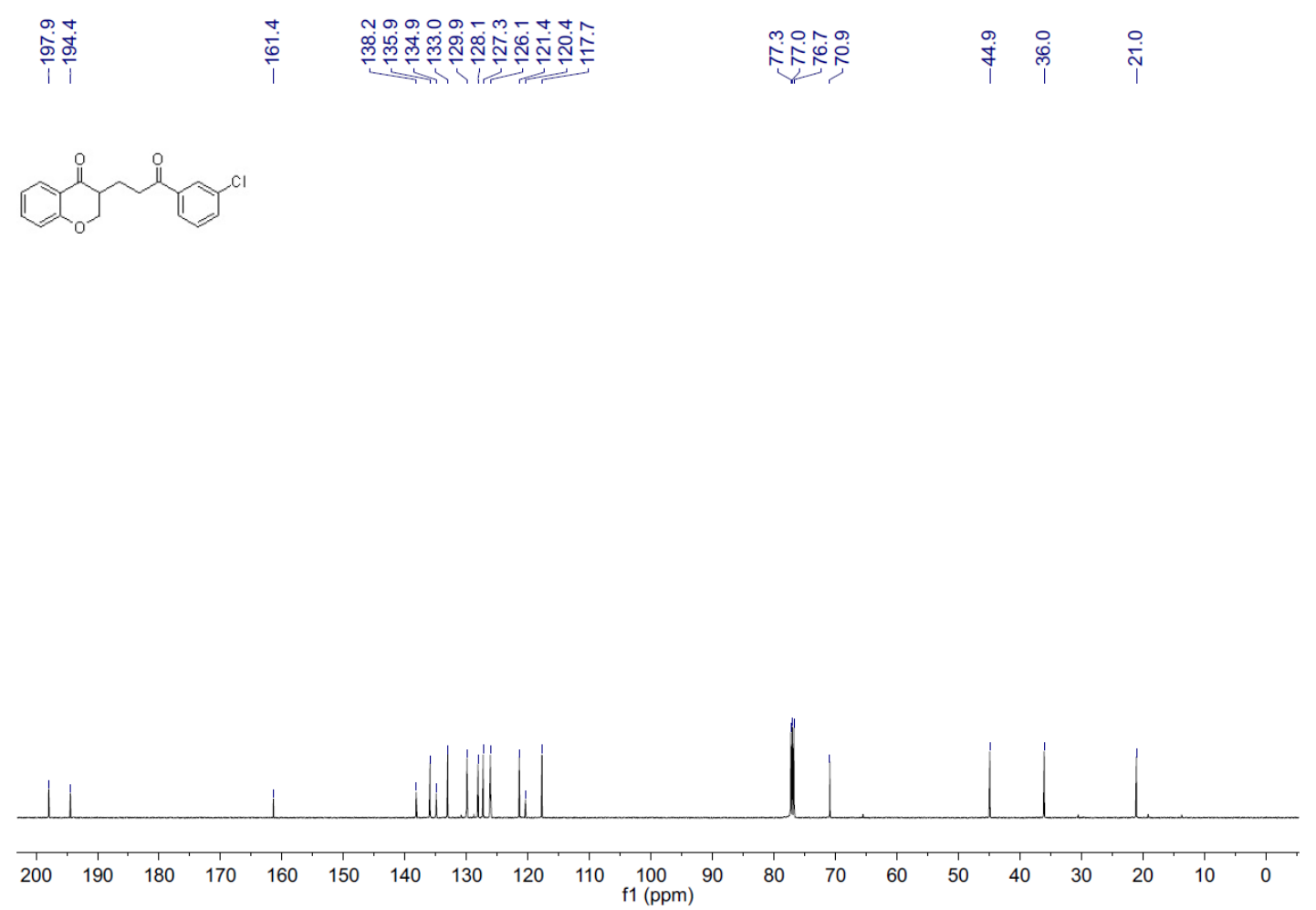

\section{3ah NMR}

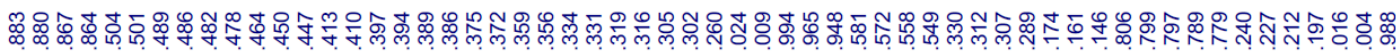

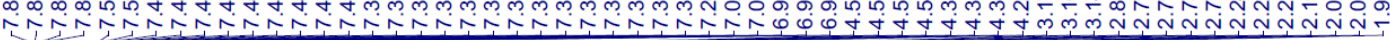<smiles>O=C(O)C1CC2C=CCC23CCCC13</smiles>

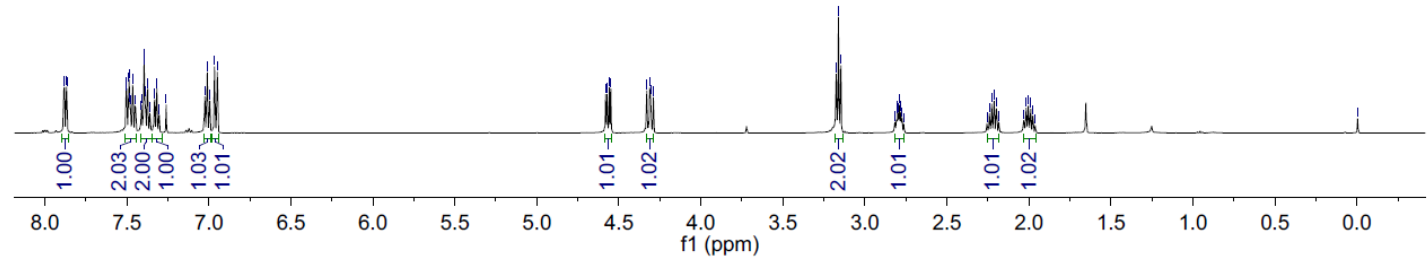



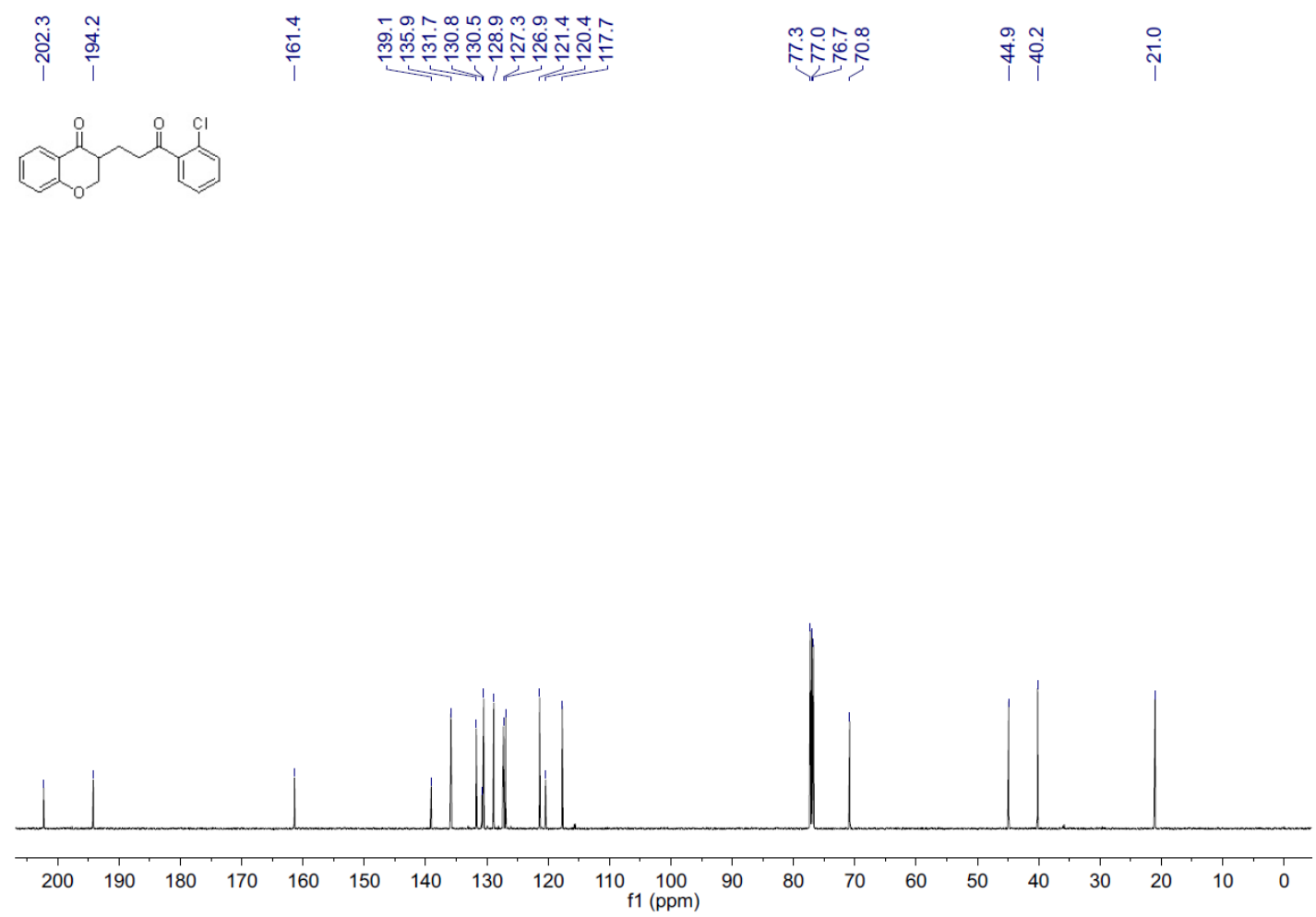

\section{3ai NMR}

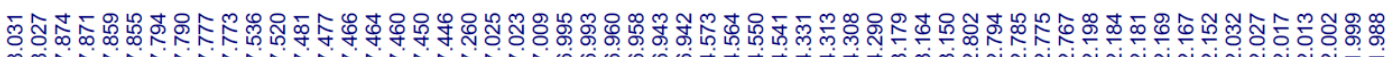

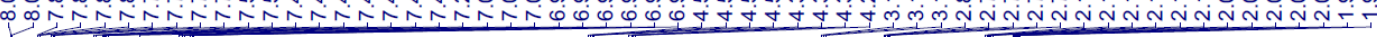<smiles>O=C(CCC1COc2ccccc2C1=O)c1ccc(Cl)c(Cl)c1</smiles>

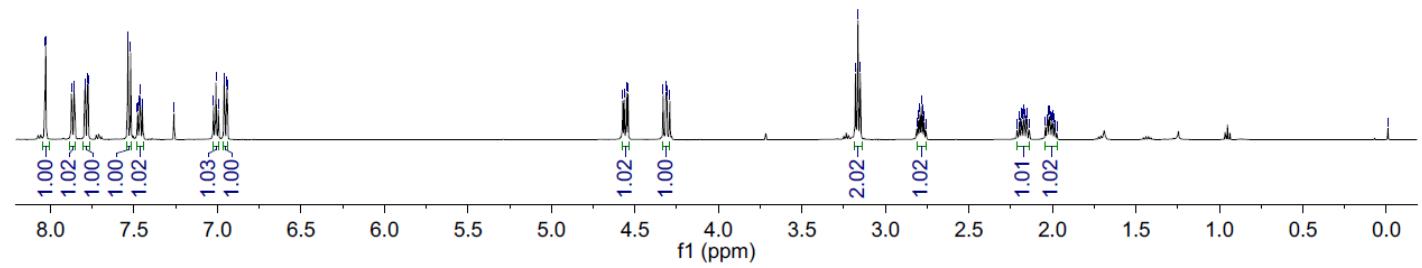




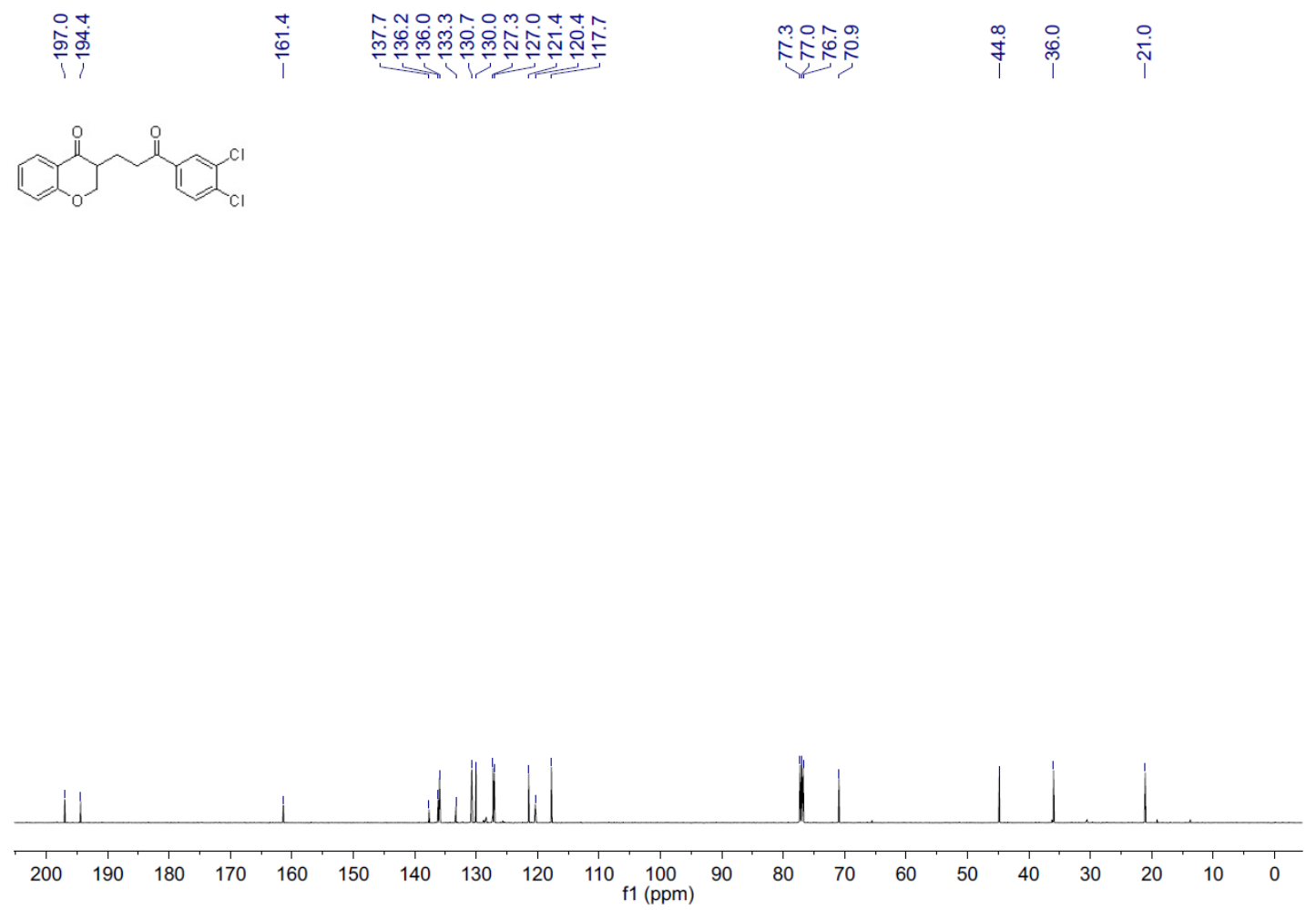

3ak NMR

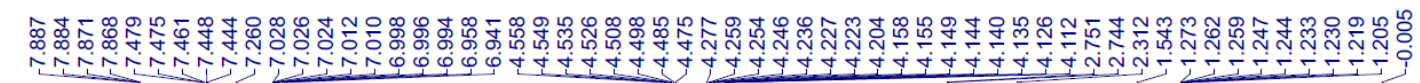

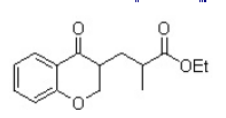

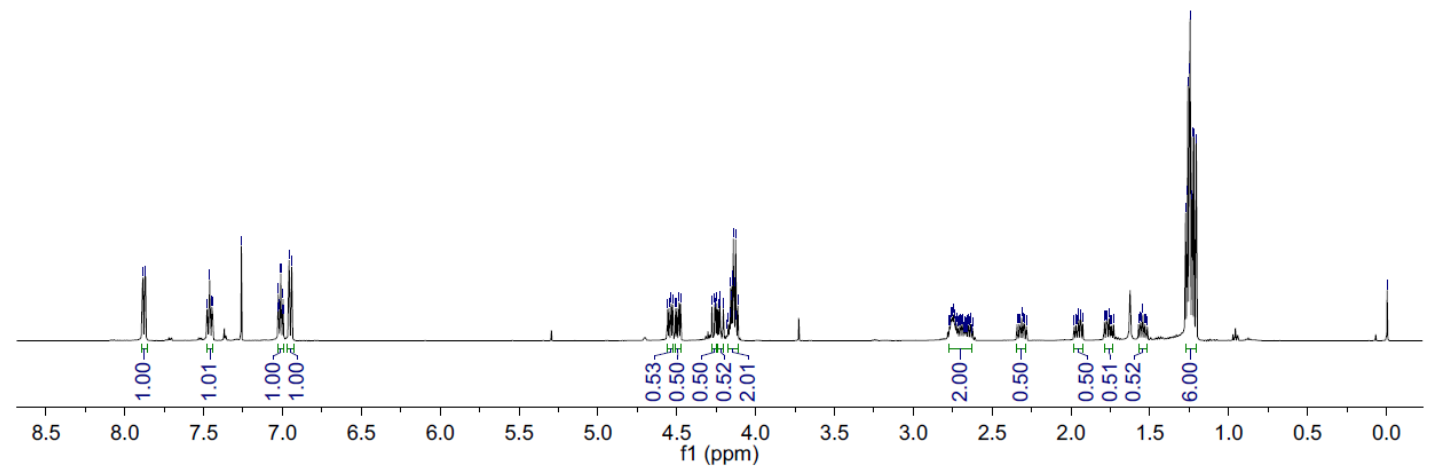




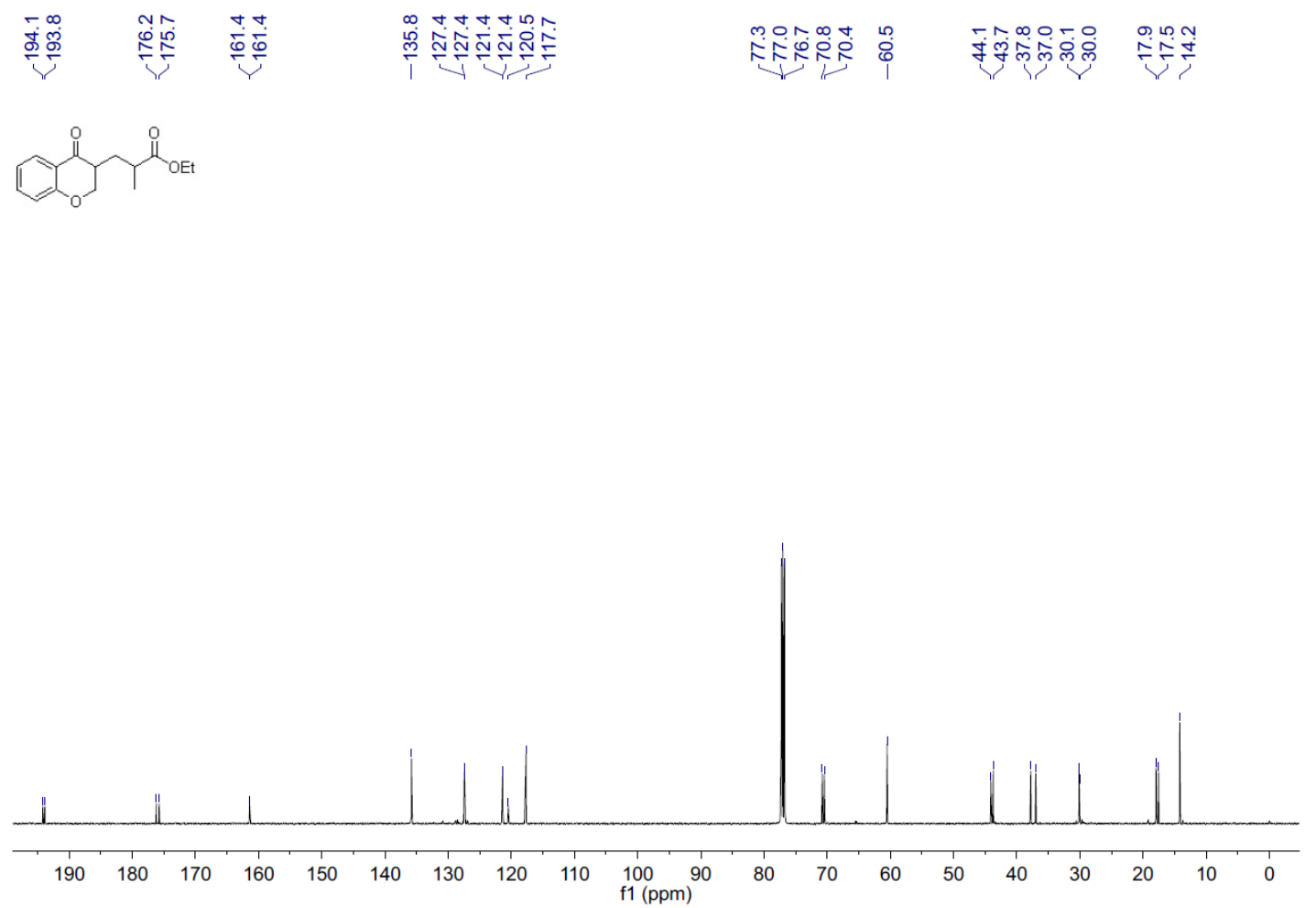

3al NMR

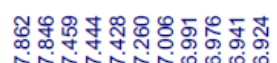

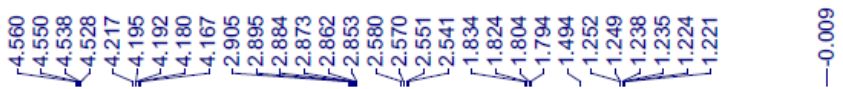

$\underbrace{\text { COOEt }}_{\substack{\text { COE } \\ \text { COOEt }}}$

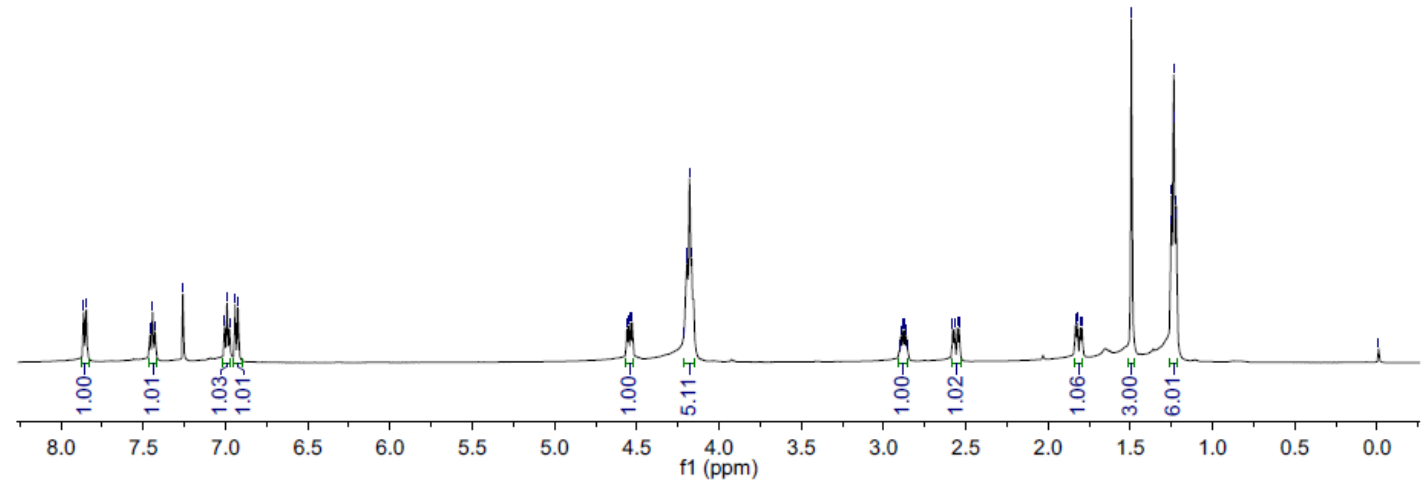



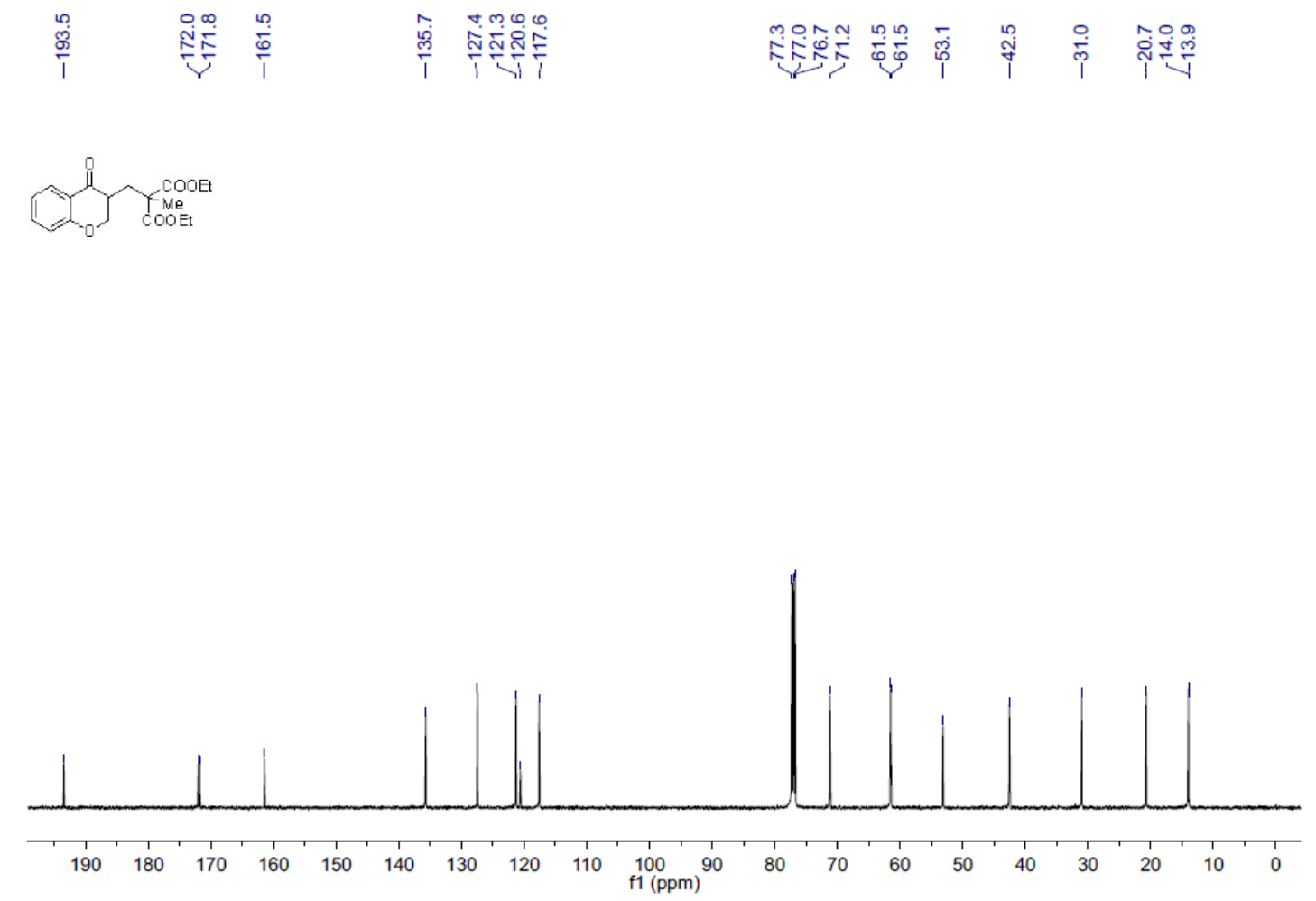

\section{3am NMR}

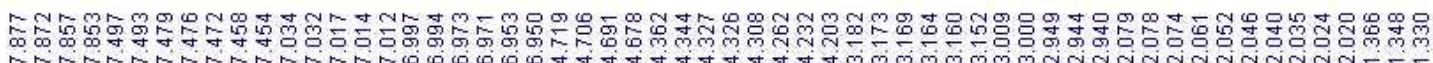

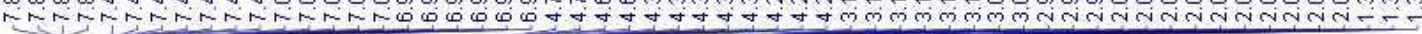<smiles>CCOC(C)(C)CC1COc2ccccc2C1=O</smiles>

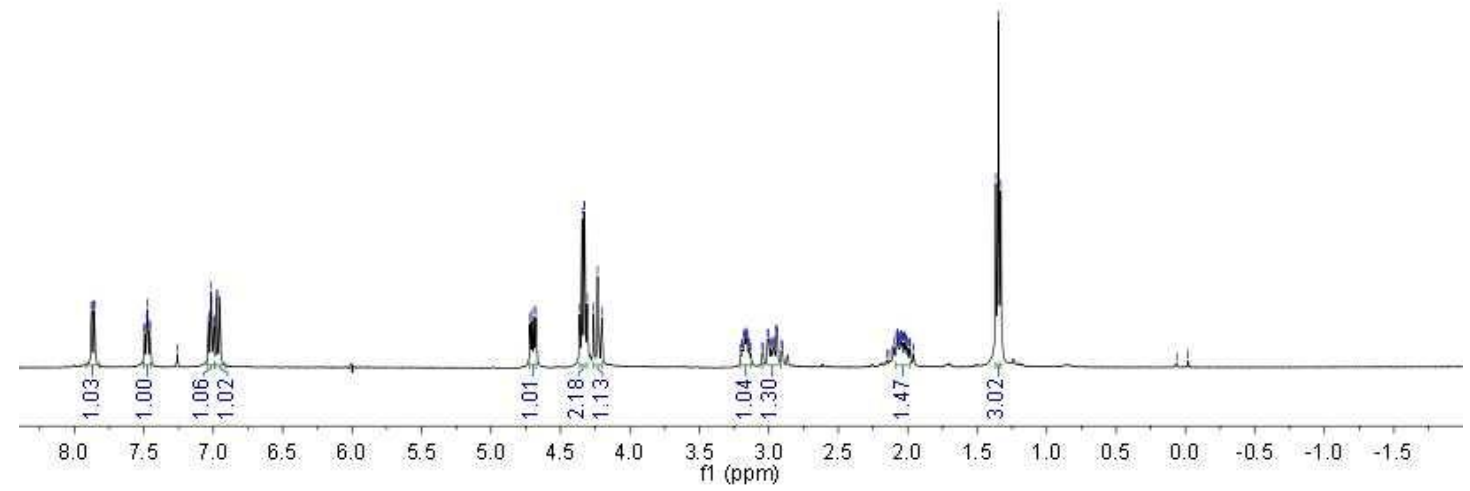



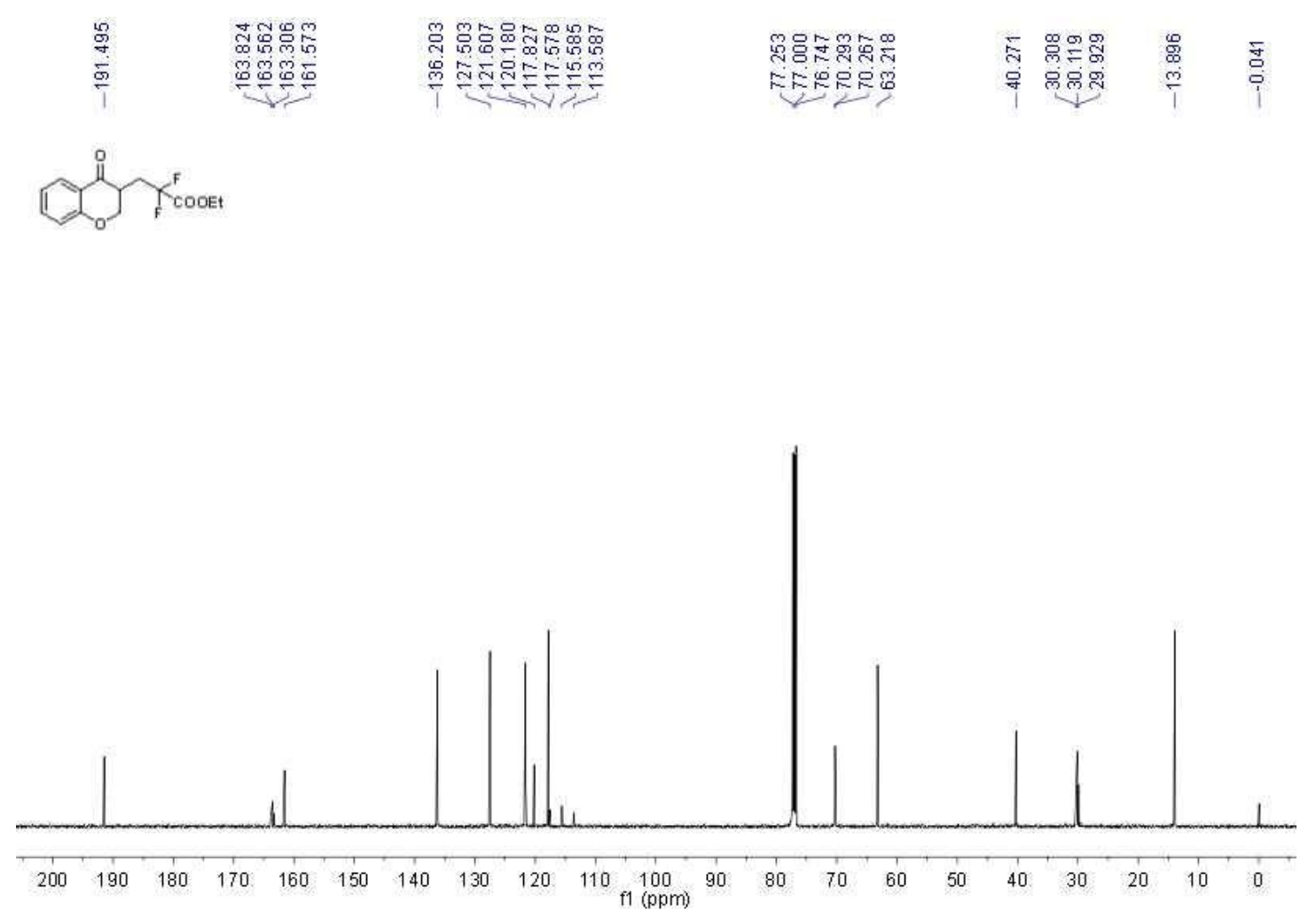

声品呵

$\overbrace{0}^{i} Y_{\text {COOEt }}^{F}$

酧兽

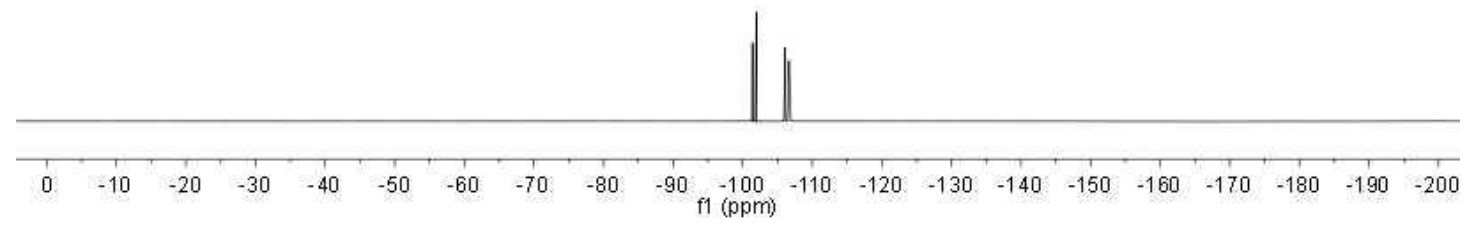




\section{NMR}

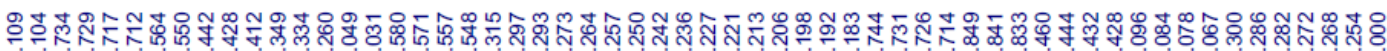

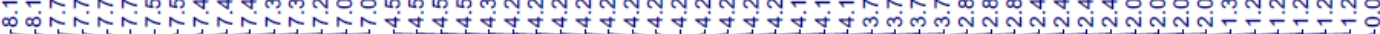
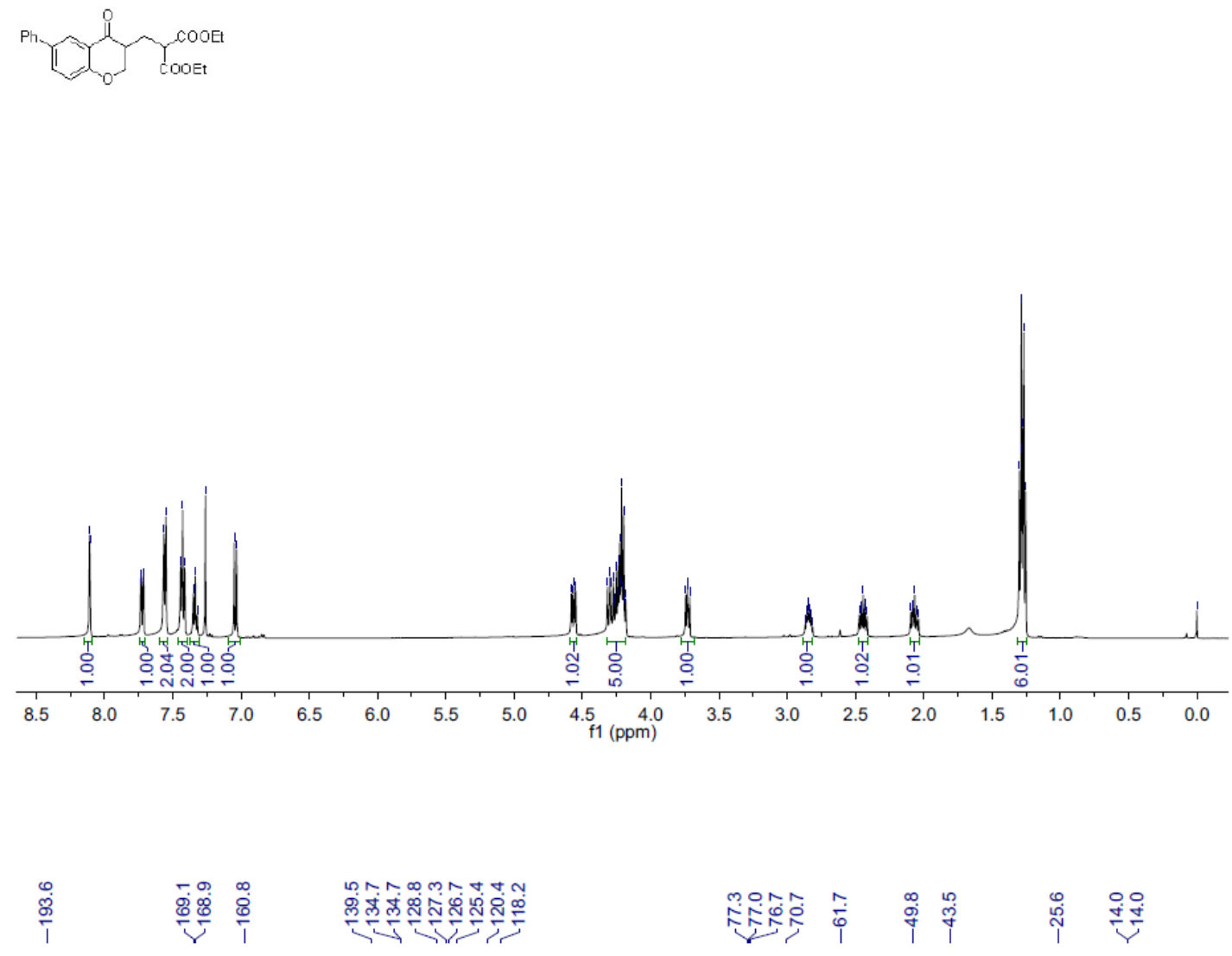

[Ifle cooet

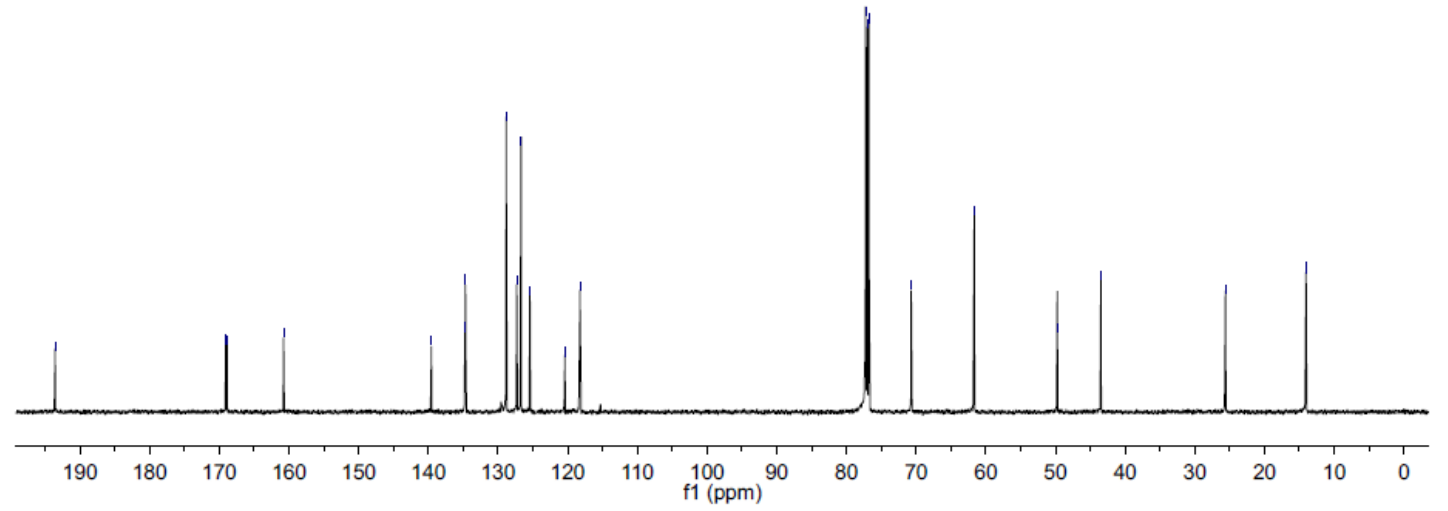

